\title{
The Inverted Leading Indicator Property and Redistribution Effect of the Interest Rate
}

\author{
Patrick A. Pintus ${ }^{1}$, Yi Wen ${ }^{2} \&$ Xiaochuan Xing $^{3}$ \\ Working Paper \#616
}

Decembre 2016

\begin{abstract}
The interest rate at which US firms borrow funds has two features: (i) it moves in a countercyclical fashion and (ii) it is an inverted leading indicator of real economic activity: low interest rates today forecast future booms in GDP, consumption, investment, and employment. We show that a Kiyotaki-Moore model accounts for both properties when interest-rate movements are driven, in a significant way, by self-fulfilling shocks that redistribute income away from lenders and to borrowers during booms. The credit-based nature of such self-fulfilling equilibria is shown to be essential: the dynamic correlation between current loanable funds rate and future aggregate economic activity depends critically on the property that the interest rate is state-contingent. Bayesian estimation of our benchmark DSGE model on US data shows that the model driven by redistribution shocks results in a better fit to the data than both standard RBC models and KiyotakiMoore type models with unique equilibrium..

Keywords : Endogenous Collateral Constraints, State-Contingent Loan Repayment, Redistribution Shocks, Multiple Equilibria.

JEL classification : E21, E22, E32, E44, E63.
\end{abstract}

\footnotetext{
${ }^{1}$ Banque de France, patrick.pintus@banque-france.fr

${ }^{2}$ Federal Reserve Bank of St. Louis \& Tsinghua University, yi.wen@stls.frb.org

${ }^{3}$ Yale University, xiaochuan.xing@yale.edu
} 


\section{NON-TECHNICAL SUMMARY ${ }^{4}$}

The lead-lag correlations between the borrowing cost and aggregate variables is a long-standing puzzle. In US data, low real interest rates paid by borrowing firms are associated with both current and future investment and output booms. However, standard real business-cycle (RBC thereafter) models deliver the opposite relationship: high investment and output are associated with high interest rate (see, e.g., King and Watson, 1996). There is a simple explanation for such counterfactual predictions in one-sector RBC models. In such models the real interest rate is determined by the marginal product of capital, which is proportional to the output-to-capital ratio and procyclical. In addition, of course the plain-vanilla model does not include a credit market and therefore cannot address the issue.

In this paper, we resolve this puzzle by introducing a credit market that channels funds from lenders to borrowers, albeit imperfectly due to borrowing constraints à la Kiyotaki and Moore (1997) - KM thereafter. In such a setting, debt is guaranteed by some form of collateral. Our main theoretical finding is the following. If the interest rate is not set when the loan is negotiated, but instead responds to changes in credit market conditions, then low interest rates and strong investment can go together because the value of collateral increases.

When the demand for loans increases, the supply of loans increases by more in response to the higher credit demand because of a collateral effect, so that the equilibrium interest rate falls instead of rising. As a consequence, real interest rates are countercyclical. This also suggests that lowinterest-rate-based economic booms can be entirely self-fulfilling: in the absence of any "fundamental" shocks, the very anticipation by borrowers of a lower debt payment due to a lower expected interest rate can stimulate credit demand and aggregate investment, resulting in an economic boom that fulfills the initial optimistic expectations. A striking implication of our results is therefore that self-fulfilling swings triggered by redistribution shocks from lenders to borrowers and supported by collateralized borrowing may be an important driver behind actual business cycles both in theory and in the data.

The contribution of this paper is twofold. Theoretically, we show that borrowing constraints of the KM type are sufficient to generate expectation-driven business cycles in asset prices and aggregate output, even in simple versions of the basic model with realistic parameter values. This happens when loans have state-contingent repayment. The intuition is straightforward: simply relaxing the borrowing constraint via a higher value of the collateral does not by itself generate a higher demand for loans if the interest repayment on loans is expected to rise. Hence, once the credit market is in equilibrium, an expectation of a higher asset value cannot be self-fulfilling unless the loanable funds rate is countercyclical. This stark distinction between predetermined-rate economies that are immune from self-fulfilling swings triggered by redistribution shocks and economies with statecontingent repayment that are highly exposed to them has eluded the literature, largely because most contributions assume that the interest rate is either exogenous or predetermined.

\footnotetext{
${ }^{4}$ This paper supersedes a previous version circulated under the title "Interest Rate Dynamics, Variable-Rate Loans, and the Business Cycle". We thank very much our discussants Nobuhiro Kiyotaki and Paul Gomme, as well as David Andolfatto, Jess Benhabib, Florin Bilbiie, Fernando Broner, Nuno Coimbra, Nicolas Dromel, Gaetano Gaballo, Luca Guerrieri, Roger Guesnerie, Leo Kaas, Todd Keister, John Landon-Lane, Giovanni Nicolo, Gilles Saint-Paul, Jacek Suda, Roman Sustek, Venky Venkateswaran, Mike Woodford for discussions and comments, Tao Zha for kindly sharing his codes, seminar participants at Banque de France, XIIth Dynare conference, Econometric Society NASM 2016, Vienna Macro Workshop 2016, SED 2016 annual meeting, RIDGE 2015 workshop on "Macreoconomic Crises" at Universidad de Buenos Aires, Collège de France, University of Konstanz, National Bank of Poland, Paris School of Economics, NYU Stern, Rutgers University, and Maria Arias for excellent research assistance. The usual disclaimer applies.
} 
Empirically, we construct a new measure of the borrowing cost faced by US firms. We then estimate the extended model on US data 1975-2010. Our main findings are as follows. First, we show that multiple equilibria and redistribution shocks are quantitatively important to explain the volatility of output, investment, credit, and labor hours along US business and credit cycles. Second, we show that the multiple-equilibria model explains the data better than the determinate model. This is, to our knowledge, the first evidence that self-fulfilling redistribution shocks matter quantitatively in a DSGE model with financial frictions.

The main implication of our results for policy is that if loan interest rates are predominantly at varying rates (as in the US and the UK for mortgages, or loans to firms in the Eurozone) and credit markets rely on collateral, then animal spirits shocks to expectations can drive boom-bust patterns cycles in output and investment,. Conversely, fixed-interest loans to households that are common in continental Europe countries can rule out self-fulfilling equilibria. Therefore, how the fraction of variable-rate loans evolves over time should be a key indicator for monetary/prudential authorities. For example, the increased use of variable-rate loans could be an important explanation of the boom and bust in housing investment before 2007-08 crisis. The main mechanism that we emphasize in this paper could also be important for the transmission of monetary policy. 


\section{Résumé: Le Taux d'intérêt Débiteur comme Indicateur Avancé et ses Conséquences Redistributives.}

Le taux d'intérêt débiteur auquel sont confrontées les entreprises localisées aux USA a deux caractéristiques principales: (i) il est contra cyclique ; (ii) il est un indicateur avancé de l'activité économique réelle : un faible taux d'intérêt aujourd'hui est associé à une future expansion du PIB, de la consommation, de l'investissement et de l'emploi. Nous montrons qu'un modèle à la KiyotakiMoore reproduit ces deux propriétés lorsque les variations du taux d'intérêt sont conduites par des chocs purement auto-réalisateurs, qui redistribuent le revenu des prêteurs vers les emprunteurs en période d'expansion. L'importance du marché du crédit dans l'émergence d'équilibres autoréalisateurs est cruciale : les corrélations dynamiques entre taux d'intérêt courant et variables agrégées futures dépendent du fait que le coût de l'emprunt est contingent. L'estimation bayésienne de notre cadre DSGE de référence montre que le modèle avec chocs redistributifs s'accorde mieux avec les données provenant des USA qu'un modèle RBC standard ou qu'un modèle avec équilibre unique.

Mots-clés : Contraintes endogènes de crédit, Remboursement de crédit contingent, Chocs redistributifs, Equilibres multiples. 


\section{Introduction}

The inverted leading indicator property of the borrowing cost is a long-standing puzzle. In US data, low real interest rates are associated with both current and future investment (and output) booms. However, standard real business-cycle (RBC thereafter) models deliver the opposite relationship: high investment and output are associated with a high interest rate (see, e.g., King and Watson, 1996). The reason behind such counterfactual predictions is rather simple. In such models the real interest rate is dictated by the marginal product of capital, which is proportional to the output-to-capital ratio. Given that output is more cyclical than the capital stock, high output thus always implies a high interest rate regardless of the source of shocks. Solutions to such a puzzle $^{1}$ are so scarce that, in fact, we know of only one in flexible-price settings: the two-sector RBC model of Boldrin, Christiano and Fisher (2001). ${ }^{2}$

In this paper, we tackle this long-standing puzzle by introducing a credit market that channels funds from lenders to borrowers. Due to borrowing constraints à la Kiyotaki and Moore (1997) - KM thereafter - the credit market friction creates a wedge between credit supply and credit demand. However, this wedge by itself is not sufficient for the loanable funds rate to be countercyclical because in equilibrium credit demand still depends on the rate of return to capital: the cost of borrowing is still dictated by the benefit of borrowing and investing, that is, by the marginal product of capital, so that high credit demand (associated with high capital returns) results in high interest rates. Our main theoretical finding is that if the loan is such that the interest rate is not pre-determined, or set when the loan is negotiated, but instead is state-contingent and responds to changes in credit market conditions when the loan payment is due, then the credit market features an interesting property: when the demand for loans increases, the supply of loans increases by more in response to the higher credit demand, so that the equilibrium interest rate falls instead of rising, leading to countercyclical real interest rates. This also suggests that the low-interest-rate-based economic boom can be self-fulfilling: in the absence of any fundamental shocks, the very anticipation by borrowers of a lower expected interest rate can stimulate credit demand and aggregate investment, resulting in an economic boom and fulfilling the initial optimistic expectations. Conversely, expectations of a high interest rate can trigger a recession and an interest rate hike in the credit market, as if a higher credit risk had materialized and reduced loanable funds even though it is in fact not the case.

The fact that the borrowing cost faced by US firms is countercyclical has far-reaching macroeconomic consequences. When the borrowing cost is low, financing investment is easier and the economy booms. Figures 1 and 2 report the impulse response functions (IRFs thereafter), at quarterly frequency, of real land price, the inverse relative price of capital, real consumption, real investment, real business debt, hours worked, real GDP, and real borrowing interest rate faced by corporate and noncorporate firms. Those IRFs are obtained from two vector autoregressive (VAR) models, using Cholesky decomposition and ordering first either land price (figures

\footnotetext{
${ }^{1}$ Backus, Kehoe and Kydland (1994) addressed a similar puzzle arising from international trade data, using a two-country RBC model.

${ }^{2}$ Alternatively, King and Watson (1996) argue that sticky-price models are promising to address the puzzle they document.
} 
1) or investment (figure 2). ${ }^{3}$ Both figures make clear that all variables are procyclical, except the borrowing interest rate. When there is a positive shock to either land price or investment, the interest rate stays below trend for several quarters while all variables boom. To the extent that both credit demand (by firms) and credit supply (by investors and financial intermediaries) are procyclical, this evidence suggests that changes in the supply of loanable funds dominate those in the demand for loans. While data clearly shows that the borrowing cost is countercyclical, standard RBC models counterfactually predict that the interest rate is procyclical, as noticed above. ${ }^{4}$ Since there is no credit market in the standard one-sector RBC model, one might wonder whether or not theoretical predictions agree with empirical evidence in meaningful extensions of the textbook model.

In this paper, we consider various versions of dynamic models that incorporate a credit market and endogenous collateral constraints following the seminal contribution of KM, whose setting has become a workhorse of DSGE theory with financial frictions. Our main contribution is to show that the loanable funds rate is countercyclical only in versions of the model such that the unique steady state is indeterminate, which in turn happens if loan repayments are state-contingent. In other words, collateralized lending with predetermined interest rate delivers a procyclical interest rate that is at odds with data while, in sharp contrast, collateralized loans with state-contingent interest rate accord with empirical evidence. A striking implication of our results is therefore that self-fulfilling swings, and in particular fluctuations in real economic activity caused by interest-rate movements that redistribute income between lenders and borrowers, are an important driver behind actual business cycles both in theory and in the data.

Our focus on credit markets that feature collateral requirements is dictated by the fact that they are a prominent feature of loans in many economies around the world, both in developed and in developing countries. It is well understood both in practice and in theory that contractual agreements involving some form of collateral brought by borrowers mitigate the consequences of asymmetric information in debtor-creditor relationships (see for example the textbook by Tirole, 2006, chapter 4). In particular, because collateralized borrowing reduces default risk, conventional wisdom holds that financial institutions that rely more on secured debt - and less on unsecured debt - should be less prone to financial crisis. ${ }^{5}$ This paper shows, however, that such conventional wisdom is not necessarily correct: even collateralized lending can itself be a source of self-fulfilling credit cycles and financial instability. This finding is thus surprising for two reasons: $(i)$ it is against the common view that secured borrowing is safer and thus promotes macroeconomic stability; (ii) it is a salient feature of KM-type models.

Collateralized borrowing hinges on market values, yet such market values are endogenous to the economy and out of control by competitive creditors and debtors. Thus, intuition tells us that endogenous collateral constraints may subject the economy to speculation and self-fulfilling financial crisis. When the market value of collateral is above trend, for example, the practice of collateralized borrowing stimulates, instead of curtail-

\footnotetext{
${ }^{3}$ The first source of shocks is consistent with the collateral channel documented, among others, by Chaney, Sraer and Thesmar (2012) while the second embodies the keynesian notion of investment booms and busts.

${ }^{4}$ Of course, such a negative correlation between the market cost of borrowing and aggregate variables is at the heart of countercyclical policies, which aim at lowering the nominal interest rate in recessions so as to boost investment. Our results suggest such monetary policies - that set the nominal short term rate - may not be the full story behind countercyclical real interest rate movements.

${ }^{5}$ For recent theoretical models that shows the inherent instability of financial institutions under uncollateralized lending practices, see Gu, Mattesini, Monnet, and Wright (2013), Azariadis, Kaas, and Wen (2015).
} 
Figure 1: IRFs from VAR model with land price ordered first - one standard deviation shock $( \pm 2$ standard-error bands)

Response of Land Price to Land Price

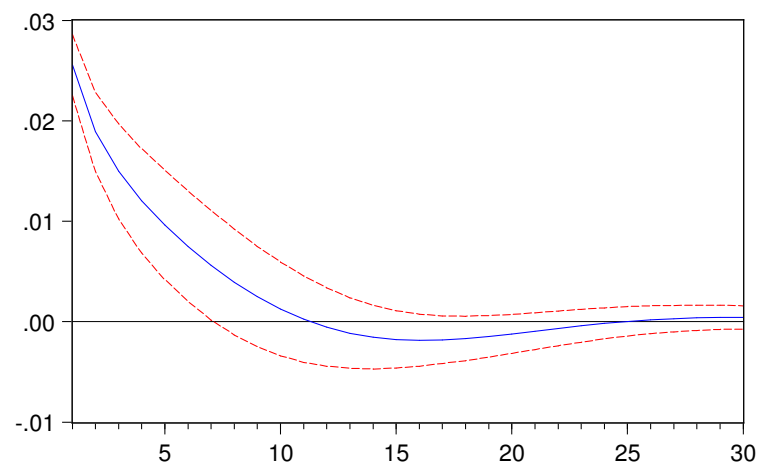

Response of Output to Land Price

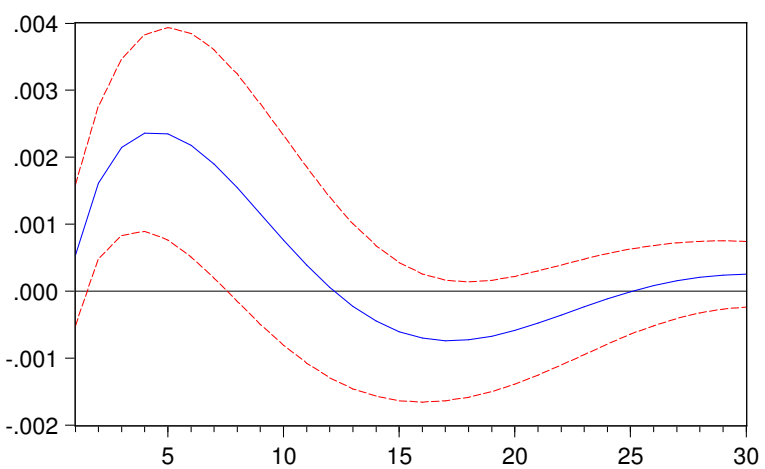

Response of Worked Hours to Land Price

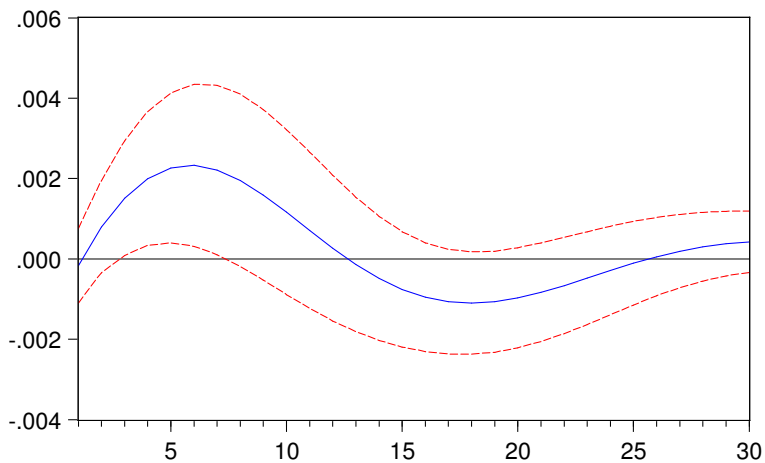

Response of Inverse Investment Price to Land Price

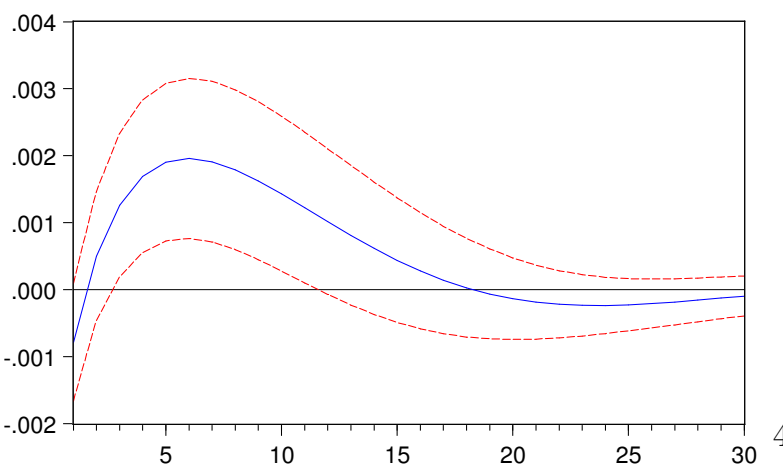

Response of Investment to Land Price

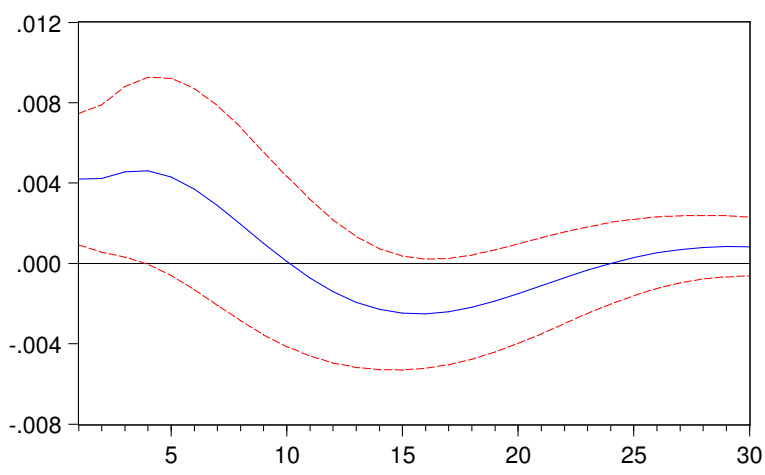

Response of Debt to Land Price

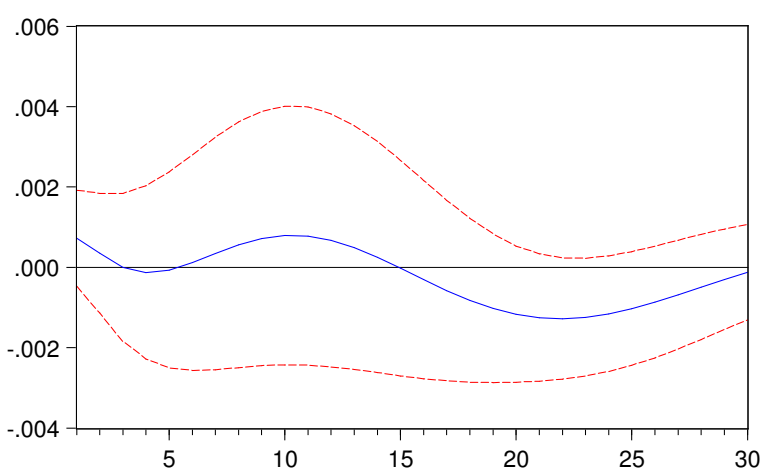

Response of Consumption to Land Price

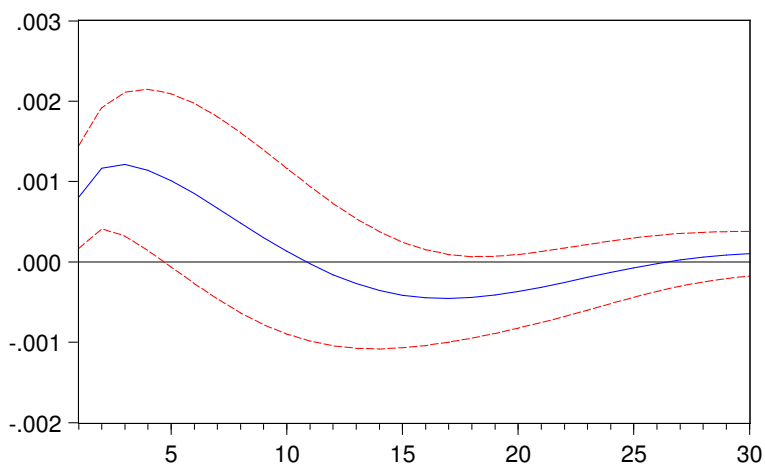

Response of Borrowing Interest Rate to Land Price

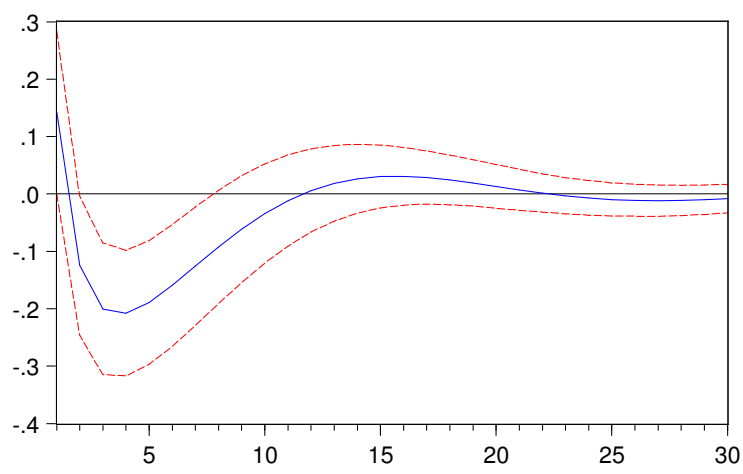


Figure 2: IRFs from VAR model with investment ordered first - one standard deviation shock ( \pm 2 standard-error bands)

Response of Investment to Investment

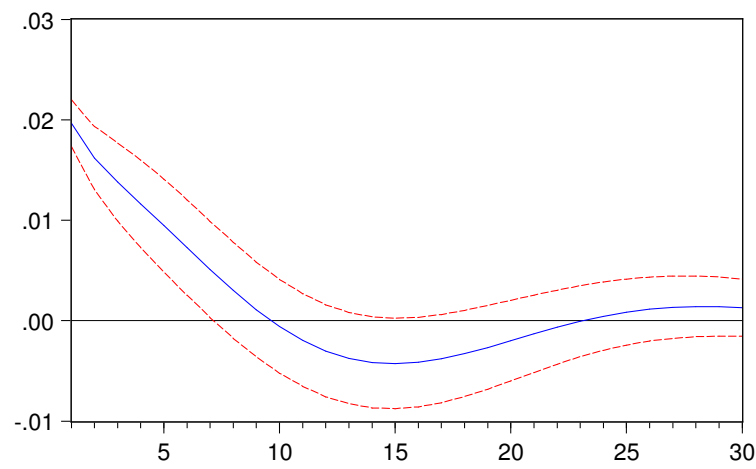

Response of Output to Investment

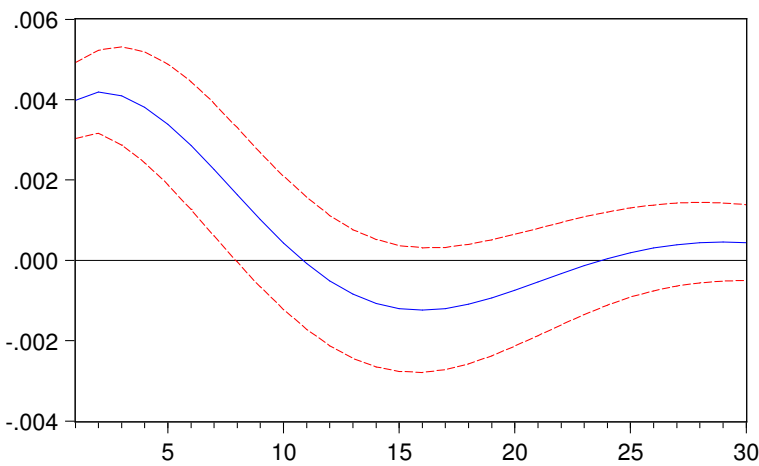

Response of Worked Hours to Investment

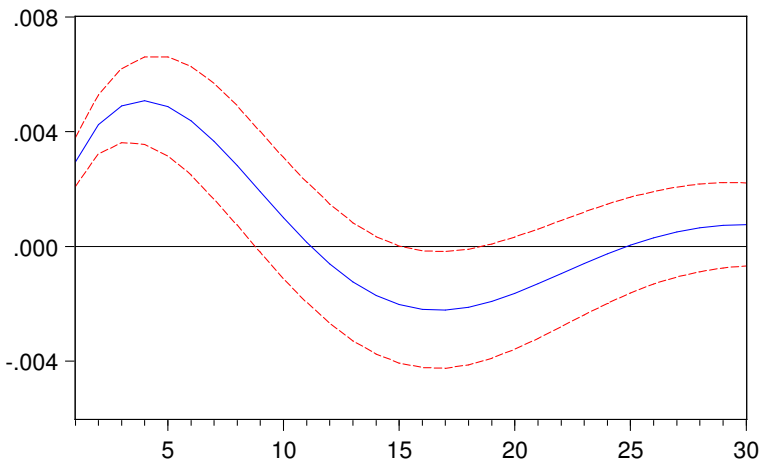

Response of Inverse Investment Price to Investment

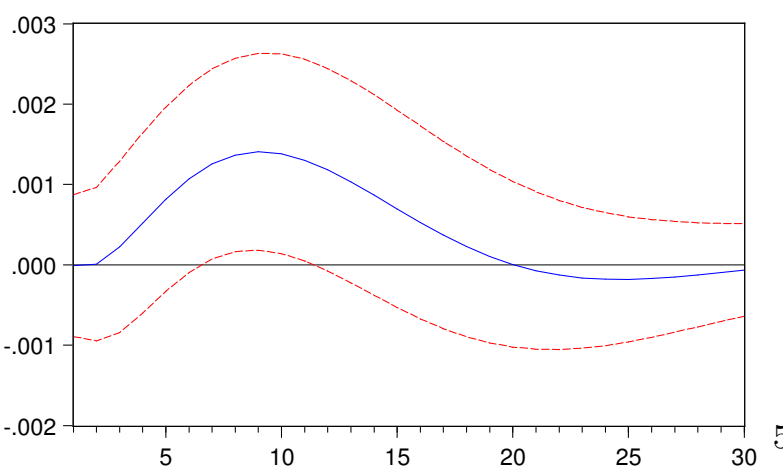

Response of Land Price to Investment

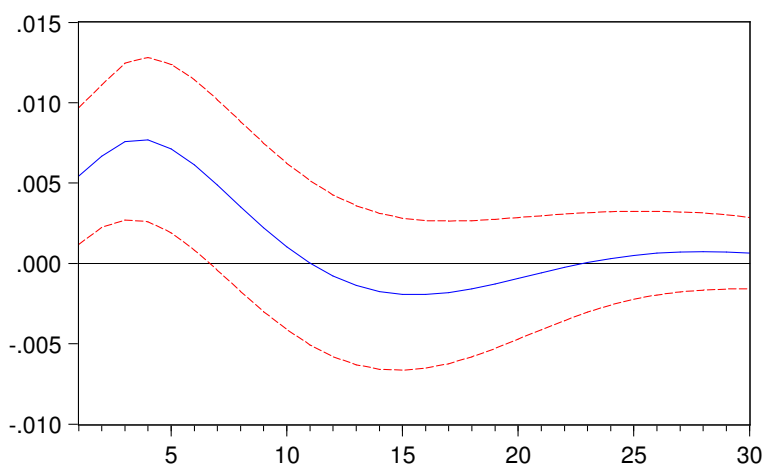

Response of Debt to Investment

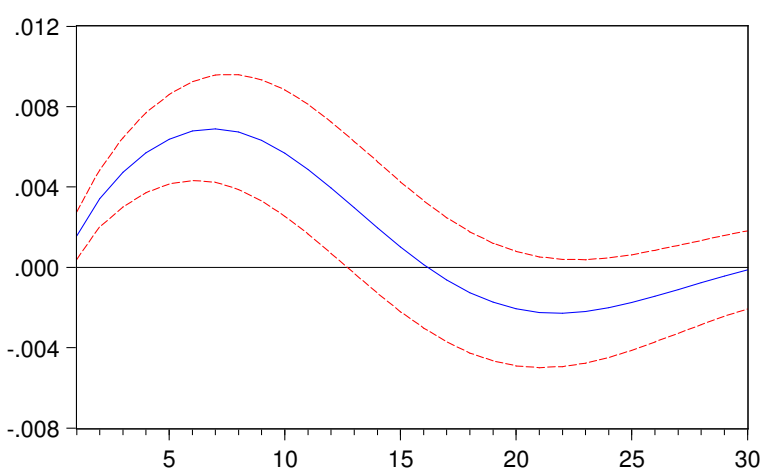

Response of Consumption to Investment

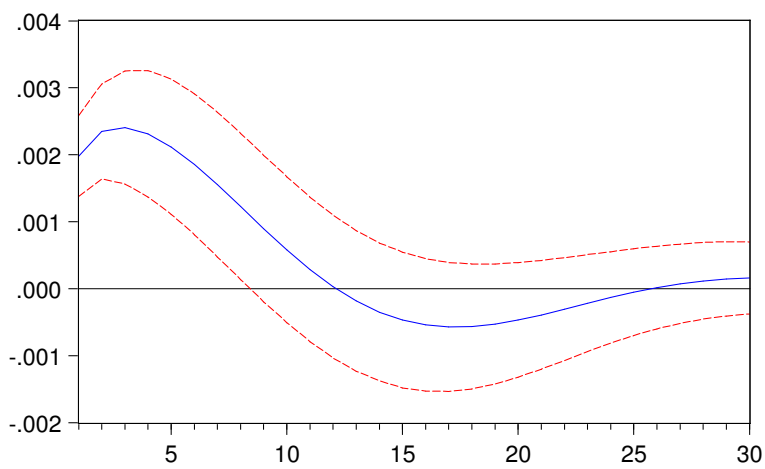

Response of Borrowing Interest Rate to Investment

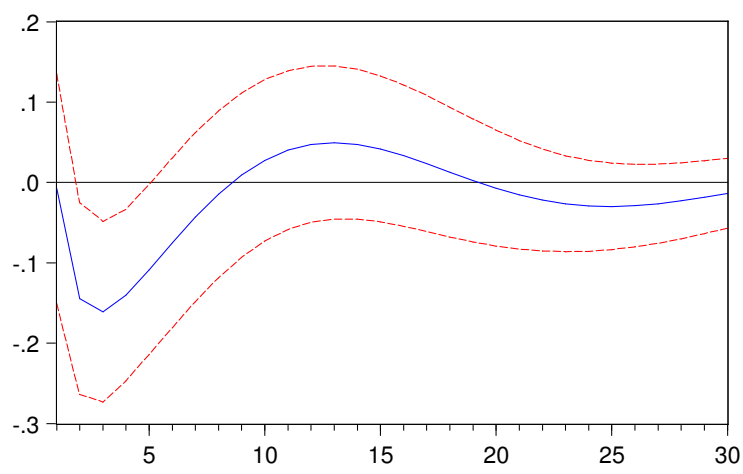


ing, credit lending, fueling the asset boom. Conversely, when the market value of collateral is below trend, collateralized borrowing restricts credit lending instead of relaxing it, exacerbating the crisis in a downturn. Hence, the market value of collateral generates an externality that serves not only to amplify and propagate business cycle shocks, but may also make expected changes in asset prices self-fulfilling, creating business-cycle movements even without any fundamental shocks to the economy. Of course, the amplification and propagation mechanism of collateralized borrowing through such an externality has long been noticed in the literature, and the seminal contribution by KM precisely emphasized such a mechanism. However, this literature shows that the KM constraint alone is not sufficient for generating the anticipated propagation mechanism (Kocherlakota, 2000, Cordoba and Ripoll, 2004, Pintus and Wen, 2013) and self-fulfilling business cycles, unless additional features or frictions such as fixed cost of production or transaction are added in conjunction with collateralized borrowing to generate self-fulfilling business cycles (see e.g. Benhabib and Wang, 2013, Liu and Wang, 2014).

The contribution of this paper is twofold. On the theory side, we show that borrowing constraints of the KM type are sufficient to generate self-fulfilling business cycles in asset prices and aggregate output, even in simple versions of the original model with realistic parameter values, provided interest payments are allowed to be state-contingent, as opposed to being predetermined as implicitly assumed in the existing literature. The intuition is straightforward: under a predetermined interest rate, simply relaxing the borrowing constraint via a higher value of the collateral does not by itself generate a higher demand for loans if the loan interest rate is expected to rise. Hence, once the credit market is in an equilibrium, an expectation of a higher asset value cannot be self-fulfilling unless the loanable funds rate is countercyclical. Therefore, key to our results is to relax the assumption that the interest rate on loan interest rate is predetermined. Vickery (2008) documents that US firms have been relying to a large extent on variable-rate borrowing over the last four decades. Although less important since the 2007-08 financial crisis, adjustable-rate mortgages have been a major source of financing for US households over the same time period (see Moench, Vickery, and Aragon, 2010). We show in this paper that collateralized loans with state-contingent interest rate produce financial instability, as they generate self-fulfilling equilibria for virtually all plausible parameter values.

On the empirical side, we perform a Bayesian estimation of the extended model on US data 1975-2010 and we show that self-fulfilling redistribution shocks are important, as their presence affect the propagation of fundamental financial shocks that have been stressed by previous quantitative studies. In addition, our estimation results establish that data overwhelmingly favor the (indeterminate) model with state-contingent interest rate over the traditional predetermined-interest rate (determinate) model à la KM, and that the former produces the $S$-shaped inverted leading indicator property of the real interest rate found in the data while the latter does not.

Regarding our theoretical contribution, we show that while loans with state-contingent interest rate lead to self-fulfilling, multiple equilibria near the steady state, loans with predetermined (or constant) interest rate do not. Multiplicity arises in our model because of an aggregate credit-demand externality: equilibria with lower interest rate imply lower debt repayment, making larger loan amounts affordable, which in turn imply larger investment demand and higher asset prices that benefit the lenders and encourage them to issue more loans to push down the interest rate. Intuitively, everything else equal, the expectation of a higher price of collateral 
is unable to induce a higher demand for loans unless the interest rate on loan payment is simultaneously lowered, which nonetheless cannot happen in a fixed-rate environment, thus preventing the original optimistic expectation of an asset boom to be self-fulfilling. In summary, self-fulfilling shocks that redistribute income away from lenders and benefit borrowers in booms are key in our model. The occurrence of self-fulfilling equilibria is shown to be very pervasive both in the basic model and in the extended quantitative model that we consider next, as it happens for virtually all parameter values. The technical reason why indeterminacy is so pervasive is easy to grasp, if not trivial. Essentially, moving from the fixed-interest rate economy to the state-contingent interest rate economy involves moving the time index of the interest one period ahead. Therefore, when the loan interest rate is predetermined, shocks that occur in period $t$ do not affect the interest payment due in the same period, in contrast with what happens in the state-contingent interest rate economy. More formally, this means that both economies share identical steady states and identical eigenvalues at their linearizations, but the economy with state-contingent interest rate has one more jump variable - since the loan interest rate is no longer predetermined - compared to the fixed-interest rate economy, which obviously leads to one-dimensional indeterminacy. Not surprisingly, multiplicity generates endogenous persistence of iid shocks and it is associated with different impulse responses to fundamental shocks as well as with a new role for redistibutions shocks through the borrowing cost in triggering volatility of the asset price and other aggregates.

This stark distinction between fixed-interest rate economies that are immune from self-fulfilling equilibria and state-contingent interest rate economies that are highly prone to self-fulfilling disturbances has eluded the literature, largely because most contributions assume that the interest rate is either exogenous (as in KM and more recently Mendoza, 2010, among others) or predetermined (as in Iacoviello, 2005, Iacoviello and Neri, 2010, Liu, Wang and Zha, 2013, Guerrieri and Iacoviello, 2013, Justiniano, Primiceri and Tambalotti, 2015a,b, among others). We argue that our results point at expectation-driven movements as a potential empirically relevant force behind credit booms and busts, since loans with state-contingent interest rate are a widespread form of borrowing in the US economy. This mechanism is tightly related to the recent work by Benhabib, Wang and Wen (2015), who show in otherwise standard RBC models that self-fulfilling equilibria arise naturally when producers make production decisions based on expected demand and consumers make consumption decision based on expected labor income, yet production takes place before goods markets clear and before real wages are realized. We add to their contribution by showing in a dynamic model that a similar insight applies to credit markets where lenders make loans based on expected collateral value of the borrowers and the borrowers make borrowing decisions based on expected interested payment, yet the volume of loans are negotiated in advance based on state-contingent interest rate, that is, when the interest rate on loan payments is allowed to fluctuate according to changes in credit market conditions. In such a natural environment with rational expectations, we show that credit-led boom-bust cycles can become self-fulfilling as outlined above: suppose the lender anticipates an investment boom with higher collateral value and thus unleashes more loans into the credit market, then a lowered interest rate would induce more demand for loans, which enables the borrowers to finance more investment and, consequently, increases their collateral value, thus fulfilling the lender's original optimistic expectations.

As a first step towards addressing the question of whether or not indeterminacy matters in quantitative 
terms, we use as a benchmark setup the more elaborated model of Liu, Wang and Zha (2013) in which there is a unique steady state that is determinate. We show that, just as in our basic model, determinacy is due to the assumption that the loan repaymnent is predetermined in the bond market formulation used by those authors. When the interest rate is assumed to be fixed or predetermined, a pecuniary externality (of the sort analyzed in Bianchi, 2011, and the references therein) is not sufficient for generating self-fulfilling asset price and investment fluctuations because the demand for credit depends not only on borrower's collateral value but also on the anticipated interest rate because of debt repayments. However, allowing loans with state-contingent interest rate leads to indeterminacy for virtually all plausible parameter values also in Liu, Wang and Zha (2013) since the borrowing cost falls in booms, which enables borrowers to borrow and invest more even though the price of the collateralizable asset may be fixed. We perform a Bayesian estimation of the extended quantitative model. The novelty of our estimation procedure is that we use our constructed measure of US firms' borrowing cost, that we compute using data from both Flow of Funds and NIPA accounts, on top of the US data 19752010 used by in Liu, Wang and Zha (2013). We estimate both the determinate model that obtains when the fraction of fixed-interest rate loans in the economy is large enough, and the indeterminate model (using the technique proposed in Farmer, Khramov, and Nicoló, 2015) when the fraction of loans with state-contingent interest rate in the economy is not too small. Our main findings are as follows. First, adding interest rate data alters results reported by Liu, Wang and Zha (2013) in the sense that housing demand shocks are found to be less important while risk-premium shocks turn out to be more important to explain the variances of output, investment, and worked hours. Second, we show that the occurrence of self-fulfulling equilibria drastically changes the propagation of fundamental shocks and the variance decomposition of output, investment, credit, and labor hours along US business and credit cycles. Finally, we show that the indeterminate model with selffulfilling redistribution shocks has a much better fit than the determinate model: the latter is overwhelmingly rejected against the former. This is, to our knowledge, the first set of evidence showing why redistribution shocks between lenders and borrowers matter quantitatively in a DSGE model with financial frictions.

In policy terms, the main implication of our results is that asset-backed credit markets are likely to experience boom-bust patterns driven by expectations when loans have a large state-contingent interest rate component, as in the US or the UK. Conversely, fixed-interest rate loans that are common practice in many continental Europe countries are an efficient tool to rule out self-fulfilling equilibria. Therefore, how the fraction of loans with state-contingent interest rate evolves over time should be a key indicator for monetary/prudential authorities.

Related Literature: Our analysis relates to the growing literature about debt deflation and redistribution (e.g. Calza, Monacelli and Stracca, 2013, Gomes, Jermann and Schmid, 2014, Auclert, 2016, Kaplan, Moll and Violante, 2016). Our results show that even if monetary policy is able to perfectly anchor inflation, shocks that redistribute income between lenders and borrowers may still occur as long as credit instruments allow for floating debt repayment. Financial innovation is an obvious force behind the development of such instruments and a contribution of this paper is to show that the associated redistributive effects are quite important for the business cycle. Our results are arguably reminiscent of earlier and famous views about how capitalist economies work. In particular, the main mechanism that is formalized in this paper can be viewed as the outcome of combining Keynes' idea of "animal spirits" as important drivers of investment decisions, on the one hand, and Minsky's 
views on financial instability driven by debt accumulation, on the other. This paper connects, of course, to more recent strands of research. We very much follow Backus, Kehoe and Kydland (1994) (see also, more recently, Gomme, Kydland and Rupert, 2001, and Kydland, Rupert and Šustek, 2015) by considering how the model matches not only contemporaneous correlations in the data but also dynamic lead-lag relationships, in our case between the borrowing cost and aggregate variables. In so doing, we provide a theoretical interpretation of the leading indicator property of interest rates pointed out by King and Watson (1996), that we also document for US firms borrowing cost. There is by now a large literature, to which this paper also belongs, about whether credit cycles are mostly explained by fundamental shocks, expectation - self-fulfilling - shocks or a combination of the two, which remains an unsettled issue and calls for further evidence both to understand the mechanisms at work and to guide sound policy. As part of the ongoing research agenda that tries to address this issue, a large literature has developed, building upon the seminal contributions of Bernanke and Gertler (1989) and KM. ${ }^{6}$ On the one hand, a robust result that several attempts to fit DSGE models with fundamental disturbances to data share is that financial shocks are important (Kiyotaki, Michaelides and Nikolov, 2011, Liu, Wang and Zha, 2013, Justiniano, Primiceri and Tombalotti, 2015a, among others). More precisely, land demand shocks, and to a lesser extent leverage shocks, are key drivers that help account for business-cycle data. In line with such an approach, Pintus and Wen (2013) have provided quantitative results showing how simple variants of KM's setting indeed produce significant and robust amplification of productivity and financial shocks that is line with evidence on credit booms, thus addressing early criticism about the plausibility of the collateral channel (e.g. Kocherlakota, 2000, Cordoba and Ripoll, 2004). On the other hand, in addition to amplifying fundamental shocks, endogenous borrowing constraints have been shown to originate multiple equilibria, as the early numerical examples in Cordoba and Ripoll (2004) have revealed in a simple RBC setup. In this approach, the emphasis is on self-fulfilling shocks as a possible driver of credit cycles. Building on these early examples, Benhabib and Wang (2013) and Liu and Wang (2014) have further examined how various forms of fixed costs and the associated increasing returns - make indeterminacy and self-fulfilling business cycles more likely than the model without fixed cost analyzed by Cordoba and Ripoll (2004). ${ }^{7}$ In contrast with Benhabib and Wang (2013) and Liu and Wang (2014), we do not introduce fixed costs. Multiplicity is shown to be very pervasive both in our basic model and in the extended quantitative model that we consider next, as it happens for virtually all parameter values. This is in sharp contrast with Benhabib and Wang (2013) and Liu and Wang (2014), who show that the indeterminacy parameter region such is rather small. In addition, the novelty of our paper, compared to earlier studies, is to provide estimation results about the quantitative importance of self-fulfilling shocks in US data.

In what follows, Section 2 reports some empirical motivation of the paper. Section 3 presents a basic setup with loans that are collateralized and have state-contingent interest rate and it shows that such model generates local indeterminacy and self-fulfilling collateral cycles for virtually all parameter values. Section 4 shows that

\footnotetext{
${ }^{6}$ This strand of literature has shown how endogenous borrowing constraints amplify shocks and generate excess-volatility that would not materialize absent credit markets. Early papers include Carlstrom and Fuerst (1997), Krishnamurthy (2003), Cooley, Marimon, and Quadrini (2004), Iacoviello (2005), Campbell and Hercowitz (2006), Boháček and Rodríguez Mendizábal (2007), Christiano, Motto, and Rostagno (2010) among many others.

${ }^{7}$ More recently, He, Wright and Zhu (2014) have shown that bubbly and cyclical patterns driven by expectations arise in search environments subject to KM constraints. In addition, labor and credit market frictions interact to create indeterminacy in the model of Kaas, Pintus, and Ray (2014).
} 
local indeterminacy is robustly pervasive by considering extensions of the basic model that we use to conduct our estimation analysis and to show that redistribution shocks matter. Section 5 concludes the paper with remarks for future research, and an Appendix gathers proofs.

\section{Empirical Motivation: Lead-Lag Correlations from Aggregate Data}

We first present some stylized facts about the dynamic relationships between macroeconomic variables at quarterly frequency. More precisely, we report the lead-lag correlations of all variables with the interest rate, which we construct from the time series generated by the impulse responses in Figures 1 and 2. In all figures of this section, all variables are real, with $R$ denoting the interest rate, $Q l$ land price, $C$ consumption, $B$ corporate and noncorporate nonfinancial firms' debt, $I$ capital investment, $N$ working hours. The dynamic correlations that we obtain are therefore conditional on either a land price shock (Figure 3) or an investment shock (Figure 4). The most striking feature in both Figure 3 and Figure 4 is that the empirical dynamic correlations of the interest rate with all other variables have an $S$-shaped pattern. While King and Watson (1996) reported a similar pattern for the rate on three month Treasury bills, which is a policy instrument, our VAR results extend their findings to a measure of market borrowing cost faced by US firms. Consistent with the IRFs reported above, the contemporaneous correlations of the interest rate with virtually all variables are negative. So as to get a first sense of how empirically relevant the settings developed and estimated in the next sections are, in the next two figures we report the dynamic correlations that are predicted by our two competing models. More specifically, the question we now ask is whether the determinate model with predetermined loan interest rate, the indeterminate model with state-contingent loan interest rate, or both replicate the lead-lag correlations reported in Figures 3-4. The response is that the latter does while the former does not.

Figure 5 reports the theoretical lead-lag correlations that are produced by the determinate model with predetermined loan interest rate, when a positive shock to household's land demand hits and triggers a boom. Dynamic correlations in Figure 6 arise in the indeterminate model with loans that have state-contingent interest rate, when a negative shock to the interest rate redistributes income from lenders to borrowers.

Inspection of Figures 5 and 6 clearly shows that while the determinate model does not produce the $S$-shape pattern that is a feature of the data in view of Figures 3 and 4, the indeterminate model is more successful in that respect. 8 This is because while both models predict that credit demand and credit supply go up in booms, they reach opposite conclusions regarding the net effect of those changes. The determinate model predicts that the interest rate is procyclical, which suggests that changes in the rate that is charged in the credit market are mainly determined by a rise of credit demand during good times. In contrast, the loan interest rate is countercyclical in the indeterminate model, which means that supply changes dominate demand changes so that the interest rate falls during booms. The evidence from both VAR models and dynamic correlations reported in this section suggests that the indeterminate model with state-contingent loan interest rate is more in line with the data than the determinate model with predetermined interest rate. In particular, the indeterminate model not only correctly predicts that contemporaneous correlations between the interest and macroeconomic variables are negative but also that low levels of borrowing cost predicts future booms. We examine more formally those

\footnotetext{
${ }^{8}$ We have checked that similar conclusions are reached under other sources of shocks.
} 
Figure 3: Empirical dynamic correlations from VAR with land price ordered first
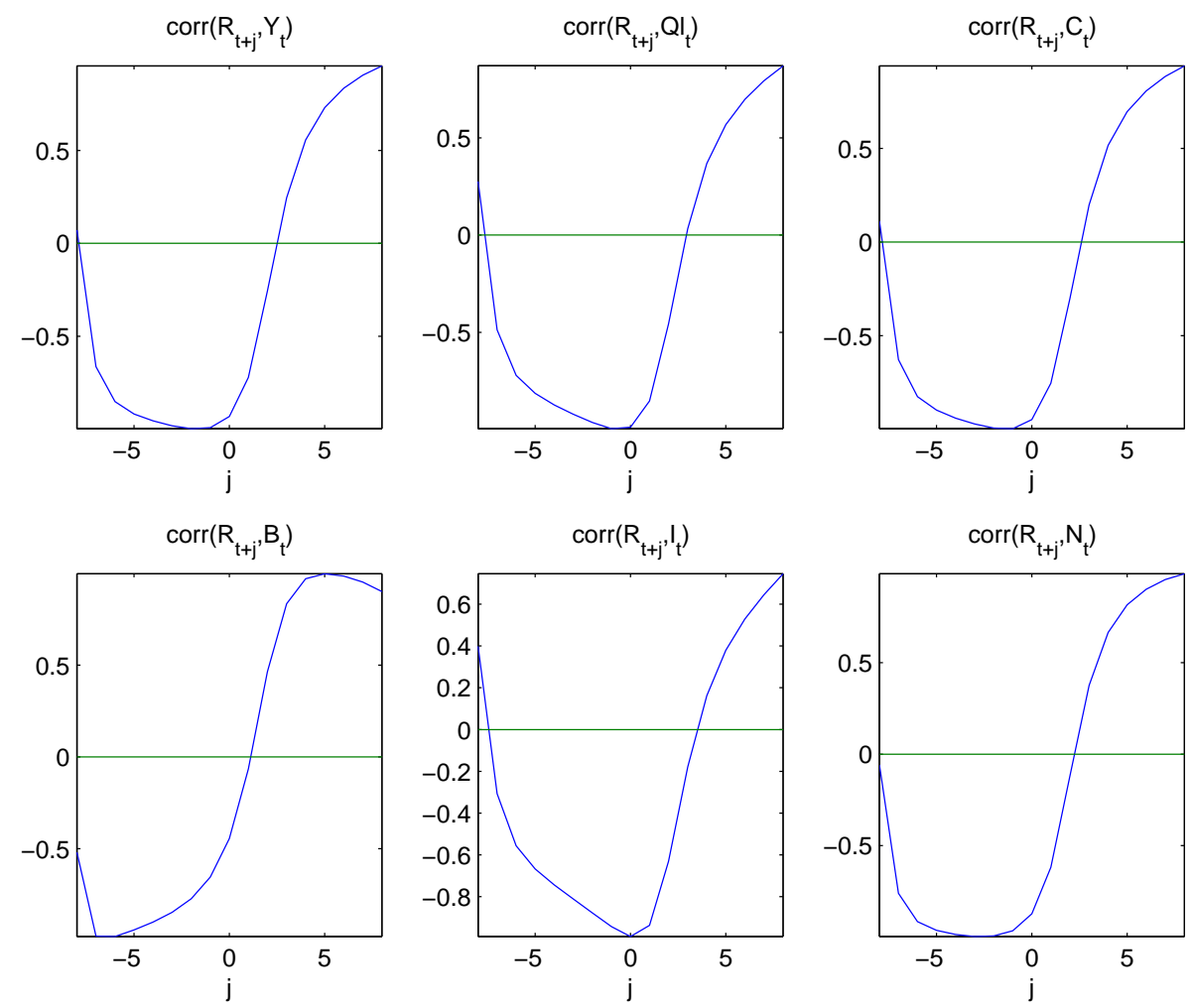

Figure 4: Empirical dynamic correlations from VAR with investment ordered first
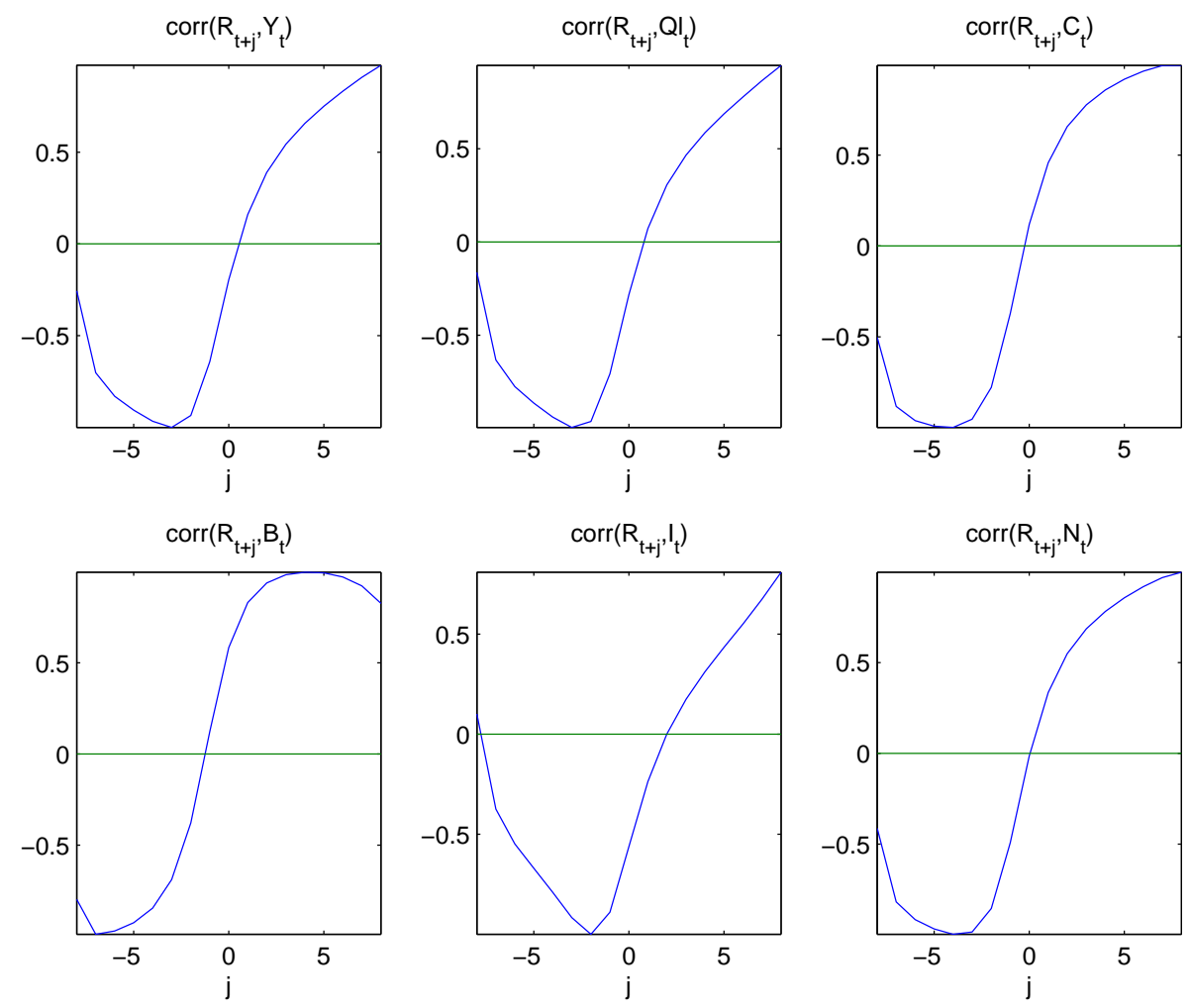
Figure 5: Theoretical dynamic correlations from determinate model with land price shock (95\% confidence bands)
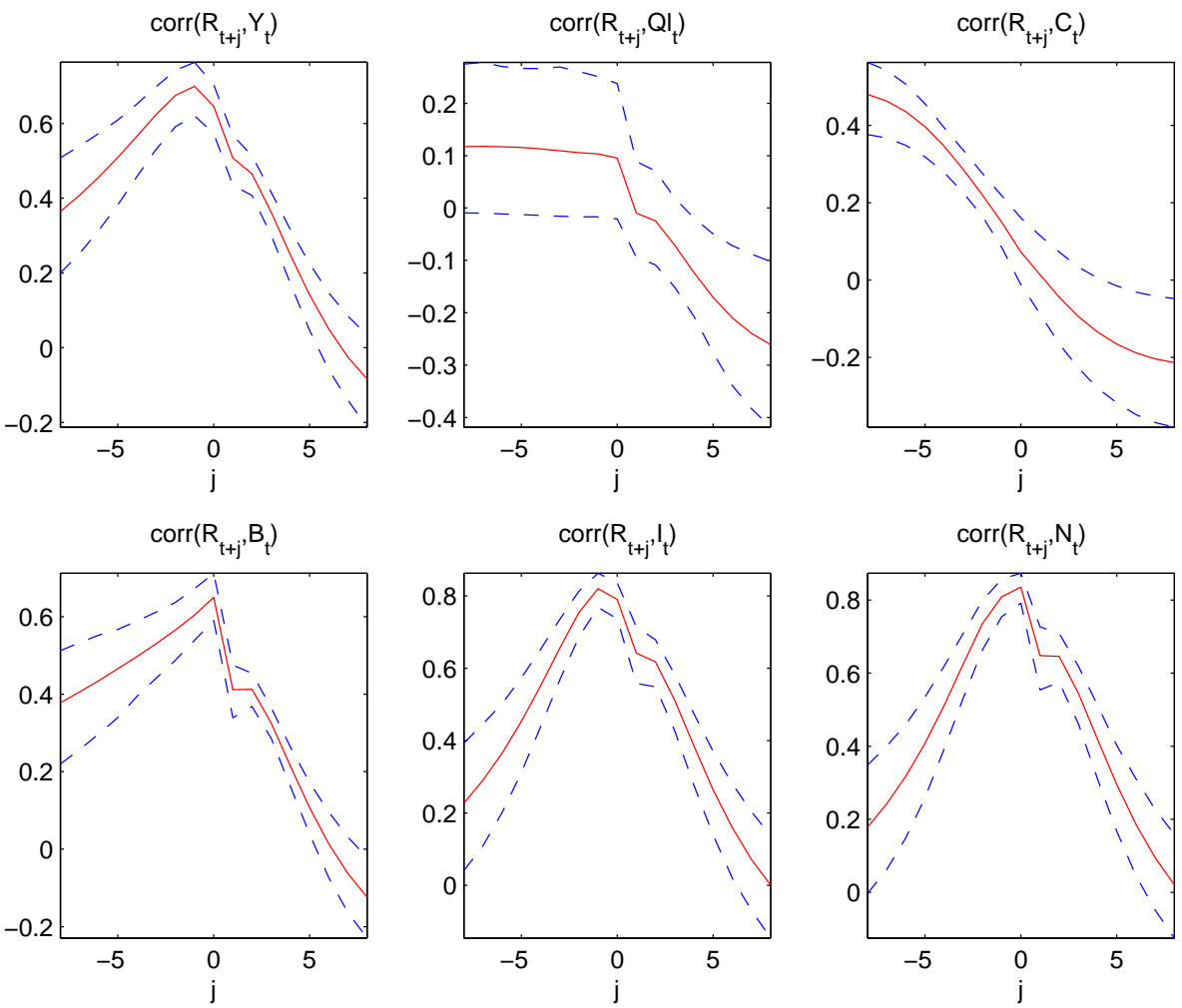

Figure 6: Theoretical dynamic correlations from indeterminate model with redistribution shock (95\% confidence bands)
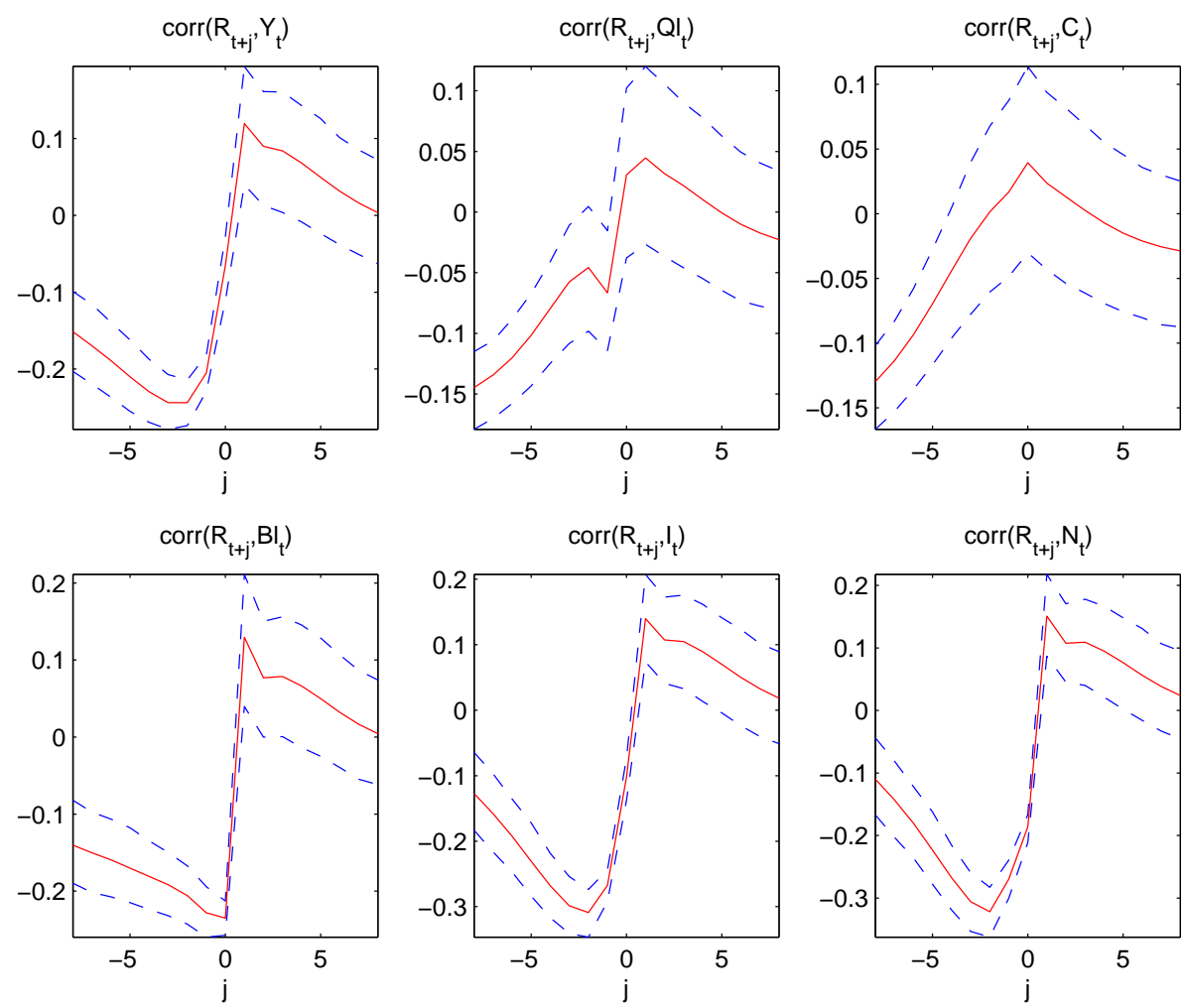
aspects in the following sections, which develop and estimate both models, where we show that the self-fulfilling model does a good job along other dimensions as well.

\section{Self-Fulfilling Equilibria in a Basic Model with State-Contingent Interest Rate}

In this section we show that incorporating loans with state-contingent interest rate into the small-scale setup developed in Pintus and Wen (2013) triggers an aggregate credit-demand externality that leads to steady-state indeterminacy for virtually all parameter values. We provide a simple example in which the existence of global self-fulfilling equilibria is derived analytically and then show how local self-fulfilling equilibria occur in the linearized version of the more general version of the model. The key shock that is emphasized is one that redistributes income away from lenders and to borrowers in booms because of countercyclical loan repayments.

\subsection{Assumptions}

There are two types of infinitely-long lived agents in the economy, lenders and borrowers. Lenders do not produce, but provide loans (credit) to borrowers. In this sense, lenders serve the role of banks or financial intermediaries in the economy. The type of credit provided by lenders are one-period loans that can be used to finance consumption and land investment. Lenders derive utilities from consumption and land, ${ }^{9}$ do not accumulate fixed capital, and use interest income from payment on previous loans to finance current consumption and land investment. The budget constraint of a representative lender is given by

$$
\tilde{C}_{t}+Q_{t}\left(\tilde{L}_{t+1}-\tilde{L}_{t}\right)+B_{t+1}^{l} \leq R_{t} B_{t}^{l}
$$

where $\tilde{C}_{t}$ denotes consumption, $\tilde{L}_{t}$ the amount of land owned by the lender in the beginning of period $t, Q_{t}$ the relative price of land, $B_{t+1}^{l}$ the amount of new loans (credit lending) generated in period $t$, and $R_{t}$ the gross real interest rate. The instantaneous utility function of the lender is given by

$$
U_{L}=\frac{\tilde{C}_{t}^{1-\sigma_{L}}}{1-\sigma_{L}}+\psi_{t} \frac{\tilde{L}_{t}^{1-\sigma_{W}}}{1-\sigma_{W}}, \quad\left\{\sigma_{L}, \sigma_{W}\right\} \geq 0
$$

and the time discounting factor is $\tilde{\beta} \in(0,1)$. In addition, $\psi_{t}$ is a scale parameter affecting lender's preference for land, that we will use as a source of fundamental shocks to the land price.

We later use both TFP and financial shocks in our quantitative analysis and we use changes in the loan-tovalue ratio and in the scale factor of land utility as proxies for financial shocks that affect the land price.

Borrowers can produce goods using land and capital. ${ }^{10}$ The production technology is given by

$$
Y_{t}=A_{t} K_{t}^{\alpha} L_{t}^{\gamma}, \quad \alpha, \gamma \in(0,1), \alpha+\gamma<1
$$

\footnotetext{
${ }^{9}$ As in Iacoviello (2005), the lender's asset demand comes from utility attached to land.

${ }^{10}$ Labor supply is assumed to be fixed in the basic model and elastic labor will be introduced in Section 4.
} 
where $A_{t}$ is TFP, $L_{t}$ denotes the amount of land owned by the borrower, and $K_{t}$ denotes capital stock. Capital is reproducible but the total amount of land is in fixed supply,

$$
L_{t}+\tilde{L}_{t}=\bar{L}
$$

We allow land in the model so as to study asset price and collateral movements and also to keep the model comparable to KM and the related literature.

A representative borrower in each period needs to finance consumption $C_{t}$, land investment $L_{t+1}-L_{t}$, capital investment $K_{t+1}-(1-\delta) K_{t}$, and loan interest rate $R_{t} B_{t}^{l}$, where $\delta \in(0,1)$ is the depreciation rate of capital. The budget constraint of the borrower is given by

$$
C_{t}+K_{t+1}-(1-\delta) K_{t}+Q_{t}\left(L_{t+1}-L_{t}\right)+R_{t} B_{t}^{l} \leq B_{t+1}^{l}+A_{t} K_{t}^{\alpha} L_{t}^{\gamma}
$$

An important feature of the budget constraint is that the debt repayment is not predetermined in period $t$, as the endogenous interest rate adjusts to fundamental and possibly self-fulfilling shocks. The per-period utility function of the representative borrower is given by

$$
U_{B}=\frac{C_{t}^{1-\sigma_{B}}}{1-\sigma_{B}}, \quad \sigma_{B} \geq 0
$$

and her discount factor is $\beta \in(0,1)$. Borrowers are assumed to be less patient than lenders, that is, their time discounting factor satisfies $\beta<\tilde{\beta}$.

The ex-ante borrowing constraint faced by the borrower is

$$
\mathbb{E}_{t} R_{t+1} B_{t+1}^{l} \leq \theta_{t} \mathbb{E}_{t} Q_{t+1} L_{t+1}
$$

where $\theta_{t}$ is the loan-to-value ratio and reflects shocks to terms of loans or current financial conditions. For example, a positive shock to $\theta_{t}$ implies that creditors are willing to lend more with the same collateral value of land. Following KM, reproducible capital does not have collateral value in our model but relaxing this assumption does not affect our results. ${ }^{11}$ The borrowing constraint imposes that the amount of debt in the beginning of the next period cannot exceed a fraction $\theta_{t}(\leq 1)$ of the collateral value of assets owned by the borrower next period. The rationale for this constraint is that, due to lack of contractual enforceability, the lender has incentives to lend today only if the loan is secured by the value of the collateral that will be realized tomorrow. Therefore, the lender has to forecast in period $t$ both the debt obligations that will be redeemed and the market value of collateral that will prevail in $t+1$. In contrast with $\mathrm{KM}$, who assume a fixed interest rate, the fact that the interest rate is variable is a key feature for our results. ${ }^{12}$ Before we analyze competitive equilibria with debt constraint, it is perhaps useful to recall that in the first-best allocation, absent such constraint, the dynamics of the model is very similar to that of a standard RBC model. Equilibrium near steady-state is unique and there is no hump-shaped cyclical propagation mechanism in such a model for realistic parameter values on the lender side (see Pintus and Wen, 2013).

\footnotetext{
${ }^{11}$ Section 4 develops a model with collateralizable capital.

${ }^{12}$ As long as what matters in the borrowing constraint is the amount of outstanding debt, it is possible to relax the assumption that debt matures after one period while keeping our main results unchanged.
} 


\subsection{Competitive Equilibrium with Borrowing Constraints}

Denoting $\tilde{\Lambda}_{t}$ the Lagrangian multiplier of the constraint (1), the first-order conditions of the lender with respect to consumption, land investment, and lending are given, respectively, by

$$
\begin{gathered}
\tilde{C}_{t}^{-\sigma_{L}}=\tilde{\Lambda}_{t} \\
Q_{t} \tilde{\Lambda}_{t}=\tilde{\beta} \mathbb{E}_{t} Q_{t+1} \tilde{\Lambda}_{t+1}+\tilde{\beta} \psi_{t} \tilde{L}_{t+1}^{-\sigma} \\
\tilde{\Lambda}_{t}=\tilde{\beta} \mathbb{E}_{t} R_{t+1} \tilde{\Lambda}_{t+1} .
\end{gathered}
$$

Denoting $\left\{\Lambda_{t}, \Phi_{t}\right\}$ the Lagrangian multipliers of constraints (5) and (7), respectively, the first-order conditions of the borrower with respect to consumption, land investment, capital investment, and borrowing are given, respectively, by

$$
\begin{gathered}
C_{t}^{-\sigma_{B}}=\Lambda_{t} \\
Q_{t} \Lambda_{t}=\beta \mathbb{E}_{t} Q_{t+1} \Lambda_{t+1}+\beta \gamma \mathbb{E}_{t} \frac{Y_{t+1}}{L_{t+1}} \Lambda_{t+1}+\theta_{t} \Phi_{t} \mathbb{E}_{t} Q_{t+1} \\
\Lambda_{t}=\beta \mathbb{E}_{t} \Lambda_{t+1}\left[\alpha \frac{Y_{t+1}}{K_{t+1}}+1-\delta\right] \\
\Lambda_{t}=\mathbb{E}_{t} R_{t+1}\left(\beta \Lambda_{t+1}+\Phi_{t}\right) .
\end{gathered}
$$

A rational expectations competitive equilibrium is a sequence of allocations $\left\{C_{t}, \tilde{C}_{t}, B_{t+1}^{l}, K_{t+1}, L_{t+1}, \tilde{L}_{t+1}\right\}_{t=0}^{\infty}$ and prices $\left\{Q_{t}, R_{t}\right\}_{t=0}^{\infty}$ such that, given exogenous processes for $\theta_{t}, \psi_{t}, A_{t}$ :

(i) $\left\{C_{t}, \tilde{C}_{t}, B_{t+1}^{l}, K_{t+1}, L_{t+1}, \tilde{L}_{t+1}\right\}_{t=0}^{\infty}$ satisfies the first-order conditions (8)-(14), the transversality conditions, $\lim _{t \rightarrow \infty} \beta^{t} \Lambda_{t} L_{t+1}=\lim _{t \rightarrow \infty} \beta^{t} \Lambda_{t} K_{t+1}=\lim _{t \rightarrow \infty} \tilde{\beta}^{t} \tilde{\Lambda}_{t} \tilde{L}_{t+1}=0$, and the complementarity condition, $\Phi_{t}\left[\theta_{t} \mathbb{E}_{t} Q_{t+1} L_{t+1}-\mathbb{E}_{t}\left(1+R_{t+1}\right) B_{t+1}^{l}\right]=0$ for all $t \geq 0$, given $\left\{Q_{t}, R_{t}\right\}_{t=0}^{\infty}$ and the initial endowments $L_{0} \geq$ $0, \tilde{L}_{0} \geq 0, B_{0}^{l} \geq 0, K_{0} \geq 0$

(ii) The good and asset markets clear for all $t, C_{t}+\tilde{C}_{t}+K_{t+1}-(1-\delta) K_{t}=A_{t} K_{t}^{\alpha} L_{t}^{\gamma}$ and $L_{t}+\tilde{L}_{t}=\bar{L}$, respectively.

The model has a determinate steady-state equilibrium and a unique saddle-path that converges to it, for which the borrower is credit-constrained, i.e., equation (7) binds for all $t$, provided that the number of stable eigenvalues is equal to the number of predetermined variables. In contrast, the steady-state is an indeterminate saddle with a binding credit-constraint if there are more stable eigenvalues than predetermined variables. It turns out that, as shown in Section 3.4, the indeterminacy is one-dimensional, which means that there is only one more stable eigenvalue.

We abstract from any corner solutions with zero credit and, for simplicity, we assume that the steady state value of $\theta_{t}=1$ in the benchmark model. ${ }^{13}$ In the steady state, equation (10) indicates that the interest rate is determined by the lender's time discounting factor, $R=\tilde{\beta}^{-1}$. This interest rate of loanable funds is lower than

\footnotetext{
${ }^{13}$ Our results remain qualitatively the same if $\theta<1$ as shown below.
} 
the return determined by the firm's marginal product of capital. Equation (14) then implies $\Phi=(\tilde{\beta}-\beta) \Lambda>0$, suggesting that the borrowing constraint binds around the steady state. Equation (13) implies that the capitalto-output ratio is given by $\frac{K}{Y}=\frac{\beta \alpha}{1-\beta(1-\delta)}$. The capital-to-output ratio determines the return from capital, which is equal to the loanable funds rate if $\beta=\tilde{\beta}$; or, as in the first-best economy, if there exists perfect risk sharing without borrowing constraints. Since $\theta=1$, equation (12) implies $Q=(1-\tilde{\beta})^{-1} \beta \gamma \frac{Y}{L}=\sum_{j=0}^{\infty} \tilde{\beta}^{j} \beta \gamma \frac{Y}{L}$, suggesting that the price of land is determined by the present value of its marginal products. If $\theta<1$, the price of land, $Q=(1-\beta-\theta(\tilde{\beta}-\beta))^{-1} \beta \gamma \frac{Y}{L}<(1-\tilde{\beta})^{-1} \beta \gamma \frac{Y}{L}$, is adjusted downward by the loan-to-collateral ratio because, other things equal, a tighter credit constraint decreases incentives for accumulating land. If $\theta=1$, the lender's budget constraint implies $\tilde{C}=(1-\tilde{\beta}) Q L=\beta \gamma Y$, suggesting that the lender's consumption level is just the interest income, which is proportional to aggregate output. The borrower's budget constraint implies $C+[\delta K+\beta \gamma Y]=Y$, where the bracketed term denotes savings, and part of the savings, $\beta \gamma Y=(1-\tilde{\beta}) Q L$, is used to finance the loan and equals the lender's interest income. This indicates that the lender serves essentially as a bank and the borrower's total business investment can deviate from own savings because of bank's credit lending. In addition, since the value of $\gamma$ is small, lender's consumption share $(\beta \gamma)$ will be small, so lender does not play a direct role in aggregate consumption and this is what we have in mind for the financial sector. All of the great ratios (e.g., capital-to-output ratio, land-to-output ratio, consumption-to-output ratio) are determined as functions of the model's structural parameters only. Once the steady-state distribution of land is determined, the steady-state values of all other variables are determined through the great ratios. Because equation (12) is the demand curve of land and equation (9) gives the supply curve of land, the steady-state distribution of land across agents is determined uniquely by the implicit equation,

$$
\beta \gamma \frac{Y(L)}{L}=\tilde{\beta} \psi(\bar{L}-L)^{-\sigma_{W}} \tilde{C}(L)^{\sigma_{L}}
$$

where the left-hand side decreases in $L$ and the right-hand side increases in $L$, resulting in a unique solution for land allocation in steady state.

\subsection{Global Self-Fulfilling Equilibria: an Analytical Example}

The purpose of this section is to provide a constructive proof that global self-fulfilling equilibria exist in the economy with state-contingent interest rate and that they do not in the corresponding fixed-interest rate economy. All fundamental shocks are shut down in this section. So as to get closed-form decision rules and analytical results, we assume away capital and we simplify preferences and technology. More precisely, technology is linear (that is, $\gamma=1$ ), the lender has linear utility (that is, $\sigma_{L}=\sigma_{W}=0$ ) while the borrower has log utility (that is, $\left.\sigma_{B}=1\right)$. In addition, the loan-to-collateral ratio, TFP and the scale parameter for land utility are constant over time, with $A=1$ so that $Y_{t}=L_{t}, \theta=1$, whereas $\psi$ is fixed so as to ensure that a steady-state exists.

Under $\sigma_{L}=\sigma_{W}=0$, the first-order conditions (8)-(10) imply that both the expected interest rate and the land price are constant over time, that is $\mathbb{E}_{t} R_{t+1}=\tilde{\beta}^{-1}$ and, using the steady-state expressions for (12) and 
(14), $Q=\beta /(1-\tilde{\beta})$ is the constant land price. ${ }^{14}$ In addition, (14) can be solved for $\Phi_{t}$, the expression of which can then be plugged into (12) to get:

$$
\Lambda_{t}=\mathbb{E}_{t} X_{t+1} \Lambda_{t+1}
$$

where $X_{t} \equiv 1+Q\left(1-\tilde{\beta} R_{t}\right)$ represents borrower's income net of interest payment, that is therefore available for consumption and down-payment for land investment. In addition, the binding credit constraint gives $B_{t+1}^{l}=$ $\tilde{\beta} Q L_{t+1}$, which we plug into the borrower's budget constraint to get:

$$
C_{t}+Q(1-\tilde{\beta}) L_{t+1}=X_{t} L_{t}
$$

It is then easy to show that the lender's consumption and land demand have closed-form solutions that are given by $C_{t}=(1-\beta) X_{t} L_{t}$ and $Q(1-\tilde{\beta}) L_{t+1}=\beta X_{t} L_{t}$. It follows that equilibria are in this simplified economy given by $L_{t+1}=X_{t} L_{t}$ with $X_{t} \equiv 1+Q\left(1-\tilde{\beta} R_{t}\right)$ and $\mathbb{E}_{t} R_{t+1}=\tilde{\beta}^{-1}$. Therefore, self-fulfilling equilibria are simply constructed as solutions to $L_{t+1}=\left[1+Q\left(1-\tilde{\beta} R_{t}\right)\right] L_{t}$ and $\tilde{\beta} R_{t}=1+\varepsilon_{t}$, where the innovation $\varepsilon_{t}$ is any i.i.d. random variable with zero mean, given initial value $L_{0}>0$. The dynamics of consumption, output and borrowing all follow from that of the land stock allocated to the borrower. ${ }^{15}$ As as apparent from 16 and 17 , the key driver is a redistributive shock that affects the borrower's return from accumulating land, that is, $R$, hence his income. The notion is that state-contingent interest rate is countercyclical so that income is redistributed away from lenders in booms that feature higher investment and output. Formally, we can state the following result.

\section{Proposition 1 (An Analytical Example of Global Self-Fulfilling Equilibria)}

Suppose there is no capital, technology is linear $(\gamma=1)$, lender has linear utility $\left(\sigma_{L}=\sigma_{W}=0\right)$, borrower has $\log$ utility $\left(\sigma_{B}=1\right)$ and $A=1, \theta=1, \psi=\beta / \tilde{\beta}$. In addition, all fundamental shocks are shut down.

Then there exist global self-fulfilling equilibria such that the dynamics of the land stock allocated to the borrower follows the stochastic difference equation $L_{t+1}=\left[1+Q\left(1-\tilde{\beta} R_{t}\right)\right] L_{t}$ for all $t \geq 0$, given initial value $L_{0}>0$, where the gross interest rate is given by $R_{t}=\tilde{\beta}^{-1}\left(1+\varepsilon_{t}\right)$ and the innovation $\varepsilon_{t}$ is an i.i.d. random variable with zero mean.

Before moving on to the analysis of the basic model in its general form that is developed in the next section, it is interesting to contrast the above results with what happens in the economy with fixed-interest rate loans. By this we mean that the borrower's budget and credit constraints are now:

$$
\begin{gathered}
C_{t}+Q\left(L_{t+1}-L_{t}\right)+R_{t-1} B_{t}^{l} \leq B_{t+1}^{l}+L_{t} \\
R_{t} B_{t+1}^{l} \leq Q L_{t+1}
\end{gathered}
$$

\footnotetext{
${ }^{14}$ In addition, (9) imposes that $\psi=\beta / \tilde{\beta}<1$.

${ }^{15}$ Obviously, the logarithm of land stock follows a random walk in the analytical example of this section, with absorbing barriers at the values 0 and $\bar{L}$ for $L$. Standard theory of random processes shows that the probability of non-absorbing states tends to zero geometrically fast as time goes to infinity. Alternatively, reflecting (or more generally elastic) barriers at the end points of the feasible interval can be introduced so as to ensure permanent fluctuations along a self-fulfilling equilibrium.
} 
while the lender's budget constraint is:

$$
\tilde{C}_{t}+Q\left(\tilde{L}_{t+1}-\tilde{L}_{t}\right)+B_{t+1}^{l} \leq R_{t-1} B_{t}^{l}
$$

so that the interest repayment due in period $t$ is now predetermined while the interest rate that enters the credit constraint is variable but now known in period $t$. It is then easy, using again the lender's first-order condition (10), to show that the interest rate is constant over time, that is, $R_{t}=\tilde{\beta}^{-1}$, so that $X_{t}=1$ at all dates and the economy is forever in steady state absent fundamental shocks.

In contrast Proposition 1 shows that the economy with state-contingent interest rate is subject to global selffulfilling equilibria, with both the growth rate $X$ and output $Y=L$ driven by self-fulfilling redistribution innovations. As an illustrative example, Figure 7 reports a sample path of such an economy when $\beta=0.95$ and $\tilde{\beta}=0.99$, while the innovations have zero mean and standard deviation close to zero. Figure 7 makes clear that the state-contingent interest rate economy is subject to self-fulfilling innovations, whereas the fixed-interest rate economy is not and stays at steady state. The main mechanism is that a falling interest rate triggers a boom, as we now explain in a more detailed way.

\section{Dissecting the Mechanism: Self-fulfilling Countercyclical Changes in the Interest Rate}

The small-scale model of this section is useful to develop some intuition about the mechanisms at work and why those differ in the fixed-interest rate and state-contingent interest rate economies. It is perhaps enlightening to proceed in two steps, by considering first the simplified version of this section, so as to extract the essence of the main channels, and to turn next to the general version discussed in Section 3.4.

In the model without capital and risk-neutral lender of this section, let us notice first that land price is fixed, as it equals $Q=\beta /(1-\tilde{\beta})$, which means that the existence of self-fulfilling equilibria is not due to the pecuniary externality (through asset price) that has been stressed by the existing literature. In addition, in this simplified model output is split between borrower and lender since there is no aggregate investment in capital, so that any change in borrower's consumption crowds out lender's, that is, $\tilde{C}_{t}=L_{t}-C_{t}$. What matters most is how income is distributed between lenders and borrowers, which in turn depends on loan interest rate that is state-contingent.

Now suppose that the borrowing cost that governs interest payments in period $t$, that is, $R_{t}$, is expected to go down because of a redistribution shock. Because the stock of outstanding debt $B_{t}^{l}$ is predetermined, the borrower benefits from some additional income, hence she raises her consumption $C_{t}$ and land holdings $L_{t+1}$ so that output goes up. Larger land investment is partly financed by borrowing. This can be seen by defining credit demand as:

$$
B_{t+1}^{d}=\tilde{\beta} Q L_{t+1}
$$

which is simply (7) rewritten as an equality using that $\mathbb{E}_{t} R_{t+1}=\tilde{\beta}^{-1}$ when the lender is risk neutral, in view of (10), and $\theta=1$. Of course, that the borrower is able to get more land is consistent with equilibrium reallocation from lender to borrower in the land market and the associated rise in borrower's collateral. However, if the rise in credit demand would stand alone, the market interest rate that clears the market would go up, thus invalidating the initial expectation of a falling borrowing cost. We now show that a self-fulfilling, countercyclical interest 
Figure 7: Global self-fulfilling equilibria in the simplified model with risk-neutral lender and linear technology. The top panel reports the growth rate of output while the bottom panel reports the level of output (both in percentage deviations from their steady-state values).
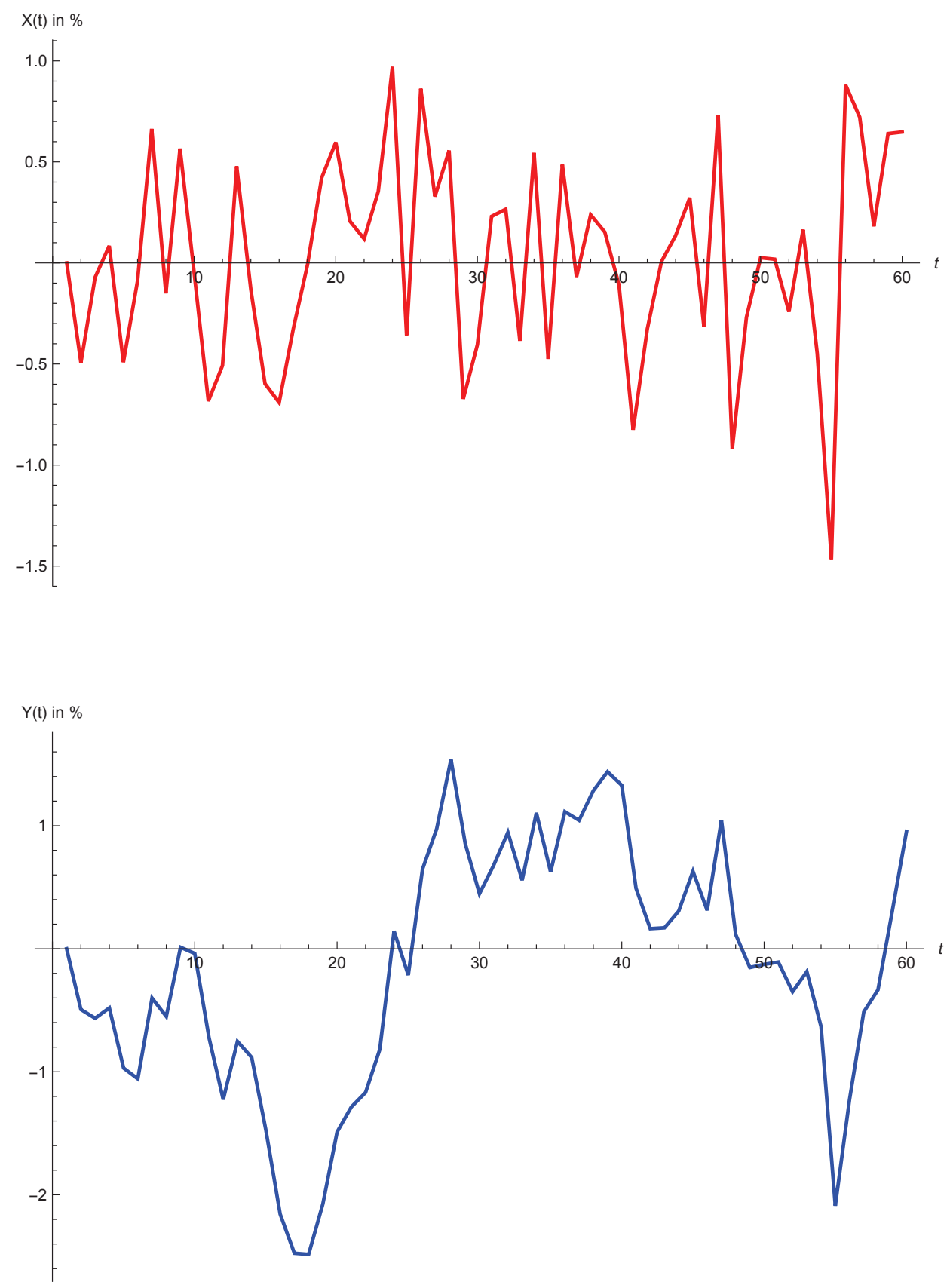
rate arises in a boom only if the supply of credit goes up as well. To see this, define credit supply from (1), using that $\tilde{C}_{t}=L_{t}-C_{t}$ and replacing borrower's consumption $C_{t}=(1-\beta) X_{t} L_{t}$, as:

$$
B_{t+1}^{s}=Q L_{t+1}-\beta X_{t} L_{t}
$$

where $X_{t} \equiv 1+Q\left(1-\tilde{\beta} R_{t}\right)$.

Now suppose again that the borrower expects the interest rate to go down. Then the borrower increases consumption and land investment $L_{t+1}$. In addition to being a shifter of credit demand through the collateral channel - see (21) - $L_{t+1}$ is also a shifter of credit supply through land reallocation to the borrower - see (22). As can be seen from Figure 8, the net effect is a fall of the interest rate. This is because in view of equations (21) and (22), the credit supply curve shifts to the right by more than the credit demand curve when $L_{t+1}$ goes up: when the borrower's land demand goes up by $\Delta L_{t+1}$, the lender's land holdings go down by the same amount since land is in fixed supply, which means that the lender's savings in the form of lending goes up by $Q \Delta L_{t+1}$. On the other hand, borrower's credit demand goes up by $\tilde{\beta} Q \Delta L_{t+1}$, that is, by a little less since the loan-to-value ratio is smaller than one. The bottom line is that the interest rate goes down and the initial expectation is fulfilled. In other words, the interest rate is countercyclical in the indeterminate model. ${ }^{16}$ Appendix 6.1 shows that global self-fulfilling equilibria survive when, more realistically, both fixed and state-contingent interest rate loans are used, provided that the constant share of variable-rate loans is larger than 0.5 . In contrast, the economy with predetermined interest rate stays in steady state forever, absent fundamental shocks, because the interest rate is constant through time and there is no reallocation of land that can trigger shifts in credit supply or demand. It turns out that self-fulfilling equilibria are also ruled out in the simple economy with predetermined interest rate even if we allow the land price to move over time, typically in a procyclical fashion, and despite the associated pecuniary externality. An easy way to see this analytically is to suppose that while the lender has linear utility in consumption $\left(\sigma_{L}=0\right)$ so that the interest rate is constant, she now has logarithmic utility for land $\left(\sigma_{L}=1\right)$. Then the land price is no longer constant but moves over time because land reallocation between lender and borrower changes lender's marginal utility from land and this reflects into asset price. It is then not difficult to show that in the deterministic version of such an economy, the land price dynamic equation can be solved forward and delivers a unique $Q_{t}$ so that self-fulfilling equilibria are ruled out. This is in line with the intuition stated earlier. With a constant interest rate, the pecuniary externality is not strong enough to generate self-fulfilling equilibria because a high land price in a boom relaxes the borrowing constraint but at the same time makes collateral more expensive. In contrast, with a constant land price but variable loan interest rate, self-fulfilling equilibria arise because the borrowing cost is countercyclical so that the borrower can afford more credit and invest more in a boom. Of course, the simplified model of this section obtains under extreme assumptions but it turns out that the intuition developed in this context carries through in the more general model with capital and risk-averse lender to which we come back next, in Section 3.4. Before doing so, a few remarks about the welfare consequences of self-fulfilling equilibria are in order.

In the context of Proposition 1, it may seem that state-contingent interest rate contracts should not be

\footnotetext{
${ }^{16}$ Note that if one plugs the expression of optimal land holdings by the borrower, that is, $L_{t+1}=X_{t} L_{t}$, into equation (22) and equates credit demand to credit supply, then the current interest rate $R_{t}$ disappears. This is why one needs the additional equation $\mathbb{E}_{t} R_{t+1}=\tilde{\beta}^{-1}$ to pin down the interest rate.
} 
Figure 8: Both credit demand $B^{d}$ and credit supply $B^{s}$ shift rightward when the borrower expects a fall in interest rate and invests more in land so that $L_{t+1}$ goes up, resulting in a self-fulfilling fall in $R_{t}$.

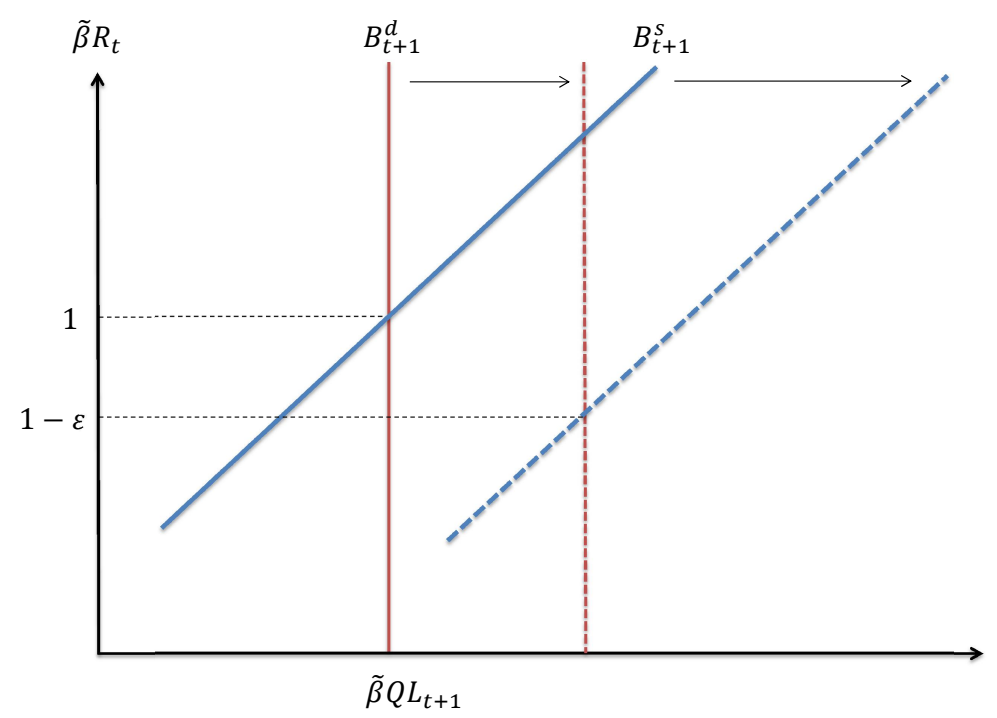

proposed by competitive lenders as long as they make borrowers worse-off compared to fixed-interest rate contracts. And indeed in this simple example, it is possible that the risk-averse borrower prefers the fixedinterest rate loan, that is immune from self-fulfilling innovations, to the state-contingent interest rate loan that leads to volatile outcomes, while the risk-neutral lender is indifferent. ${ }^{17}$ Deriving the optimal contract is beyond the scope of this paper so we think of the credit market as a centralized market allocating loans among atomistic participants that are price takers. Howewer, even if one think in terms of loan contract, it is not necessarily the case in our simple model that state-contingent interest rate contracts make agents worse-off. For instance, results not reported here show that occasionally binding credit constraints generate asymmetric self-fulfilling business cycles, as in Guerrieri and Iacoviello (2013), that make the lender better-off because booms are less pronounced than busts so that on average lenders enjoy higher consumption and more land compared to the steady state. In that case, the lender would have incentives to propose state-contingent interest rate contracts as a take-or-leave-it offer. In addition, it is also easy to show that in an enriched version of the example in which there are fundamental shocks that correlate with innovations, the borrower may be better-off under loans with state-contingent interest rate even in the linearized model. In general, therefore, there is no reason why contracts with state-contingent interest rate would not materialize in equilibrium. Elaborating further on this issue seems promising but beyond the scope of our analysis, which focuses on the macroeconomic consequences of loans that have a state-contingent interest rate and are collateralized. ${ }^{18}$

\footnotetext{
${ }^{17}$ We thank Fernando Broner for drawing our attention to this point.

${ }^{18}$ Relatedly, Carlstrom, Fuerst and Paustian (2016) show in a financial-accelerator environment under which conditions the optimal lending contract has indeed a variable interest rate.
} 


\subsection{Steady-State Indeterminacy and Local Self-Fulfilling Equilibria}

Going back to the full model described in Section 3.1, the model's stationary equilibrium path is solved by log-linearizing the model around the interior steady state (see the equations in Appendix 6.2). Under the assumption of rational expectations, we check the uniqueness of a determinate equilibrium near-steady state or the multiplicity of a continuum of indeterminate equilibria by the eigenvalue method. Because the dynamical system is high-dimensional, we resort to numerical methods to compute eigenvalues for the determinate model.

For all parameter values, the unique steady state turns out to be locally indeterminate. More precisely, the difference between the number of stable eigenvalues and the number of predetermined variables equals one so that local indeterminacy is one-dimensional. This leaves room for one jump variable to be affected by non-fundamental or self-fulfilling shocks and in the remainder of the paper we will assume that this variable is investment. ${ }^{19}$ To show that indeterminacy arises, it is useful to go back to Pintus and Wen (2013), who develop a version of the very same model in which the interest rate is predetermined and the steady state is determinate. More precisely, in Pintus and Wen (2013) the lender's and borrower's budget constraints and the borrowing constraint are respectively:

$$
\begin{gathered}
\tilde{C}_{t}+Q_{t}\left(\tilde{L}_{t+1}-\tilde{L}_{t}\right)+B_{t+1}^{l} \leq R_{t-1} B_{t}^{l} \\
C_{t}+K_{t+1}-(1-\delta) K_{t}+Q_{t}\left(L_{t+1}-L_{t}\right)+R_{t-1} B_{t}^{l} \leq B_{t+1}^{l}+A_{t} K_{t}^{\alpha} L_{t}^{\gamma} \\
R_{t} B_{t+1}^{l} \leq \theta_{t} \mathbb{E}_{t} Q_{t+1} L_{t+1}
\end{gathered}
$$

Given the above budget and borrowing constraints, equations (10) and (14) are replaced by, respectively:

$$
\begin{gathered}
\tilde{\Lambda}_{t}=\tilde{\beta} R_{t} \mathbb{E}_{t} \tilde{\Lambda}_{t+1} . \\
\Lambda_{t}=R_{t} \mathbb{E}_{t}\left(\beta \Lambda_{t+1}+\Phi_{t}\right) .
\end{gathered}
$$

It is straightforward to show that this formulation is in fact equivalent to assuming that, in period $t$, the borrower issues one-period bonds in quantity $B_{t+1} \equiv R_{t} B_{t+1}^{l}$, at given unit price $1 / R_{t}$, and has to repay $B_{t} \equiv R_{t-1} B_{t}^{l}$. In both interpretations, the key feature is that what the borrower has to repay in period $t$ is predetermined, hence does not adjust to shocks that occur at $t$. Therefore, the market interest rate is fixed when the lender and borrower agree on the level of credit and one can think of such an arrangement as a fixed-interest rate loan.

In contrast, the agreement that is described in Sections 3.1-3.3 is a loan with state-contingent interest rate, whereby the borrower's repayment in $t$ adjusts to any shock, fundamental or self-fulfilling, that occurs within the period and the lender has to forecast both the market value of collateral and the debt obligations that will prevail in $t+1$. In other words, one goes from the fixed-rate economy, described in the last paragraph, to the variable-rate economy simply by moving the time index of the interest rate one period ahead. More precisely, on the one hand the fixed interest rate $R_{t-1}$ that has to be paid in period $t$ becomes variable $R_{t}$, while on the other hand what is $R_{t}$ in the fixed-rate economy becomes $\mathbb{E}_{t} R_{t+1}$, which is now the relevant expression to

\footnotetext{
${ }^{19}$ Which variable is subject to self-fulfilling shocks is irrelevant for the model impulse responses, though not for the estimation results that we report in the next section.
} 
determine how much to lend today in the variable-rate economy.

Of course, the fixed-interest rate economy and the state-contingent interest rate economy have in common equations (8), (9), (11), (12) and (13), since these do not have the interest rate in them. Not surprisingly, therefore, comparing the constraints and first-order conditions (23)-(27) and their analogs in Sections 3.1 and 3.2 reveals that the variable-rate economy has an additional jump variable, compared to he fixed-interest rate economy, because the interest rate is now nonpredetermined. Since it is easily established that both economies have identical steady-states and identical eigenvalues at their linearizations, the following proposition follows.

\section{Proposition 2 (Local Indeterminacy in the State-Contingent Repayment Economy)}

Suppose that first-order conditions (8), (9), (11), (12) and (13) hold. Moreover, define the fixed-interest rate economy by the additional conditions (23) to (27) while the state-contingent interest rate economy is defined by the alternative set of additional conditions (1), (5) (7), (10) and (14).

Then both economies have identical steady states and their linearizations at that unique steady state have identical eigenvalues. It follows that whenever the unique steady state is locally determinate in the fixed-rate economy, it is locally indeterminate in the variable-rate economy and local indeterminacy is one-dimensional. Therefore, local self-fulfilling equilibria can be constructed near the steady state in the latter case.

Pintus and Wen (2013) have shown that the unique steady state of the fixed-interest rate economy is locally determinate so it follows that the steady state is locally indeterminate in the state-contingent interest rate economy. ${ }^{20}$ In Section 4 we show that Proposition 2 can be adapted to a larger model with elastic labor and many additional features that are required to take the model to the data, with identical conclusions. Before doing so, we now come back to the intuition developed in Section 3.3 and show that it carries through in the linearized model of this section.

Although relaxing the assumptions of Proposition 1 rules out closed-from solutions, it is still possible to derive analytical expressions for credit demand and credit supply arising in the linearized version of this section's model. In particular, suppose we slightly modify the model without capital of Section 3.3 by allowing now the lender's utility for consumption to be logarithmic (that is, $\sigma_{L}=1$ ), so that the endogenous land price is no longer constant. Manipulating the linearized equations in Appendix 6.2, we get among other conditions that $(1-\beta) c_{t}+\beta \tilde{c}_{t}=l_{t}, q_{t}=\tilde{c}_{t}, \mathbb{E}_{t} r_{t+1}=\mathbb{E}_{t}\left[q_{t+1}-q_{t}\right]$ and $b_{t+1}=l_{t+1}+q_{t}$ (where lowercase letters denote deviations from steady state), which together with the lender's budget constraint, allow to derive credit demand and supply as respectively:

$$
\begin{gathered}
b_{t+1}^{d}=l_{t+1}+q_{t} \\
b_{t+1}^{s}=l_{t+1}[Q-\beta(1-\tilde{\beta})] /(\tilde{\beta} Q)+\left(r_{t}+q_{t-1}\right)(Q-\beta) /(\tilde{\beta} Q)
\end{gathered}
$$

where steady-state land price is $Q=\beta /(1-\tilde{\beta})$. The borrower's budget constraint simplifies to:

$$
(1-\beta) c_{t}+\beta(1-\tilde{\beta}) l_{t+1}=-\beta r_{t}
$$

\footnotetext{
${ }^{20}$ To be more precise, there is a typo in the published paper that sets the time index for the interest rate incorrectly. All figures reported in Pintus and Wen (2013) are produced by a code that assumes a predetermined interest rate. The correction appears as an online appendix available at the Review of Economic Dynamics.
} 
if the economy was in steady state prior to period $t$, that is, $l_{t}=q_{t-1}=0$. Suppose that the borrower expects at date $t$ that the interest rate goes below its steady-state value, that is, she expects $r_{t}<0$. Then she benefits here again from a positive income shock and it is straightforward to show that she decides to consume more and invest more in land, in view of equation (30). But then from equations (28) and (29), we see that expectations of lower interest rate again shift rightward both credit demand and credit supply, and it is not difficult to show that the latter shifts by more than the former. Therefore, in the linearized version with risk-averse lender, the intuition for self-fulfilling interest rate expectation that is pictured in Figure 8 still holds. Of course, a major difference is that land price now reacts to self-fulfilling shocks to the interest rate. In view of the linearized equations reported above, one sees that $q_{t}=\tilde{c}_{t}$ so that a falling interest rate leads to declines of both land price and lender's consumption at impact of equal magnitudes (although both go above steady state in the following periods so that land price is overall procyclical). This means that credit demand shifts rightward but by less than the full amount of land reallocation. ${ }^{21}$ This accords with the above intuition that credit demand shifts rightward by less than credit supply, which then extends to the case with risk-averse lender. In addition, a similar intuition holds if capital is added. In summary, while countercyclical interest rate changes can be self-fulfilling in the indeterminate model with variable-interest rate loans, interest rate changes are procyclical in the determinate model with fixed-interest rate loans and fundamental shocks only. In view if the evidence reported in Section 2, the former turns out to be more in line with data than the latter. Before we move on to a quantitative assessment of such a claim, it is perhaps instructive to inquire into the robustness of, and also the very reason behind indeterminacy. This is what we do next. In particular, next section takes a broader perspective and asks why indeterminacy is so pervasive in economies with state-contingent interest rate.

\subsection{Aggregate Credit-Demand Externality and Local Indeterminacy}

The purpose of this section is to explain why state-contingent interest rate is a key feature that is required for indeterminacy to occur for all parameter values. It is perhaps useful to start with the early numerical results reported in Cordoba and Ripoll (2004). Their model is a simpler variant of our basic economy without capital accumulation and, most importantly, with a different formulation of the credit constraint that assumes a predetermined interest rate. That is, Cordoba and Ripoll (2004) model the credit market as a bond market and, using their notation, $p_{t}$ is the unit price of a bond issued in period $t$ and that promises to repay one unit of the consumption good in period $t+1$. In each period $t$ borrowers have to redeem, using their notation, $a_{t}$ units of bonds and issue new bonds with value $p_{t} a_{t+1}$ subject to the credit constraint $a_{t+1} \leq q_{t+1} k_{t+1}$, where $k$ is land in their notation. In other words, they assume a fixed-interest rate economy since the bond market formulation is equivalent to a loan market with predetermined interest rate. Results reported in Cordoba and Ripoll (2004) suggest that indeterminacy occurs in their setting for a small set of parameter values that turn out to be unrealistic. For example, their figure 4 shows that local indeterminacy arises when the land share is larger than 0.8 and provided relative risk aversion is larger than 25 (or equivalently if the consumption elasticity of intertemporal substitution is close to zero). This also explains why indeterminacy does not show up under

\footnotetext{
${ }^{21}$ It is not difficult to show, by manipulating the linearized equations, that the fall in land price is lower than the lender's land holdings increase so that debt goes up.
} 
the calibration used in Pintus and Wen (2013), which excludes those extreme values.

As stated in the previous section, the result that the steady state is unlikely to be indeterminate in the settings of Cordoba and Ripoll (2004) and Pintus and Wen (2013) hinges upon the fact that the interest rate is assumed to be predetermined. This is clearly the fact in the bond formulation used by Cordoba and Ripoll (2004), in which $a_{t}$ is a predetermined variable that can be thought of as debt repayments including interest. Similarly, the code used in Pintus and Wen (2013) implicitly assumes that the interest rate is predetermined. These observations, taken together, suggest that when one changes in our basic model the credit constraint (7) to:

$$
R_{t} B_{t+1}^{l} \leq \theta_{t} \mathbb{E}_{t} Q_{t+1} L_{t+1}
$$

and both budget constraints (1) and (5) accordingly as in Section 3.4 (see equations (23) and (24)), then determinacy prevails in the fixed-rate economy. ${ }^{22}$ Comparing (7) and (31) then indicates that two types of externalities are at play, with different outcomes regarding the determinacy properties of the unique steady state. Under credit constraint (31), a pecuniary externality is at work, such that borrowers do not take into account that whenever they decide to accumulate more land today so as to borrow more tomorrow, their action triggers an upward pressure on the land price that relaxes the borrowing constraint for everybody else, including those inactive agents that chose no to invest more in the first place. When the pecuniary externality alone is at work, indeterminacy either does not occur ${ }^{23}$ or arises for a small set of unrealistic parameter values.

To further check that the intuition reported above is correct, we have experimented with alternative formulations of the credit constraints, such as the following:

$$
B_{t+1}^{l} \leq \theta_{t} \mathbb{E}_{t} Q_{t+1} L_{t+1} \quad \text { or } \quad \frac{B_{t+1}^{l}}{R_{t}} \leq \theta_{t} \mathbb{E}_{t} Q_{t+1} L_{t+1}
$$

while the lender's and borrower's budget constraint are modified in a consistent way. In both formulations in (32) there is no role for expectations about the interest rate in the borrowing constraint but indeterminacy still arises for some parameter values. We have also checked that the intuition developed above still holds under (32) provided that $\theta<1$. As under credit constraint (7), the credit market equilibrium is susceptible to self-fulfilling swings. Here again, if one expects the loan interest rate to be low, then there is ample credit available so that high levels of investment, economic activity, land price and collateral materialize, which is consistent with one's expectations. However, such an expectation-driven boom coexists with another equilibrium where the interest rate is high, which depresses investment and puts downward pressure on land price so that collateral and credit are scarce resources. In other words, an aggregate credit-demand externality comes to life. Of course, in this case i.i.d. self-fulfilling shocks can drive land price, credit and economic activity. In addition, responses to fundamental shocks are possibly altered by the very property that the steady state is indeterminate. More precisely, local indeterminacy typically originates endogenous persistence so that fundamental shocks with zero autocorrelation can nevertheless have persistent effects. These are the issues we address in the next section within a more elaborated model.

\footnotetext{
${ }^{22}$ In other words, our basic model is under (31) an extension of that in Cordoba and Ripoll (2004) with capital accumulation, in which the price of bonds and the interest rate relate through the equality $p_{t}=1 / R_{t}$.

${ }^{23}$ Cordoba and Ripoll (2004) also report that indeterminacy is not robust in their setting, in the sense that it does not survive the introduction of heterogeneity in risk aversion between lender and borrower. This is not the case with our indeterminacy results.
} 


\section{An Estimated Model with State-Contingent Interest Rate}

This section shows that indeterminacy is pervasive also in extensions of the basic model. To do so we introduce loans with state-contingent interest rate in the medium-scale model of Liu et al. (2013), that originally deals with fixed-interest rate loans. Such an extended setup is useful in quantitatively assessing whether or not indeterminacy and self-fulfilling shocks are relevant and we show that they are. More precisely, we perform a Bayesian estimation of both the determinate and the indeterminate models. To estimate the latter, we following the approach developed in Farmer et al. (2015). Redistribution shocks are shown to be quantitatively important, as their presence alter significantly the propagation of other shocks, including land demand shocks, to explain US business and credit cycles. In addition the determinate model is rejected against the indeterminate model according to the Bayes factor criterion.

\subsection{Determinate Economy with Predetermined Interest Rate}

So as to make clear how and why loans with state-contingent interest rate modify the analysis, we first expose briefly the original model of Liu et al. (2013) in which the debt repayment is predetermined and the steady state is determinate, using the same notation as in their paper, including the end-of-period convention for stock variables.

Household: The infinitely-long lived representative household consume and supply both labor and credit in each period. They take decisions that maximize lifetime utility, defined as:

$$
\max \mathbb{E}_{0}\left[\sum_{t=0}^{\infty} \beta^{t} A_{t}\left(\ln \left(C_{h t}-\gamma_{h} C_{h t-1}\right)+\varphi_{t} \ln L_{h t}-\psi_{t} N_{h t}\right)\right]
$$

where $C_{h t}$ is consumption, $L_{h t}$ is the land stock, and $N_{h t}$ represents labor hours. Parameter $\beta \in(0,1)$ denotes the discount factor and consumption habits are measured by parameter $\gamma_{h} \in(0,1)$. Preferences are subject to three shocks, as follows. An intertemporal preference shock, which can be also thought as a risk premium shock, is denoted by $A_{t}=A_{t-1}\left(1+\lambda_{a t}\right)$, with $\ln \lambda_{a t}=\rho_{a} \ln \lambda_{a t-1}+\left(1-\rho_{a}\right) \ln \bar{\lambda}_{a}+\sigma_{a} \varepsilon_{a, t}, \bar{\lambda}_{a}>0, \rho_{a} \in(-1,1)$, and $\varepsilon_{a t}$ is i.i.d. and normally distributed with mean zero and unit variance so that $\sigma_{a}>0$ is the standard deviation of the innovation. In addition, a shock to land utility is denoted by $\phi_{t} \operatorname{such}$ that $\ln \varphi_{t}=\rho_{\varphi} \ln \varphi_{t-1}+\left(1-\rho_{\varphi}\right) \ln \bar{\varphi}+\sigma_{\varphi} \varepsilon_{\varphi t}$, $\bar{\varphi}>0, \rho_{\varphi} \in(-1,1)$, and $\varepsilon_{\varphi t}$ is i.i.d. and normally distributed with mean zero and unit variance so that $\sigma_{\varphi}>0$ denotes the innovation's standard deviation. Finally, a labor supply shock is denoted by $\psi_{t}$ such that $\ln \psi_{t}=\rho_{\psi} \ln \psi_{t-1}+\left(1-\rho_{\psi}\right) \ln \bar{\psi}+\sigma_{\psi} \varepsilon_{\psi_{t}}, \bar{\psi}>0, \rho_{\psi} \in(-1,1)$, and $\varepsilon_{\psi_{t}}$ is i.i.d. and normally distributed with mean zero and unit variance while $\sigma_{\psi}>0$ is the innovation's standard deviation.

Households are subject to their budget constraint:

$$
C_{h t}+q_{l t}\left(L_{h t}-L_{h t-1}\right)+\frac{S_{t}}{R_{t}} \leq w_{t} N_{h t}+S_{t-1}
$$

where $q_{l t}$ is the relative land price in terms of the produced good, $R_{t}$ is the debtor gross interest rate, $w_{t}$ is the real wage, and $S_{t}$ denotes the quantity of uncontigent bonds that each pays one consumption unit in period $t+1$. 
Defining $\mu_{h t}$ as the Lagrange multiplier attached to (34), it is straightforward to derive the following firstorder conditions with respect to consumption demand, labor demand, land demand and credit supply:

$$
\begin{gathered}
\mu_{h t}=A_{t}\left(\frac{1}{C_{h t}-\gamma_{h} C_{h t-1}}-\mathbb{E}_{t}\left[\frac{\beta \gamma_{h}}{C_{h t+1}-\gamma_{h} C_{h t}}\left(1+\lambda_{a t+1}\right)\right]\right) \\
w_{t}=\frac{A_{t} \psi_{t}}{\mu_{h t}} \\
q_{l t}=\beta \mathbb{E}_{t}\left[\frac{\mu_{h t+1}}{\mu_{h t}} q_{l t+1}\right]+\frac{A_{t} \varphi_{t}}{\mu_{h t} L_{h t}} \\
1=\beta \mathbb{E}_{t}\left[\frac{\mu_{h t+1}}{\mu_{h t}}\right] R_{t}
\end{gathered}
$$

Entrepreneur: The representative entrepreneur is also infinite-long lived and runs the productive technology that uses capital, labor and land and delivers a good that can be either consumed or used for investment. Her consumption, investment and borrowing decisions maximize lifetime utility, as defined by:

$$
\max \mathbb{E}_{0}\left[\sum_{t=0}^{\infty} \beta^{t} \ln \left(C_{e t}-\gamma_{e} C_{e t-1}\right)\right]
$$

where $C_{e t}$ is consumption and the habit parameter $\gamma_{e} \in(0,1)$. Entrepreneur operate under four types of constraints.

(i) a technological constraint:

$$
Y_{t}=Z_{t}\left(L_{e t-1}^{\phi} K_{t-1}^{1-\phi}\right)^{\alpha} N_{e t}^{1-\alpha}
$$

where $Y_{t}$ is output produced out of capital $K_{t-1}$, labor $N_{e t}$ and land $L_{e t-1}$, with $\alpha \in(0,1)$ and $\phi \in(0,1)$. Total factor productivity $Z_{t}$ is stochastic and subject to a temporary component $\nu_{z t}$ and a permanent component $Z_{t}^{p}$, with $Z_{t}=\nu_{z t} Z_{t}^{p}, Z^{p}=Z_{t-1}^{p} \lambda_{z t}, \ln \lambda_{z t}=\rho_{z} \ln \lambda_{z t-1}+\left(1-\rho_{z}\right) \bar{\lambda}_{z}+\sigma_{z} \varepsilon_{z t}, \ln \nu_{z t}=\rho_{\nu_{z}} \ln \nu_{z t-1}+\sigma_{\nu_{z}} \varepsilon_{\nu_{z} t}$. It follows that $\bar{\lambda}_{z}$ denotes the growth rate of productivity, parameters $\rho_{z}$ and $\rho_{\nu_{z}}$ belong to $(0,1)$, parameters $\sigma_{z}>0$ and $\sigma_{\nu_{z}}>0$ denote standard deviations, while $\varepsilon_{z t}$ and $\varepsilon_{\nu_{z} t}$ are i.i.d. and normally distributed with zero mean and unit variance.

(ii) a capital accumulation constraint:

$$
K_{t}=(1-\delta) K_{t-1}+\left(1-\frac{\Omega}{2}\left(\frac{I_{t}}{I_{t-1}}-\bar{\lambda}_{I}\right)^{2}\right) I_{t}
$$

where $I_{t}$ denotes investment, $\bar{\lambda}_{I}$ is the steady-state growth rate of investment, and $\Omega>0$ measures the cost of adjusting the investment flow.

(iii) a budget constraint:

$$
C_{e t}+q_{l t}\left(L_{e t}-L_{e t-1}\right)+B_{t-1}=Y_{t}-\frac{I_{t}}{Q_{t}}-w_{t} N_{e t}+\frac{B_{t}}{R_{t}}
$$


where $B_{t}$ denotes uncontingent debt that matures in period $t, Q_{t}$ denotes stochastic investment-specific technological change, with $Q_{t}=Q_{t}^{p} \nu_{q t}$. The permanent component $Q_{t}^{p}$ follows an autoregressive process, that is, $Q^{p}=Q_{t-1}^{p} \lambda_{q t}, \ln \lambda_{q t}=\rho_{q} \ln \lambda_{q t-1}+\left(1-\rho_{q}\right) \bar{\lambda}_{q}+\sigma_{q} \varepsilon_{q t}, \ln \nu_{q t}=\rho_{\nu_{q}} \ln \nu_{q t-1}+\sigma_{\nu_{q}} \varepsilon_{\nu_{q} t}$. Parameter $\bar{\lambda}_{q}$ denotes the growth rate of $Q_{t}^{p}$, parameters $\rho_{q}$ and $\rho_{\nu_{q}}$ belong to $(0,1)$, parameters $\sigma_{q}>0$ and $\sigma_{\nu_{q}}>0$ denote standard deviations, while $\varepsilon_{q t}$ and $\varepsilon_{\nu_{q} t}$ are i.i.d. and normally distributed with zero mean and unit variance.

(iv) an endogenous collateral requirement:

$$
B_{t} \leq \theta_{t} \mathbb{E}_{t}\left[q_{l t+1} L_{e t}+q_{k t+1} K_{t}\right]
$$

where $q_{k t+1}$ is tomorrow's shadow price of capital expressed in units of the produced good, and $\theta_{t}$ denotes stochastic loan-to-value ratio, with $\ln \theta_{t}=\rho_{\theta} \ln \theta_{t-1}+\left(1-\rho_{\theta}\right) \ln \bar{\theta}+\sigma_{\theta} \varepsilon_{\theta t}, \bar{\theta}>0$ is the steady-state value of the loan-to-value ratio, $\rho_{\theta} \in(-1,1)$, and $\varepsilon_{\theta t}$ is i.i.d. and normally distributed with mean zero and unit variance while $\sigma_{\theta}>0$ is the innovation's standard deviation.

Defining $\mu_{e t}, \mu_{k t}, \mu_{b t}$ as the respective Lagrange multipliers of (41), (42), and (43), it follows that relative price of capital in terms of the consumption good satisfies $q_{k t}=\frac{\mu_{k t}}{\mu_{e t}}$ and the first-order conditions with respect to demands for consumption, labor, investment, capital, land and credit are:

$$
\begin{gathered}
\mu_{e t}=\frac{1}{C_{e t}-\gamma_{e} C_{e t-1}}-\mathbb{E}_{t}\left[\frac{\beta \gamma_{e}}{C_{e t+1}-\gamma_{e} C_{e t}}\right] \\
w_{t}=(1-\alpha) Y_{t} / N_{e t} \\
q_{k t}=\frac{\mu_{k t}}{\mu_{e t}} \\
\frac{1}{Q_{t}}=q_{k t}\left(1-\frac{\Omega}{2}\left(\frac{I_{t}}{I_{t-1}}-\bar{\lambda}_{I}\right)^{2}-\Omega\left(\frac{I_{t}}{I_{t-1}}-\bar{\lambda}_{I}\right) \frac{I_{t}}{I_{t-1}}\right)+\beta \Omega \mathbb{E}_{t}\left[\frac{\mu_{e t+1}}{\mu_{e t}} q_{k t+1}\left(\frac{I_{t+1}}{I_{t}}-\bar{\lambda}_{I}\right)\left(\frac{I_{t+1}}{I_{t}}\right)^{2}\right] \\
q_{k t}=\mathbb{E}_{t}\left[\beta \frac{\mu_{e t+1}}{\mu_{e t}}\left((1-\phi) \alpha \frac{Y_{t+1}}{K_{t}}+q_{k t+1}(1-\delta)\right)+\frac{\mu_{b t}}{\mu_{e t}} \theta_{t} q_{k t+1}\right] \\
q_{l t}=\beta \frac{\mu_{e t+1}\left(\phi \alpha \frac{Y_{t+1}}{L_{e t}}+q_{l t+1}\right)+\frac{\mu_{b t}}{\mu_{e t}} \theta_{t} q_{l t+1}}{1=\mathbb{E}_{t}\left[\beta \frac{\mu_{e t+1}}{\mu_{e t}}+\frac{\mu_{b t}}{\mu_{e t}}\right] R_{t}}
\end{gathered}
$$

Finally, in all period $t$ the market clearing conditions are $Y_{t}=C_{t}+\frac{I_{t}}{Q_{t}}$ for the goods market, where $C_{t}=C_{h t}+C_{e t}$ denotes aggregate consumption, $N_{e t}=N_{h t}$ for the labor market, $L_{h t}+L_{e t}=\bar{L}$ for the land market, where land is in fixed supply given by parameter $\bar{L}>0$, and finally $B_{t}=S_{t}$ for the credit market.

The stationary version of the model, its linearization at the unique steady state and the calibration strategy are given in Appendix 6.3.1. 


\subsection{Indeterminate Economy with State-Contingent Interest Rate}

As explained in Section 3, the bond formulation used by Liu et al. (2013) is equivalent to a loan. We switch to the latter and then move the time index of the interest rate one period ahead, in order to introduce loans with state-contingent interest rate. Consider the situation where the borrower repays $R_{t} B_{t-1}^{l} \equiv B_{t-1}$ and gets loanable fund $B_{t}^{l} \equiv B_{t} / R_{t+1}$ in period $t$, which means he will have to repay $R_{t+1} B_{t}^{l} \equiv B_{t}$ in period $t+1$. All conditions can now be expressed in terms of the amount borrowed $B^{l}$ and moving from the fixed-rate economy in Section 4.1 to the variable-rate economy implies the following changes in equations:

$(34) \rightarrow$

$$
C_{h t}+q_{l t}\left(L_{h t}-L_{h t-1}\right)+S_{t}^{l} \leq w_{t} N_{h t}+R_{t} S_{t-1}^{l}
$$

$(38) \rightarrow$

$$
1=\beta \mathbb{E}_{t}\left[\frac{\mu_{h t+1}}{\mu_{h t}} R_{t+1}\right]
$$

$(42) \rightarrow$

$$
C_{e t}+q_{l t}\left(L_{e t}-L_{e t-1}\right)+R_{t} B_{t-1}^{l}=Y_{t}-\frac{I_{t}}{Q_{t}}-w_{t} N_{e t}+B_{t}^{l}
$$

$(43) \rightarrow$

$$
\mathbb{E}_{t}\left[R_{t+1}\right] B_{t}^{l} \leq \theta_{t} \mathbb{E}_{t}\left[q_{l t+1} L_{e t}+q_{k t+1} K_{t}\right]
$$

$(50) \rightarrow$

$$
1=\mathbb{E}_{t}\left[\left(\beta \frac{\mu_{e t+1}}{\mu_{e t}}+\frac{\mu_{b t}}{\mu_{e t}}\right) R_{t+1}\right]
$$

It is straightforward to show that the fixed-rate and variable-rate economies have the same steady state. In addition, the linearized system for the variable-rate economy obtains from that of the fixed-rate economy by replacing $\hat{R}_{t}$ with $\hat{R}_{t+1}, \hat{B}_{t-1}$ with $\hat{R}_{t}+\hat{B}_{t-1}^{l}$ and $\hat{B}_{t}$ with $\hat{R}_{t+1}+\hat{B}_{t}^{l}$. The resulting linearized system appears in Appendix 6.3.2.

\subsection{Comparing Propagation in Determinate and Indeterminate Economies}

We calibrate the model following Liu et al. (2013) to match some key ratios and use their posterior means for the other deep parameters. More details about the calibration strategy are given in Appendix 6.3.1. Parameter values are set according to Table 1 .

Determinate Economy: Since it is the most important shock in Liu et al. (2013), we activate only the (fundamental) land demand shock while all other shocks are shut down in the determinate economy with fixed-interest rate loans. Figure 9 reports the corresponding IRFs while Table 2 reports moment statistics. A noticeable and surprising feature of Figure 9 is that although the shock to the lender's utility for land is positive, which implies that households are willing to hold more land, it turns out that land is reallocated to the entrepreneur at impact, as explained in Liu et al. (2013). This happens because land price goes up, 


\begin{tabular}{cccccccccc}
\multicolumn{10}{c}{ Table 1: Parameter values } \\
\hline \multirow{3}{*}{ Structural parameters } & $g_{\gamma}$ & $\lambda_{q}$ & $\gamma_{h}$ & $\gamma_{e}$ & $\Omega$ & $\bar{L}$ & $\alpha$ & & \\
& 1.004221 & 1.012126 & 0.4976 & 0.6584 & 0.1753 & 1 & 0.3 & & \\
\cline { 2 - 10 } Targeted steady state values & $\frac{I}{K}$ & $\frac{K}{Y}$ & $\frac{q_{l} L_{e}}{Y}$ & $\frac{q_{l} L_{h}}{Y}$ & $N$ & $\theta$ & & & \\
& 0.052325 & 4.6194 & 2.6 & 5.8011 & 0.25 & 0.75 & & & \\
\cline { 2 - 11 } & $\rho_{a}$ & $\rho_{z}$ & $\rho_{\nu_{z}}$ & $\rho_{q}$ & $\rho_{\nu_{q}}$ & $\rho_{\psi}$ & $\rho_{\theta}$ & $\rho_{\varphi}$ & \\
Shock parameters & 0.9055 & 0.4263 & 0.0095 & 0.5620 & 0.2949 & 0.9829 & 0.9804 & 0.9997 & \\
\cline { 2 - 10 } & $\sigma_{a}$ & $\sigma_{z}$ & $\sigma_{\nu_{z}}$ & $\sigma_{q}$ & $\sigma_{\nu_{q}}$ & $\sigma_{\psi}$ & $\sigma_{\theta}$ & $\sigma_{\varphi}$ & $\sigma_{\text {red }}$ \\
& 0.1013 & 0.0042 & 0.0037 & 0.0042 & 0.0029 & 0.0073 & 0.0112 & 0.0462 & 0.0462 \\
\hline
\end{tabular}

Table 2: Moments under positive land demand shock in the - determinate - economy with fixed interest rate $\left(\rho_{\varphi}=0.9997, \sigma_{\varphi}=0.0462\right)$

\begin{tabular}{cccccccc}
\hline Variable $(\log )$ & S.D. relative to output (\%) & CORR with output & ACF1 & ACF2 & ACF3 & ACF4 & ACF5 \\
\hline$Y$ & 100 & 1 & 0.9815 & 0.9424 & 0.8974 & 0.8527 & 0.8113 \\
$I$ & 253.5463 & 0.8403 & 0.9478 & 0.8394 & 0.7156 & 0.5954 & 0.4881 \\
$K$ & 129.4317 & 0.8322 & 0.9958 & 0.9841 & 0.966 & 0.9427 & 0.9156 \\
$B$ & 324.038 & 0.8729 & 0.9412 & 0.8815 & 0.8258 & 0.7725 & 0.7239 \\
$R$ & 5.6797 & 0.4798 & 0.5321 & 0.6048 & 0.5555 & 0.4464 & 0.3431 \\
$N$ & 65.2197 & 0.6661 & 0.9299 & 0.8089 & 0.666 & 0.5279 & 0.4066 \\
$w$ & 74.5977 & 0.7581 & 0.9933 & 0.988 & 0.9798 & 0.9702 & 0.9603 \\
$C$ & 77.5277 & 0.825 & 0.9987 & 0.9955 & 0.9904 & 0.9837 & 0.9758 \\
$C_{e}$ & 274.0718 & 0.8797 & 0.9856 & 0.9537 & 0.9118 & 0.8647 & 0.8159 \\
$C_{h}$ & 74.0065 & 0.7748 & 0.9984 & 0.9948 & 0.9894 & 0.9828 & 0.9755 \\
$L_{e}$ & 2445.2123 & 0.8033 & 0.9954 & 0.9911 & 0.9871 & 0.9833 & 0.9801 \\
$L_{h}$ & 1095.9218 & -0.8033 & 0.9954 & 0.9911 & 0.9871 & 0.9833 & 0.9801 \\
$q_{l}$ & 2277.1502 & -0.6026 & 0.9994 & 0.9989 & 0.9983 & 0.9977 & 0.9971 \\
$q_{k}$ & 8.3326 & 0.3343 & 0.6876 & 0.2773 & 0.0763 & -0.0239 & -0.0594 \\
\hline
\end{tabular}

which relaxes the entrepreneur's credit constraint and generates a boom that initially reallocates land to the borrower. Because the shock to land utility is very persistent (see Table 1), the response of land price and other aggregates are also very persistent. In addition, the interest rate is procyclical while the land price looks strongly countercyclical in Figure 9, which is confirmed by Table 2 and is at odds with evidence reported in Section 2 .

Indeterminate Economy: There is one-dimensional indeterminacy in the economy with state-contingent loan interest rate and we assume that self-fulfilling innovations affect redistribution flows between lenders and borrowers (though similar qualitative results obtain if, for instance, either the land price or investment reacts to extrinsic uncertainty instead). We first investigate what happens in the indeterminate economy when redistribution shocks are inactive while a land demand shock hits. Figure 10 reports the IRFs to a land demand shock and Table 3 reports moment statistics. In Figure 10, a positive land demand shock generates an expansion, similar to what happens in fixed-interest rate economy (see Figure 9). Second, we shut down all fundamental shocks and feed the model with a redistribution shock only. Figure 11 reports the IRFs to a negative shock to loan interest rate and Table 4 reports moment statistics. The main features of Figure 11 are that indeterminacy generates persistence endogenously, since the shock has zero autocorrelation, and a higher level of volatility 
Figure 9: IRFs to a positive land demand shock in the - determinate - economy with fixed interest rate $\left(\rho_{\varphi}=\right.$ $\left.0.9997, \sigma_{\varphi}=0.0462\right)$
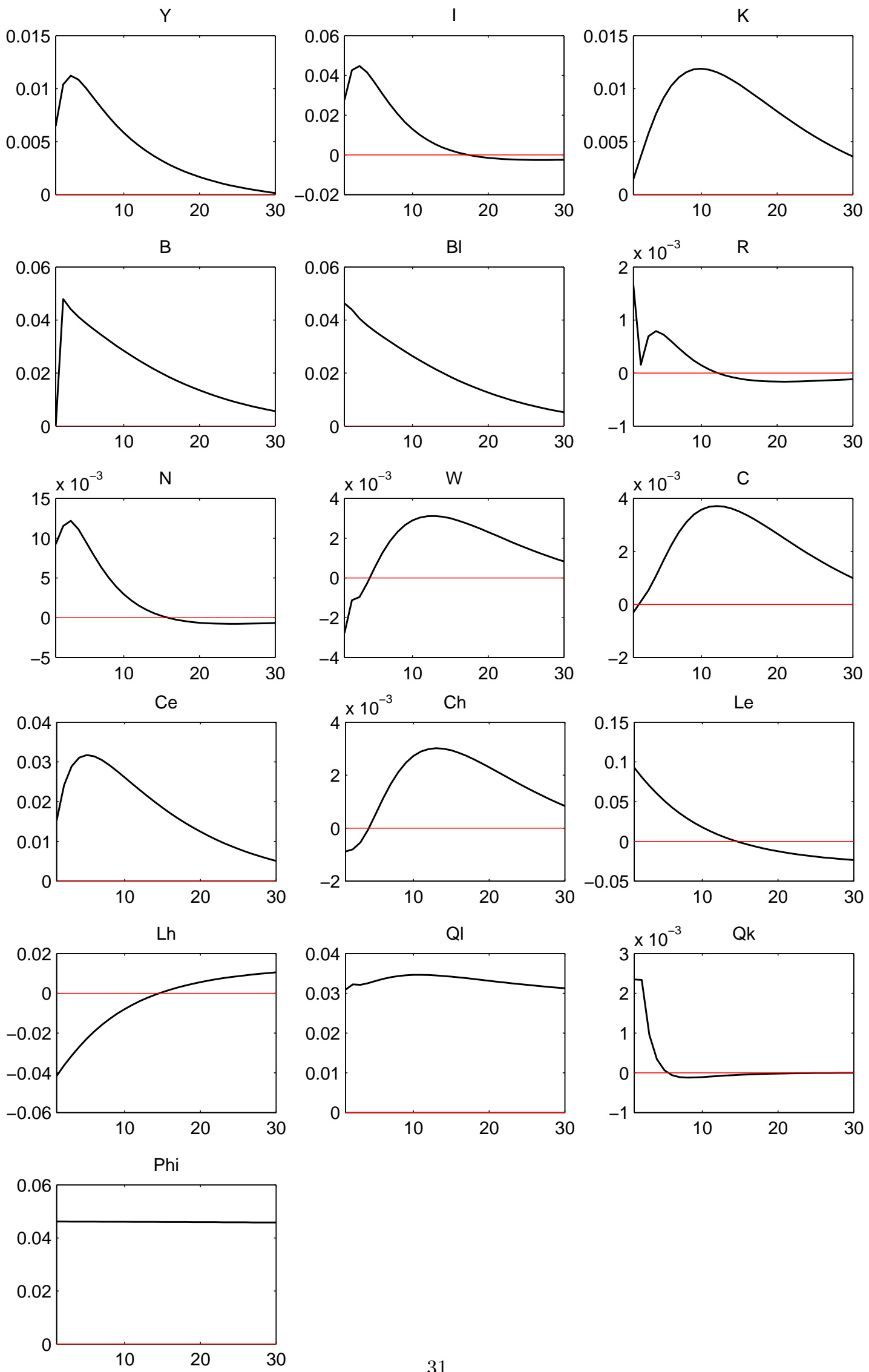
Table 3: Moments under positive land demand shock in the - indeterminate - economy with state-contingent interest rate $\left(\rho_{\varphi}=0.9997, \sigma_{\varphi}=0.0462\right)$

\begin{tabular}{cccccccc}
\hline Variable $(\log )$ & S.D. relative to output (\%) & CORR with output & ACF1 & ACF2 & ACF3 & ACF4 & ACF5 \\
\hline$Y$ & 100 & 1 & 0.9821 & 0.9443 & 0.9007 & 0.8574 & 0.8171 \\
$I$ & 251.7177 & 0.8396 & 0.9487 & 0.8422 & 0.7203 & 0.602 & 0.4961 \\
$K$ & 129.8306 & 0.8344 & 0.9959 & 0.9846 & 0.9669 & 0.9442 & 0.9178 \\
$B$ & 325.3979 & 0.8614 & 0.9402 & 0.8828 & 0.8279 & 0.7746 & 0.7259 \\
$R$ & 5.544 & 0.52 & 0.5475 & 0.617 & 0.566 & 0.4561 & 0.3518 \\
$N$ & 64.7279 & 0.6631 & 0.9309 & 0.8115 & 0.6705 & 0.5341 & 0.4141 \\
$w$ & 74.8738 & 0.7624 & 0.9936 & 0.9884 & 0.9804 & 0.971 & 0.9615 \\
$C$ & 77.856 & 0.8286 & 0.9988 & 0.9956 & 0.9906 & 0.9841 & 0.9765 \\
$C_{e}$ & 273.7372 & 0.8789 & 0.9861 & 0.9552 & 0.9145 & 0.8688 & 0.8213 \\
$C_{h}$ & 74.2978 & 0.7787 & 0.9984 & 0.9949 & 0.9897 & 0.9833 & 0.9761 \\
$L_{e}$ & 2454.9207 & 0.8032 & 0.9958 & 0.9917 & 0.988 & 0.9844 & 0.9814 \\
$L_{h}$ & 1100.273 & -0.8032 & 0.9958 & 0.9917 & 0.988 & 0.9844 & 0.9814 \\
$q_{l}$ & 2289.2229 & -0.6053 & 0.9994 & 0.9989 & 0.9983 & 0.9977 & 0.9971 \\
$q_{k}$ & 8.1954 & 0.329 & 0.6864 & 0.2781 & 0.0779 & -0.0223 & -0.0579 \\
\hline
\end{tabular}

of output, investment and worked hours compared to Figure 9 (given the same standard deviations for both shocks' innovations). Land price, credit, consumption and labor are procyclical while and the interest rate is countercyclical, which accords with evidence reported in Section 2. Comparing Figures 9 and 11 suggests that self-fulfilling redistribution shocks could potentially be as quantitatively important as land demand shocks in explaining booms and busts in the credit market and real production activities. This is what we examine next in the estimation section of the paper.

\subsection{Bayesian Estimation of Determinate and Indeterminate Models with Hybrid Interest Rate}

This section addresses the following questions: is indeterminacy important to explain to US business cycles and does it affect the propagation of other fundamental shocks? Our estimation results, reported below, unambiguously yield "yes" and "yes" as the answers. For comparison purpose, we use Bayesian techniques and all estimation results reported below are based on the dataset made available by Liu et al. (2013) - obtained through the Econometrica website referenced in the published version of that paper, to which we add our interest rate data.

Our estimation strategy is as follows. It is obvious that the determinate and indeterminate models are both unrealistic in the sense that the firm sector as a whole is expected to use a combination of fixed-interest rate and variable-interest rate loans at any point in time. ${ }^{24}$ We therefore estimate hybrid versions of the model

\footnotetext{
${ }^{24}$ To our knowledge, there exists no comprehensive measure of how prevalent variable-interest rate loans to US firms are. Historically, floating-rate debt was introduced in the US in 1974 (see Allen and Gale, 1994, page 19). Since then it has been increasingly used by companies to borrow funds, with a pronounced acceleration in the 1980s and 1990s when non-bank investors like mutual funds and insurance companies massively entered the market as buyers, followed by collateralized loan obligations structures and hedge funds in the 2000s. Modern forms of floating-rate loans are investment-grade corporate floaters and sub-investment-grade bank loans (also referred to as senior secured loans, leveraged loans, or syndicated loans), which are both classified as senior collateralized debt in the borrowing firm's capital structure. Although this is only indicative, we notice that, at least since 2000, the market size for floating-rate loans has been exceeding that of high-yield (usually fixed-rate and unsecured) bonds. As of De-
} 
Figure 10: IRFs to a positive land demand shock in the - indeterminate - economy with state-contingent interest rate $\left(\rho_{\varphi}=0.9997, \sigma_{\varphi}=0.0462\right)$
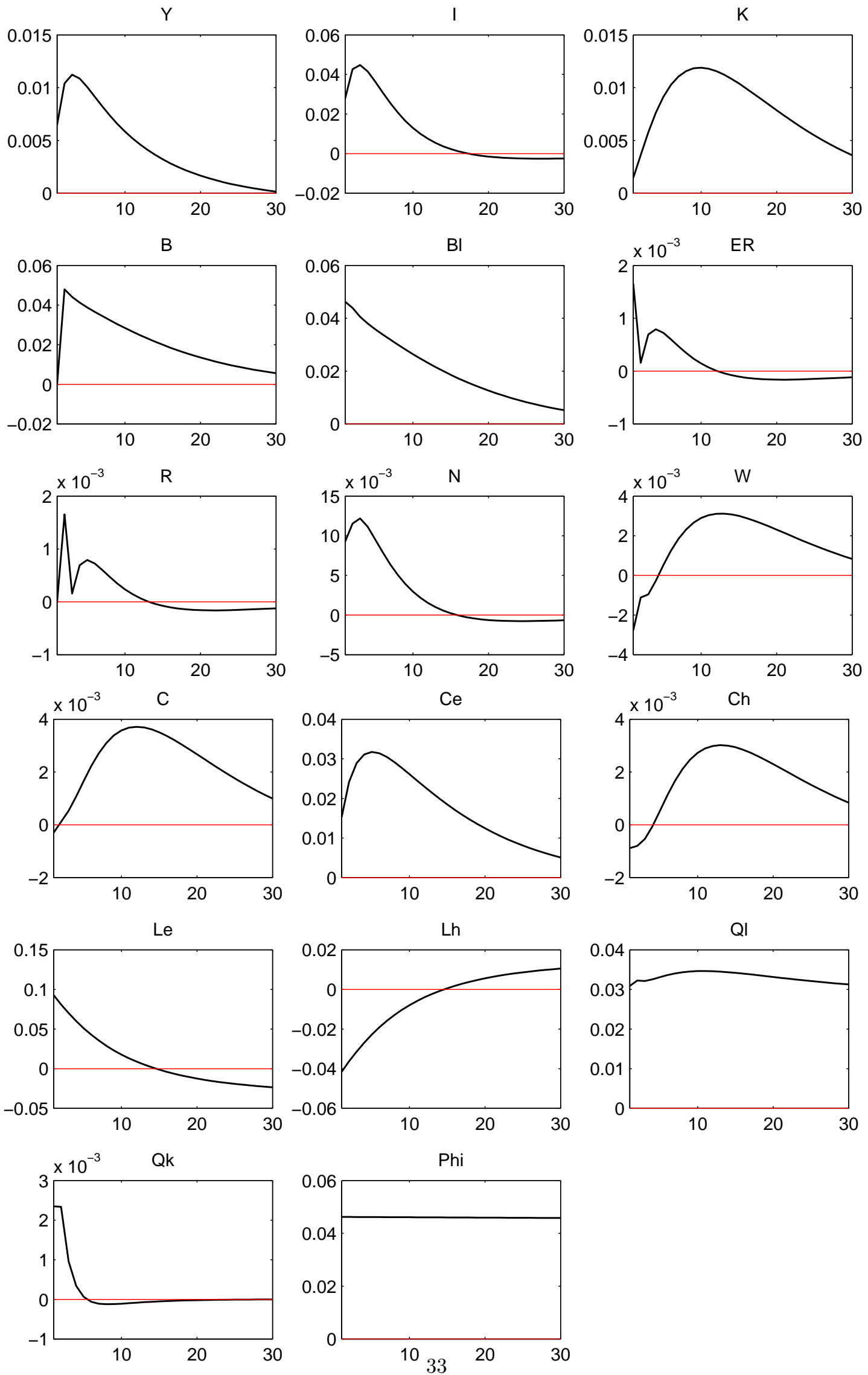
Figure 11: IRFs to a redistribution shock in the - indeterminate - economy with state-contingent interest rate (zero autocorrelation, $\sigma_{\text {red }}=0.0462$ )
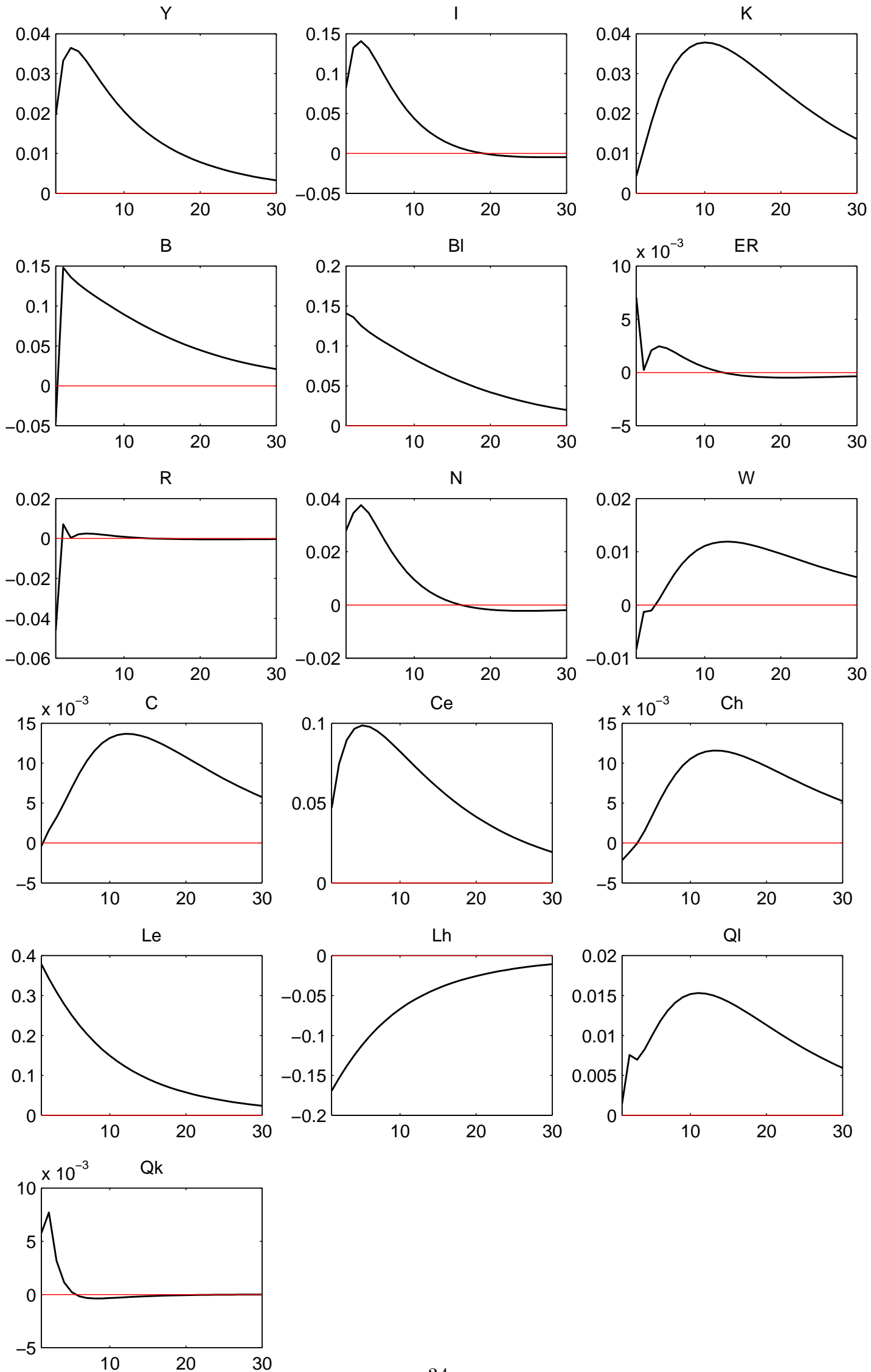
Table 4: Moments under redistribution shock in the - indeterminate - economy with state-contingent interest rate (zero autocorrelation, $\sigma_{\text {red }}=0.0462$ )

\begin{tabular}{cccccccc}
\hline Variable $(\log )$ & S.D. relative to output (\%) & CORR with output & ACF1 & ACF2 & ACF3 & ACF4 & ACF5 \\
\hline$Y$ & 100 & 1 & 0.9685 & 0.8998 & 0.8201 & 0.741 & 0.6675 \\
$I$ & 319.7803 & 0.9231 & 0.9469 & 0.8333 & 0.7028 & 0.576 & 0.4626 \\
$K$ & 149.0911 & 0.8021 & 0.9947 & 0.9798 & 0.9567 & 0.9271 & 0.8924 \\
$B$ & 410.4521 & 0.9441 & 0.8874 & 0.829 & 0.7734 & 0.7179 & 0.6688 \\
$R$ & 45.6358 & -0.0657 & -0.1092 & 0.0151 & -0.0197 & -0.0586 & -0.0492 \\
$N$ & 84.0383 & 0.8803 & 0.9334 & 0.8181 & 0.6784 & 0.5422 & 0.4219 \\
$w$ & 47.6029 & 0.5466 & 0.9694 & 0.9502 & 0.9168 & 0.8752 & 0.8307 \\
$C$ & 54.4377 & 0.694 & 0.9953 & 0.9825 & 0.9623 & 0.9355 & 0.9035 \\
$C_{e}$ & 339.0278 & 0.9641 & 0.9847 & 0.9506 & 0.9058 & 0.8554 & 0.803 \\
$C_{h}$ & 45.9859 & 0.5839 & 0.9933 & 0.9771 & 0.9522 & 0.9206 & 0.884 \\
$L_{e}$ & 863.3324 & 0.962 & 0.9046 & 0.8131 & 0.7284 & 0.6503 & 0.5833 \\
$L_{h}$ & 386.9377 & -0.962 & 0.9046 & 0.8131 & 0.7284 & 0.6503 & 0.5833 \\
$q_{l}$ & 61.2425 & 0.7862 & 0.9925 & 0.9795 & 0.961 & 0.9363 & 0.9063 \\
$q_{k}$ & 10.1782 & 0.4464 & 0.7109 & 0.2854 & 0.0778 & -0.0244 & -0.0609 \\
\hline
\end{tabular}

with a fixed fraction - say, $\omega \in(0,1)$ - of loans with state-contingent interest rate. It is not difficult to show numerically that such an hybrid model has a determinate steady-state if and only if $\omega<0.5$ while the steady state is indeterminate if and only if $\omega>0.5$, just as in the simple model of Section 3.3 in which it can be proved analytically (see Appendix 6.1). Of course, the versions simulated in Section 4.3 correspond to extreme cases, such that either $\omega=0$ (see Section 4.1) or $\omega=1$ (see Section 4.2). We therefore estimate the determinate model under the restriction that $\omega \in(0,0.5)$ and the indeterminate model using the restriction $\omega \in(0.5,1)$.

The simulation results reported in Section 4.3 already contain some information that can be used to form some guess about what estimating the model should deliver. First, because redistribution shocks generate a procyclical land price and a countercyclical interest rate, which is line with the data, the contribution of indeterminacy is expected to be quantitatively significant. In contrast, because land demand shocks have opposite effects in the indeterminate economy, it could well be that their contribution appears to be reduced in the variable-interest rate economy. These observations turn out to accord with the estimation results that we report next.

\section{Estimated Parameters:}

As a benchmark, we first estimate the determinate model, which is essentially Liu et al.'s (2013) with an additional parameter $(\omega)$, the share of loans with state-contingent interest rate, and, more importantly, an additional data, the borrowing cost $(R)$, used in the estimation. Table 5 reports the estimated parameters, which differ substantially from the ones found by Liu et al.'s (2013, Tables 1 and 2). In particular, the fraction of loans with state-contingent interest rate $\omega$ is estimated to be around $10 \%$ while the level of investment adjustement cost is larger. In addition, all shocks are estimated to be more persistent in Table 5, compared to

cember 2014, the former exceeds $\$ 1.9$ trillion while the latter represents slightly more than $\$ 1.3$ trillion (source: Crédit Suisse and Loan Pricing Corporation). In periods of low yields, bank loans are particularly attractive to investors and recommended by many portfolio management firms. See for example http://www.loomissayles.com/internet/internetdata.nsf/id/8yaj9c/ $\$$ file/bankloans-lookingbeyondinterestrateexpectations.pdf. 
Table 5: Estimated parameters of determinate model with hybrid interest rate

\begin{tabular}{|c|c|c|c|c|c|c|c|}
\hline \multirow{2}{*}{ parameters } & \multicolumn{3}{|c|}{ prior } & \multicolumn{4}{|c|}{ posterior } \\
\hline & distribution & mean & s.d. & mode & mean & low & high \\
\hline$\omega$ & beta & 0.167 & 0.1179 & 0.0904 & 0.1059 & 0.0148 & 0.1863 \\
\hline$\gamma_{h}$ & beta & 0.333 & 0.2357 & 0.5432 & 0.5437 & 0.4919 & 0.5973 \\
\hline$\gamma_{e}$ & beta & 0.333 & 0.2357 & 0.6373 & 0.614 & 0.4168 & 0.8484 \\
\hline$\Omega$ & gamma & 2 & 2 & 0.264 & 0.2776 & 0.1929 & 0.3541 \\
\hline $100\left(g_{\gamma}-1\right)$ & gamma & 0.618 & 0.453 & 0.0136 & 0.0292 & 0.0013 & 0.0571 \\
\hline $100\left(\lambda_{q}-1\right)$ & gamma & 0.618 & 0.453 & 0.087 & 0.1666 & 0.009 & 0.3231 \\
\hline$\rho_{a}$ & beta & 0.333 & 0.2357 & 0.967 & 0.9634 & 0.9475 & 0.98 \\
\hline$\rho_{z}$ & beta & 0.333 & 0.2357 & 0.3555 & 0.3537 & 0.2849 & 0.422 \\
\hline$\rho_{\nu_{z}}$ & beta & 0.333 & 0.2357 & 0.5605 & 0.5364 & 0.3892 & 0.6795 \\
\hline$\rho_{q}$ & beta & 0.333 & 0.2357 & 0.9926 & 0.9898 & 0.98 & 0.9995 \\
\hline$\rho_{\nu_{q}}$ & beta & 0.333 & 0.2357 & 0.9799 & 0.9767 & 0.9619 & 0.9921 \\
\hline$\rho_{\varphi}$ & beta & 0.333 & 0.2357 & 0.9989 & 0.9985 & 0.9973 & 0.9998 \\
\hline$\rho_{\psi}$ & beta & 0.333 & 0.2357 & 0.9884 & 0.9856 & 0.9759 & 0.9962 \\
\hline$\rho_{\theta}$ & beta & 0.333 & 0.2357 & 0.9931 & 0.9919 & 0.9884 & 0.9954 \\
\hline$\sigma_{a}$ & inverse gamma & 0.01 & $\infty$ & 0.1064 & 0.1285 & 0.0847 & 0.1703 \\
\hline$\sigma_{z}$ & inverse gamma & 0.01 & $\infty$ & 0.0056 & 0.0057 & 0.005 & 0.0064 \\
\hline$\sigma_{\nu_{z}}$ & inverse gamma & 0.01 & $\infty$ & 0.0035 & 0.0035 & 0.0028 & 0.0043 \\
\hline$\sigma_{q}$ & inverse gamma & 0.01 & $\infty$ & 0.0015 & 0.0016 & 0.0013 & 0.0018 \\
\hline$\sigma_{\nu_{q}}$ & inverse gamma & 0.01 & $\infty$ & 0.0072 & 0.0074 & 0.0066 & 0.0081 \\
\hline$\sigma_{\varphi}$ & inverse gamma & 0.01 & $\infty$ & 0.0381 & 0.0401 & 0.0333 & 0.0466 \\
\hline$\sigma_{\psi}$ & inverse gamma & 0.01 & $\infty$ & 0.0089 & 0.009 & 0.0078 & 0.0102 \\
\hline$\sigma_{\theta}$ & inverse gamma & 0.01 & $\infty$ & 0.0122 & 0.0123 & 0.0112 & 0.0136 \\
\hline
\end{tabular}

Liu et al.'s (2013, Table 2), expect for the land demand shock and for the TFP permanent shock. As for the standard deviations of shocks, they are of similar magnitudes in our estimation, except for the land demand shock and investment-specific permanent shock which are less volatile, and for the investment-specific temporary shock which is more volatile. Table 6 reports the estimated parameters obtained from the indeterminate model. It is important to stress that on top of the fundamental shocks that are present in the determinate model - as in Liu et al. (2013), the indeterminate model is also subject to self-fulfilling redistribution shocks. We follow the literature by assuming that such self-fulfilling shocks are both i.i.d. and orthogonal to fundamental shocks (as in, e.g., Farmer, Khramov, and Nicoló, 2015). The share $\omega$ is poorly identified in the indeterminate economy, but its estimated value is close to 0.7 , in line with the time series constructed by Vickery (2008). ${ }^{25}$ Comparing Tables 5 and 6 reveals some differences. Most notably, in the indeterminate model the patience shock has a largest autocorrelation, TFP shocks are more persistent than investment-specific disturbances, while land demand shock are moderately persistent and less so than labor supply shocks. In addition, estimated standard deviations differ between both models, with that of land demand shock much higher in the indeterminate model.

In light of these changes, one expects patience shocks to become more important and land demand shocks to be less active in the indeterminate economy, compared to what happens in the determinate model, which is

\footnotetext{
${ }^{25}$ It is not difficult to see that our hybrid economy's moments depend on $\omega$ only in the determinacy regime. In a nutshell, this happens because $\omega$ affects the set of unstable eigenvalues and the linear saddle-path solution used to solve the determinate model, and this is why $\omega$ is identified when estimating the determinate model. In contrast, as long as it is larger than 0.5 , $\omega$ does not matter in the indeterminate regime and, therefore, is not identified in that case.
} 
Table 6: Estimated parameters of indeterminate model with hybrid interest rate

\begin{tabular}{|c|c|c|c|c|c|c|c|}
\hline \multirow{2}{*}{ parameters } & \multicolumn{3}{|c|}{ prior } & \multicolumn{4}{|c|}{ posterior } \\
\hline & distribution & mean & s.d. & mode & mean & low & high \\
\hline$\omega$ & beta & 0.167 & 0.1179 & 0.6923 & 0.6905 & 0.519 & 0.8349 \\
\hline$\gamma_{h}$ & beta & 0.333 & 0.2357 & 0.5307 & 0.5306 & 0.4754 & 0.5871 \\
\hline$\gamma_{e}$ & beta & 0.333 & 0.2357 & 0.6037 & 0.5827 & 0.3388 & 0.8068 \\
\hline$\Omega$ & gamma & 2 & 2 & 0.1753 & 0.183 & 0.137 & 0.2265 \\
\hline $100\left(g_{\gamma}-1\right)$ & gamma & 0.618 & 0.453 & 0.3516 & 0.3401 & 0.2338 & 0.4324 \\
\hline $100\left(\lambda_{q}-1\right)$ & gamma & 0.618 & 0.453 & 1.1996 & 1.1977 & 1.0619 & 1.3287 \\
\hline$\rho_{a}$ & beta & 0.333 & 0.2357 & 0.9995 & 0.9992 & 0.9986 & 1 \\
\hline$\rho_{z}$ & beta & 0.333 & 0.2357 & 0.7205 & 0.7064 & 0.6022 & 0.8047 \\
\hline$\rho_{\nu_{z}}$ & beta & 0.333 & 0.2357 & 0.892 & 0.8855 & 0.85 & 0.9203 \\
\hline$\rho_{q}$ & beta & 0.333 & 0.2357 & 0.5895 & 0.5856 & 0.4838 & 0.6913 \\
\hline$\rho_{\nu_{q}}$ & beta & 0.333 & 0.2357 & 0.3931 & 0.4156 & 0.1414 & 0.697 \\
\hline$\rho_{\varphi}$ & beta & 0.333 & 0.2357 & 0.9285 & 0.9211 & 0.8975 & 0.9448 \\
\hline$\rho_{\psi}$ & beta & 0.333 & 0.2357 & 0.9934 & 0.9919 & 0.9854 & 0.9987 \\
\hline$\rho_{\theta}$ & beta & 0.333 & 0.2357 & 0.9885 & 0.9881 & 0.9832 & 0.9933 \\
\hline$\sigma_{a}$ & inverse gamma & 0.01 & $\infty$ & 0.041 & 0.0598 & 0.0168 & 0.1063 \\
\hline$\sigma_{z}$ & inverse gamma & 0.01 & $\infty$ & 0.0024 & 0.0025 & 0.0018 & 0.0032 \\
\hline$\sigma_{\nu_{z}}$ & inverse gamma & 0.01 & $\infty$ & 0.0063 & 0.0064 & 0.0057 & 0.007 \\
\hline$\sigma_{q}$ & inverse gamma & 0.01 & $\infty$ & 0.0039 & 0.004 & 0.0032 & 0.0048 \\
\hline$\sigma_{\nu_{q}}$ & inverse gamma & 0.01 & $\infty$ & 0.0033 & 0.0033 & 0.0026 & 0.004 \\
\hline$\sigma_{\varphi}$ & inverse gamma & 0.01 & $\infty$ & 0.2072 & 0.2262 & 0.1563 & 0.2924 \\
\hline$\sigma_{\psi}$ & inverse gamma & 0.01 & $\infty$ & 0.0085 & 0.0087 & 0.0075 & 0.0098 \\
\hline$\sigma_{\theta}$ & inverse gamma & 0.01 & $\infty$ & 0.0124 & 0.0126 & 0.0113 & 0.0138 \\
\hline$\sigma_{\text {red }}$ & inverse gamma & 0.01 & $\infty$ & 0.0018 & 0.0018 & 0.0014 & 0.0021 \\
\hline
\end{tabular}

confirmed in the variance decomposition that we discuss next.

\section{Variance Decomposition:}

Our metric to assess the importance of each shock at business-cycle frequency is the conditional variance decomposition at various horizons (quarters), as in Liu et al. (2013). In fact, Table 7 (see also Figure 12) shows that the variance decomposition that obtains in our hybrid version of the determinate model estimated using also interest-rate data delivers results that are quite different from those in Liu et al. (2013). More precisely, the land demand shock's contributions to the variance of output, investment and worked hours is more or less halved compared to what Liu et al. (2013) found. In addition, shocks to risk-premium (that is, patience), TFP and investment-biased technology are much more important. Focusing now on the variance of land price, Table 7 shows that the contribution of land demand shocks is reduced by about a third while that of patience shocks is multiplied five-fold compared to results in Liu et al. (2013). In that sense, estimating $\omega$ and using data on $R$ in estimation add new findings compared to Liu et al. (2013), as seen from Table 7.

Another set of new results come from the variance decomposition that arises in the indeterminate economy with redistribution shocks, and that is reported in Table 8 and Figure 13, which tells an altogether very different story. In a nutshell, risk-premium shocks play a much more important role in explaining the variances of all variables in the indeterminate model than in the determinate model. For example, they contribute between 
Table 7: Variance decomposition in determinate model with hybrid interest rate

\begin{tabular}{|c|c|c|c|c|c|c|c|c|}
\hline Horizon & $\varepsilon_{a}$ & $\varepsilon_{z}$ & $\varepsilon_{\nu_{z}}$ & $\varepsilon_{q}$ & $\varepsilon_{\nu_{q}}$ & $\varepsilon_{\varphi}$ & $\varepsilon_{\psi}$ & $\varepsilon_{\theta}$ \\
\hline \multicolumn{9}{|c|}{ Output $(Y)$} \\
\hline 1 & 17.3 & 5.24 & 0.03 & 27.5 & 5.08 & 12.53 & 23.76 & 8.56 \\
\hline 4 & 18.72 & 0.84 & 2 & 28.86 & 1.53 & 13.79 & 23.82 & 10.44 \\
\hline 8 & 18.2 & 0.46 & 1.68 & 32.43 & 0.95 & 12.05 & 25.47 & 8.76 \\
\hline 16 & 16.27 & 0.31 & 1.25 & 38.15 & 0.63 & 9.13 & 28.08 & 6.2 \\
\hline 24 & 14.47 & 0.25 & 1.03 & 42 & 0.51 & 7.44 & 29.3 & 5.01 \\
\hline \multicolumn{9}{|c|}{ Consumption $(C)$} \\
\hline 1 & 1.98 & 38.32 & 27.78 & 0.36 & 16.66 & 0.26 & 14.54 & 0.1 \\
\hline 4 & 2.04 & 36.29 & 7.45 & 0.89 & 16.51 & 0.12 & 36.44 & 0.25 \\
\hline 8 & 1.35 & 20.93 & 3.66 & 13.24 & 11.39 & 1.39 & 46.31 & 1.74 \\
\hline 16 & 3.7 & 7.09 & 1.73 & 38.2 & 4.33 & 2.86 & 39.48 & 2.62 \\
\hline 24 & 4.12 & 3.92 & 1.12 & 49.59 & 2.4 & 2.28 & 34.7 & 1.87 \\
\hline \multicolumn{9}{|c|}{ Investment $(I)$} \\
\hline 1 & 24.57 & 0.07 & 4.39 & 33.01 & 0.36 & 15.4 & 11.96 & 10.23 \\
\hline 4 & 25.37 & 1.63 & 3.42 & 31.31 & 0.06 & 15.78 & 11.28 & 11.17 \\
\hline 8 & 26.18 & 2.34 & 2.53 & 32.56 & 0.11 & 14.61 & 11.86 & 9.82 \\
\hline 16 & 26.5 & 2.53 & 2.2 & 33.42 & 0.22 & 13.35 & 13.05 & 8.73 \\
\hline 24 & 26.24 & 2.5 & 2.16 & 33.13 & 0.25 & 13.11 & 13.63 & 8.98 \\
\hline \multicolumn{9}{|c|}{ Credit $\left(B^{l}\right)$} \\
\hline 1 & 16.28 & 0 & 1.67 & 3.14 & 5.94 & 27.06 & 4.73 & 41.18 \\
\hline 4 & 16.37 & 0.12 & 1.88 & 4.63 & 5.97 & 25.69 & 4.6 & 40.74 \\
\hline 8 & 16.82 & 0.17 & 2.03 & 8.35 & 5.3 & 23.67 & 4.96 & 38.69 \\
\hline 16 & 16.92 & 0.13 & 1.89 & 17.46 & 4.08 & 19.87 & 5.63 & 34.01 \\
\hline 24 & 16.16 & 0.11 & 1.66 & 25.69 & 3.37 & 16.98 & 5.97 & 30.06 \\
\hline \multicolumn{9}{|c|}{ Labor $(N)$} \\
\hline 1 & 20.04 & 0.52 & 0.79 & 26.65 & 0.03 & 14.51 & 27.53 & 9.92 \\
\hline 4 & 19.38 & 1.13 & 2.25 & 25.64 & 0.18 & 12.9 & 30.36 & 8.16 \\
\hline 8 & 18.46 & 2.03 & 1.69 & 23.73 & 0.3 & 11.39 & 35.63 & 6.76 \\
\hline 16 & 16.34 & 2.13 & 1.39 & 20.57 & 0.41 & 9.6 & 43.8 & 5.75 \\
\hline 24 & 14.89 & 1.97 & 1.29 & 19.07 & 0.4 & 8.87 & 47.7 & 5.82 \\
\hline \multicolumn{9}{|c|}{ Wage $(w)$} \\
\hline 1 & 14.7 & 8.18 & 8.4 & 11.95 & 18.64 & 10.65 & 20.2 & 7.28 \\
\hline 4 & 7.25 & 24.92 & 3.49 & 5.77 & 29.85 & 3.54 & 22.78 & 2.41 \\
\hline 8 & 5.78 & 20.93 & 2.61 & 26.83 & 21.73 & 3.87 & 13.14 & 5.11 \\
\hline 16 & 9.18 & 6.42 & 1.64 & 61.91 & 6.87 & 4.87 & 3.53 & 5.58 \\
\hline 24 & 8.71 & 3.35 & 1.08 & 73.98 & 3.58 & 3.53 & 2 & 3.77 \\
\hline \multicolumn{9}{|c|}{ Interest rate $(R)$} \\
\hline 1 & 0.49 & 25.32 & 16.28 & 0 & 7.3 & 17.66 & 0.17 & 32.78 \\
\hline 4 & 2.51 & 23.33 & 18.52 & 4.68 & 6.21 & 16.02 & 0.8 & 27.92 \\
\hline 8 & 1.98 & 20.06 & 14.11 & 14.16 & 5.3 & 17.17 & 2.82 & 24.41 \\
\hline 16 & 6.16 & 19.72 & 12.75 & 14.43 & 5.44 & 16.12 & 2.95 & 22.43 \\
\hline 24 & 12.15 & 17.09 & 11.07 & 17.6 & 4.78 & 14.47 & 2.78 & 20.06 \\
\hline \multicolumn{9}{|c|}{ Land price $\left(q_{l}\right)$} \\
\hline 1 & 26.05 & 0.2 & 0.06 & 0.23 & 1.61 & 66.47 & 5.32 & 0.06 \\
\hline 4 & 24.61 & 0.71 & 0.03 & 0.11 & 1.85 & 67.95 & 4.7 & 0.04 \\
\hline 8 & 23.65 & 0.68 & 0.12 & 1.1 & 1.42 & 68.02 & 4.95 & 0.06 \\
\hline 16 & 21.45 & 0.39 & 0.17 & 4.6 & 0.84 & 66.99 & 5.49 & 0.07 \\
\hline 24 & 19.11 & 0.27 & 0.15 & 7.29 & 0.58 & 66.86 & 5.68 & 0.07 \\
\hline \multicolumn{9}{|c|}{ Capital price $\left(q_{k}\right)$} \\
\hline 1 & 18.8 & 0 & 19.03 & 32.76 & 2.7 & 10.23 & 11.61 & 4.86 \\
\hline 4 & 20.25 & 2.23 & 13.47 & 28.6 & 1.67 & 13.68 & 10.49 & 9.61 \\
\hline 8 & 20.24 & 2.3 & 13.49 & 28.56 & 1.67 & 13.67 & 10.46 & 9.61 \\
\hline 16 & 20.24 & 2.3 & 13.45 & 28.55 & 1.67 & 13.7 & 10.45 & 9.65 \\
\hline 24 & 20.24 & 2.3 & 13.45 & 28.55 & 1.66 & 13.7 & 10.45 & 9.65 \\
\hline
\end{tabular}


Figure 12: Variance decomposition in determinate model with hybrid interest rate Output Consumption
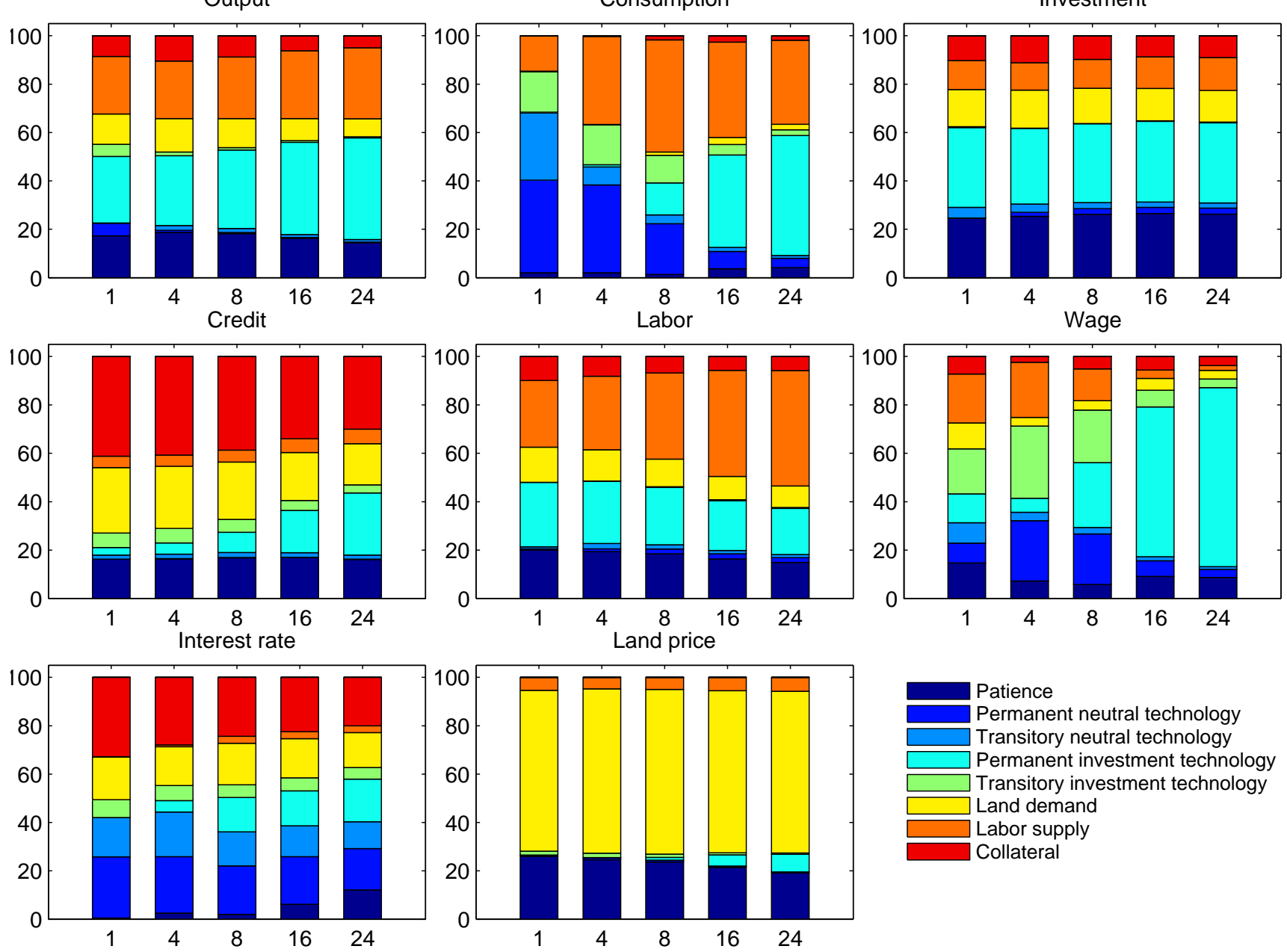

$30 \%$ and $50 \%$ to the variances of output, investment and credit. In comparison, the contribution of land demand shocks is lower. For example, a striking feature reported in Table 8 is that while patience shocks explain more than $90 \%$ of the land price's variance, the contribution of land demand shocks explains less than $8 \%$. Both Tables 7 and 8 show that productivity and investment-specific shocks are not important to account for movements in output and investment, in contrast with earlier results in the business-cycle literature (e.g. Greenwood, Hercowitz, Huffman, 1997, Justiniano, Primiceri, Tambalotti, 2011). The contributions of each fundamental shock to consumption movements are not very different in each regime.

A surprising feature in Table 8 and Figure 13 is that redistribution shocks do not contribute to the variances of aggregates, except for that of the interest rate. One might be tempted to infer from such an observation that those shocks are irrelevant in the estimation procedure and hence should be dropped. This turns out to be untrue, as we now argue in view of both models' fit.

A natural question to ask at this stage is which model does better fit the data. To that aim, Table 9 reports the marginal data density, using Geweke's criterion. The four models for which the data density is reported are Liu et al. (2013)'s original version with $\omega=$ set to 0 (second column in Table 9), the hybrid version with 
Table 8: Variance decomposition in indeterminate model with hybrid interest rate

\begin{tabular}{|c|c|c|c|c|c|c|c|c|c|}
\hline Horizon & $\varepsilon_{a}$ & $\varepsilon_{z}$ & $\varepsilon_{\nu_{z}}$ & $\varepsilon_{q}$ & $\varepsilon_{\nu_{q}}$ & $\varepsilon_{\varphi}$ & $\varepsilon_{\psi}$ & $\varepsilon_{\theta}$ & $\varepsilon_{\text {red }}$ \\
\hline \multicolumn{10}{|c|}{ Output $(Y)$} \\
\hline 1 & 36.16 & 4.86 & 0.01 & 9.64 & 0.01 & 19.81 & 20.07 & 9.17 & 0.26 \\
\hline 4 & 42.31 & 2.24 & 3.91 & 5.51 & 0.01 & 13.87 & 20.02 & 11.79 & 0.33 \\
\hline 8 & 44.41 & 1.49 & 4.47 & 4.17 & 0.03 & 9.87 & 23.99 & 11.25 & 0.33 \\
\hline 16 & 43.6 & 1.08 & 4.11 & 3.36 & 0.03 & 7.3 & 30.89 & 9.33 & 0.3 \\
\hline 24 & 41.26 & 0.94 & 3.67 & 2.96 & 0.03 & 7.13 & 35.7 & 8.03 & 0.27 \\
\hline \multicolumn{10}{|c|}{ Consumption $(C)$} \\
\hline 1 & 0.31 & 3.19 & 73.38 & 3.76 & 3.85 & 0.86 & 14.48 & 0.17 & 0 \\
\hline 4 & 0.75 & 10.59 & 31.54 & 16 & 1.24 & 0.7 & 38.91 & 0.25 & 0.02 \\
\hline 8 & 6.83 & 11.91 & 12.51 & 18.88 & 0.49 & 0.85 & 46.6 & 1.84 & 0.09 \\
\hline 16 & 16.51 & 7.75 & 7.33 & 13.01 & 0.19 & 1.18 & 50.32 & 3.54 & 0.16 \\
\hline 24 & 18.65 & 5.62 & 6.33 & 9.8 & 0.13 & 0.85 & 55.27 & 3.17 & 0.16 \\
\hline \multicolumn{10}{|c|}{ Investment $(I)$} \\
\hline 1 & 38.91 & 2.33 & 9.93 & 5.62 & 0.4 & 23.18 & 9.21 & 10.17 & 0.26 \\
\hline 4 & 46.25 & 0.66 & 10.87 & 2.2 & 0.12 & 17.65 & 9.06 & 12.87 & 0.33 \\
\hline 8 & 50.09 & 0.71 & 10.19 & 1.52 & 0.12 & 13.97 & 10.3 & 12.76 & 0.34 \\
\hline 16 & 50.46 & 1.22 & 9.27 & 1.61 & 0.14 & 13.45 & 11.79 & 11.75 & 0.32 \\
\hline 24 & 49.3 & 1.28 & 8.99 & 1.64 & 0.13 & 14.47 & 12.43 & 11.46 & 0.31 \\
\hline \multicolumn{10}{|c|}{ Credit $\left(B^{l}\right)$} \\
\hline 1 & 53.95 & 0.17 & 0.86 & 3.46 & 0.3 & 5.17 & 2.47 & 33.22 & 0.39 \\
\hline 4 & 54.94 & 0.46 & 0.93 & 4.56 & 0.17 & 2.88 & 2.45 & 33.23 & 0.39 \\
\hline 8 & 55.68 & 0.75 & 1.27 & 4.98 & 0.11 & 1.77 & 2.73 & 32.34 & 0.37 \\
\hline 16 & 56.54 & 0.83 & 1.72 & 4.65 & 0.08 & 2 & 3.33 & 30.5 & 0.34 \\
\hline 24 & 56.93 & 0.78 & 1.81 & 4.25 & 0.07 & 3.07 & 3.82 & 28.96 & 0.31 \\
\hline \multicolumn{10}{|c|}{ Labor $(N)$} \\
\hline 1 & 38.04 & 2.52 & 2.5 & 4.48 & 0.59 & 20.84 & 21.11 & 9.64 & 0.27 \\
\hline 4 & 39.65 & 0.83 & 7.42 & 1.52 & 0.19 & 15.79 & 25.13 & 9.2 & 0.28 \\
\hline 8 & 39.3 & 0.92 & 6.93 & 1.19 & 0.17 & 11.73 & 31.4 & 8.09 & 0.26 \\
\hline 16 & 34.37 & 1.36 & 5.7 & 1.39 & 0.16 & 10.58 & 39.54 & 6.69 & 0.22 \\
\hline 24 & 30.77 & 1.32 & 5.2 & 1.35 & 0.14 & 10.51 & 44.03 & 6.48 & 0.2 \\
\hline \multicolumn{10}{|c|}{ Wage $(w)$} \\
\hline 1 & 29.48 & 0 & 23.97 & 0.11 & 6.25 & 16.15 & 16.36 & 7.47 & 0.21 \\
\hline 4 & 12.88 & 7.35 & 22.86 & 19.41 & 2.79 & 10.43 & 21.41 & 2.79 & 0.07 \\
\hline 8 & 12.97 & 16.06 & 11.54 & 31.68 & 1.39 & 6.52 & 13.12 & 6.59 & 0.12 \\
\hline 16 & 29.11 & 12.68 & 9.55 & 23.92 & 0.6 & 5.7 & 5.71 & 12.47 & 0.26 \\
\hline 24 & 36.81 & 10.33 & 10.01 & 20 & 0.45 & 4.42 & 4.39 & 13.28 & 0.3 \\
\hline \multicolumn{10}{|c|}{ Interest rate $(R)$} \\
\hline 1 & 0 & 0 & 0 & 0 & 0 & 0 & 0 & 0 & 100 \\
\hline 4 & 21.46 & 17.44 & 4.63 & 7.03 & 1.08 & 8.05 & 0.64 & 22.78 & 16.88 \\
\hline 8 & 22.94 & 16.29 & 4.03 & 5.79 & 0.89 & 12.74 & 2.41 & 21.72 & 13.18 \\
\hline 16 & 22.86 & 17.44 & 4.49 & 6.97 & 0.86 & 12.39 & 2.59 & 20.33 & 12.08 \\
\hline 24 & 26.65 & 16.2 & 5.11 & 6.85 & 0.77 & 12.14 & 2.4 & 18.94 & 10.94 \\
\hline \multicolumn{10}{|c|}{ Land price $\left(q_{l}\right)$} \\
\hline 1 & 89.63 & 0 & 0.34 & 0.07 & 0.2 & 7.55 & 2.21 & 0 & 0 \\
\hline 4 & 90.96 & 0.15 & 0.23 & 0.58 & 0.07 & 5.93 & 1.98 & 0.1 & 0 \\
\hline 8 & 91.51 & 0.32 & 0.13 & 0.82 & 0.03 & 4.82 & 2.14 & 0.22 & 0.01 \\
\hline 16 & 92.89 & 0.29 & 0.19 & 0.66 & 0.02 & 3.17 & 2.46 & 0.31 & 0.01 \\
\hline 24 & 94.01 & 0.21 & 0.19 & 0.5 & 0.01 & 2.21 & 2.6 & 0.26 & 0.01 \\
\hline \multicolumn{10}{|c|}{ Capital price $\left(q_{k}\right)$} \\
\hline 1 & 19.33 & 5.52 & 22.47 & 8.37 & 7.91 & 24.97 & 7.94 & 3.39 & 0.1 \\
\hline 4 & 27.47 & 3.82 & 19.22 & 6.14 & 5.24 & 22.89 & 7.12 & 7.89 & 0.19 \\
\hline 8 & 27.35 & 3.95 & 19.13 & 6.3 & 5.24 & 22.88 & 7.08 & 7.87 & 0.19 \\
\hline 16 & 27.36 & 3.95 & 19.11 & 6.28 & 5.23 & 22.92 & 7.07 & 7.89 & 0.19 \\
\hline 24 & 27.36 & 3.95 & 19.11 & 6.28 & 5.22 & 22.92 & 7.07 & 7.89 & 0.19 \\
\hline
\end{tabular}


Figure 13: Variance decomposition in indeterminate model with hybrid interest rate Output Consumption

Investment
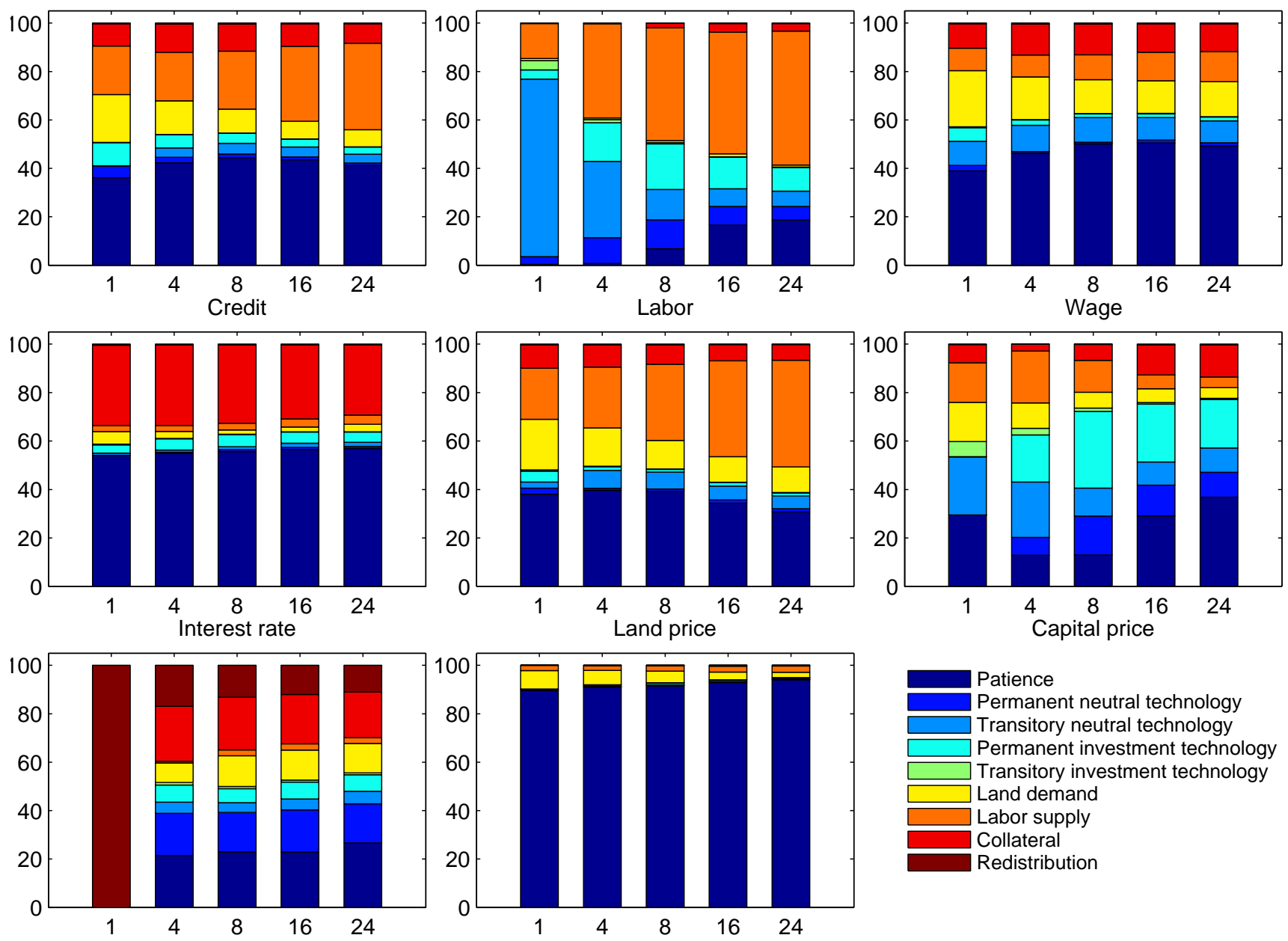

$\omega$ estimated to have a mean about 0.1 (third column), the pure indeterminate model with $\omega$ set to 1 (fourth column) and its hybrid version with $\omega$ estimated mean to be around 0.7 (fifth column). Table 9 shows that while the hybrid determinate model is preferred to the pure determinate model, they are both overwhelmingly rejected against the hybrid indeterminate model: if the prior distribution over models is agnostic, the posterior probability of the determinate models is essentially zero. On the other hand, while the data does not strongly discriminate between the determinate and the pure indeterminate models, the posterior probability of the hybrid indeterminate model is essentially one with identical priors across all models. In summary, the data strongly favors the hybrid indeterminate model with redistribution shocks. ${ }^{26}$

\footnotetext{
${ }^{26}$ We have also estimated the hybrid indeterminate without redistribution shocks and such a model turns out to have a lower fit compared to that of the same model with redistribution shocks. This suggests that the latter play a role in fitting better the data.
} 
Table 9: Model Fit

LWZ Model Hybrid LWZ Mode

Log marginal data density $\quad 2879.372221$

2879.622297

Indet. Model

$10^{-14}$

$10^{-14}$

2896.814187

Hybrid Indet. Model

Model posterior probability

We use Geweke's definition of Log marginal data density for all estimated models. LWZ Model: Liu et al.

(2013) with $\omega$ set to 0. Hybrid LWZ Model: Liu et al. (2013) with $\omega$ estimated to have mean be around 0.1 .

Indet. Model: indeterminate model with $\omega$ set to 1 . Hybrid Indet. Model: indeterminate model with $\omega$ estimated to have mean around 0.7.

\section{Conclusion}

The contribution of this paper is twofold. On the theory side, we have shown that indeterminacy and selffulfilling equilibria arise in standard versions of DSGE models with endogenous collateral constraints, provided that loans have state-contingent interest rate. The empirical part of the paper has given content to the claim that, far from being only a theoretical curiosity, the indeterminate model with self-fulfilling equilibria accords with data. In particular, while the indeterminate model with loans that have state-contingent interest rate and are collateralized predicts that the borrowing cost is countercyclical, in line with data, such a model also replicates the $S$-shaped pattern of dynamic correlations between the interest rate and aggregate variables that is also present in data. In contrast, the interest rate is procyclical in the determinate model with predetermined interest rate and its lagged values correlate positively with contemporaneous aggregates, which is at odds with quarterly data. Key to our findings are shocks that redistribute income from lenders to borrowers during booms.

We conjecture that our set of results could be of interest to understand the business-cycle consequences of household's debt and housing investment, in view of the fact that variable-interest rate loans (e.g. adjustablerate mortgages) have been an important source of funding up to the 2007-08 crisis. The main mechanism that we emphasize in this paper could in particular have first-order effects on the monetary transmission channel, when embedded in particular in the setting developed by Kydland, Rupert and Šustek (2015), Garriga, Kydland and Šustek (2013). In relation to this, it is obvious that real interest rate movements arise also in the context of nominal debt contracts when inflation is not perfectly stabilized. In that sense all loans have state-contingent real interest rates. This is a second reason why embedding the mechanism of this paper in a framework with monetary policy, whether conventional or not, is worth pursuing. Our results also complement the recent analysis of Justiniano, Primiceri, and Tambalotti (2015b), who analyze the 2000s US trend in housing and credit markets in a very similar model and show that falling interest rates must be part of the story. We have further shown that countercyclical borrowing cost and redistribution shocks are important drivers of fluctuations at businesscycle frequency in output, investment and other aggregate variables. In our model, however, countercyclical interest rate results from self-fulfilling swings in borrowing cost that move both credit supply and credit demand endogenously. In addition, because collateralized lending with variable rates is standard practice in interbank credit markets, our results point at a potentially empirically relevant force that could explain sudden freezes in those markets that have been under the spotlight after the last financial crisis (see e.g. Gorton and Metrick, 2012). In particular, self-fulfilling redistribution shocks could well be an important driver of banking crisis that reinforce fundamental shocks (see Boissay, Collard and Smets, 2015, for an analysis of the latter). Of course, some unrealistic aspects of the settings that we have used and estimated in this paper need to be fixed. At 
the top of the list, there is need for further work to incorporate debt maturity into standard macroeconomic models. This avenue is presumably one way to make the interest rate in the model as persistent as it is in the data. In addition, our models feature no policy instruments that could potentially either prevent ex-ante, or fight against the consequences of self-fulfilling market gyrations. We believe this calls for further research.

\section{Appendix}

\subsection{Global Self-Fulfilling Equilibria with Predetermined and State-Contingent In- terest Rate}

This section shows that global self-fulfilling equilibria exist in the simple model of Section 3.3 provided that the proportion of loans with state-contingent interest rate in the economy is larger than 0.5. Suppose that a constant fraction $\omega \in[0,1]$ of total loans has a state-contingent interest rate while a fraction $1-\omega$ of total loans has a fixed interest rate. This means that the interest rate paid in period $t$ is now $\mathcal{R}_{t} \equiv \omega R_{t}+(1-\omega) R_{t-1}$ and it follows that the first order condition (10) now reads $\mathbb{E}_{t} \mathcal{R}_{t+1}=\tilde{\beta}^{-1}$. Two cases occur depending on the value for $\omega$. When $\omega<0.5$, then the latter equality $\omega \mathbb{E}_{t} R_{t+1}+(1-\omega) R_{t}=\tilde{\beta}^{-1}$ can be solved forward for $R_{t}=\tilde{\beta}^{-1}$ so that the interest rate is constant and the economy stays in steady state for all $t$, exactly as in the case with $\omega=0$. In other words, the steady state solution for the interest rate is determinate. When $\omega>0.5$, however, this is no longer true and the steady state interest rate is indeterminate: $\omega \mathbb{E}_{t} R_{t+1}+(1-\omega) R_{t}=\tilde{\beta}^{-1}$ cannot be solved forward and there exist self-fulfilling equilibria such that $R_{t+1}=(\tilde{\beta} \omega)^{-1}-(1-\omega) \omega^{-1} R_{t}+\varepsilon_{t+1}$, where the innovation $\varepsilon$ is i.i.d. with zero mean.

In addition, the intuition developed in Section 3.3 still applies to the case with $\omega>0.5$. While the expression for credit demand $B_{t+1}^{d}=\tilde{\beta} Q L_{t+1}$ does not change, credit supply is now $B_{t+1}^{s}=Q L_{t+1}-\beta L_{t}\left[1+\omega Q\left(1-\tilde{\beta} R_{t}\right)\right]$, which of course collapses to (22) in Section 3.3 when $\omega=1$. The situation depicted in Figure 8 therefore applies just the same if $\omega>0.5$ : if the borrower expects a lower interest rate in period $t$, she invests more so that $L_{t+1}$ goes up and the expectation of a falling loan interest rate is self-fulfilling because credit supply shifts rightward by more than credit demand.

\subsection{Linearized Version of Basic Model}

The purpose of this appendix is to report the linearized version of the equations describing the competitive equilibrium with borrowing constraints in Section 3. In all equations below, $x_{t}$ denotes the deviation of variable $X_{t}$ from its steady-state $X$ level in percentage terms. For example, $k_{t} \equiv\left(K_{t}-K\right) / K$, where $K$ is the steady-state capital stock. The linearized versions of (1), (3)-(5) and (7)-(14) are respectively:

$$
\begin{gathered}
\frac{\tilde{C}}{Y} \tilde{c}_{t}+\frac{Q \tilde{L}}{Y}\left(\tilde{l}_{t+1}-\tilde{l}_{t}\right)+\frac{B}{Y} b_{t+1}=\frac{R B}{Y}\left(r_{t}+b_{t}\right) \\
y_{t}=a_{t}+\alpha k_{t}+\gamma l_{t} \\
\tilde{l}_{t}=-\frac{L}{\tilde{L}} l_{t}
\end{gathered}
$$




$$
\begin{gathered}
\frac{C}{Y} c_{t}+\frac{K}{Y}\left(k_{t+1}-(1-\delta) k_{t}\right)+\frac{Q L}{Y}\left(l_{t+1}-l_{t}\right)+\frac{R B}{Y}\left(r_{t}+b_{t}\right)=\frac{B}{Y} b_{t+1}+y_{t} \\
\mathbb{E}_{t}\left(r_{t+1}\right)+b_{t+1}=\mathbb{E}_{t}\left(q_{t+1}\right)+l_{t+1} \\
\sigma_{L} \tilde{c}_{t}=-\tilde{\lambda}_{t} \\
q_{t}+\tilde{\lambda}_{t}=\tilde{\beta} \mathbb{E}_{t}\left(q_{t+1}+\tilde{\lambda}_{t+1}\right)-(1-\tilde{\beta}) \sigma_{W} \tilde{l}_{t+1} \\
\tilde{\lambda}_{t}=\mathbb{E}_{t}\left(\tilde{\lambda}_{t+1}+r_{t+1}\right) \\
\sigma_{B} c_{t}=-\lambda_{t} \\
q_{t}+\lambda_{t}=\beta \mathbb{E}_{t}\left(q_{t+1}+\lambda_{t+1}\right)+\frac{\beta \gamma Y}{Q L}\left(\mathbb{E}_{t}\left(\lambda_{t+1}+y_{t+1}\right)-l_{t+1}\right)+\frac{\theta \Phi}{\Lambda}\left(\mathbb{E}_{t}\left(q_{t+1}\right)+\phi_{t}\right) \\
\lambda_{t}=\beta(1-\delta) \mathbb{E}_{t}\left(\lambda_{t+1}\right)+\frac{\alpha \beta Y}{K}\left(\mathbb{E}_{t}\left(\lambda_{t+1}+y_{t+1}\right)-k_{t+1}\right) \\
\lambda_{t}=\beta R \mathbb{E}_{t}\left(\lambda_{t+1}+r_{t+1}\right)+\frac{R \Phi}{\Lambda}\left(\mathbb{E}_{t}\left(r_{t+1}\right)+\phi_{t}\right)
\end{gathered}
$$

\subsection{Linearized Version of Extended Model}

The purpose of this appendix is to report the stationary and linearized versions of the equations describing the competitive equilibrium with borrowing constraints in Section 4.

\subsubsection{Model with Predetermined Interest Rate}

This is the model described in Section 4.1.

\section{Stationary equilibrium:}

Since there is technological progress, a steady state is defined in terms of detrended variables. Define $\tilde{X}_{1 t}=\frac{X_{1 t}}{\Gamma_{t}}$ where $\Gamma_{t}=\left(Z_{t} Q_{t}^{(1-\phi) \alpha}\right)^{\frac{1}{1-(1-\phi) \alpha}}, X_{1} \in\left\{Y, C_{h}, C_{e}, B, w, q_{l}\right\}$, define $\tilde{X}_{2 t}=X_{2 t} \Gamma_{t}$ where $X_{2} \in\left\{\mu_{e}, \mu_{b}\right\}$, define $\tilde{X}_{3 t}=\frac{X_{3 t}}{Q_{t} \Gamma_{t}}$ where $X_{3} \in\{I, K\}$ and define $\tilde{\mu}_{h t}=\frac{\mu_{h t} \Gamma_{t}}{A_{t}}, \tilde{q}_{k t}=q_{k t} Q_{t}$. The first-order and market clearing conditions in detrended variables are then:

$$
\begin{gathered}
\tilde{\mu}_{h t}=\frac{1}{\tilde{C}_{h t}-\gamma_{h} \tilde{C}_{h t-1} \Gamma_{t-1} / \Gamma_{t}}-\mathbb{E}_{t}\left[\frac{\beta \gamma_{h}}{\tilde{C}_{h t+1} \Gamma_{t+1} / \Gamma_{t}-\gamma_{h} \tilde{C}_{h t}}\left(1+\lambda_{a t+1}\right)\right] \\
\tilde{w}_{t}=\frac{\psi_{t}}{\tilde{\mu}_{h t}} \\
\tilde{q}_{l t}=\beta \mathbb{E}_{t}\left[\frac{\tilde{\mu}_{h t+1}}{\tilde{\mu}_{h t}}\left(1+\lambda_{a t+1}\right) \tilde{q}_{l t+1}\right]+\frac{\varphi_{t}}{\tilde{\mu}_{h t} L_{h t}} \\
1=\beta \mathbb{E}_{t}\left[\frac{\tilde{\mu}_{h t+1}}{\tilde{\mu}_{h t}} \frac{\Gamma_{t}}{\Gamma_{t+1}}\left(1+\lambda_{a t+1}\right)\right] R_{t} \\
\tilde{\mu}_{e t}=\frac{\beta \gamma_{e}}{\tilde{C}_{e t}-\gamma_{e} \tilde{C}_{e t-1} \Gamma_{t-1} / \Gamma_{t}}-\mathbb{E}_{t}\left[\frac{\beta \tilde{C}_{e t+1} \Gamma_{t+1} / \Gamma_{t}-\gamma_{e} \tilde{C}_{e t}}{\tilde{C}_{e t}}\right]
\end{gathered}
$$




$$
\begin{aligned}
& \tilde{w}_{t}=(1-\alpha) \tilde{Y}_{t} / N_{e t} \\
& 1=\tilde{q}_{k t}\left(1-\frac{\Omega}{2}\left(\frac{\tilde{I}_{t}}{\tilde{I}_{t-1}} \frac{Q_{t} \Gamma_{t}}{Q_{t-1} \Gamma_{t-1}}-\bar{\lambda}_{I}\right)^{2}-\Omega\left(\frac{\tilde{I}_{t}}{\tilde{I}_{t-1}} \frac{Q_{t} \Gamma_{t}}{Q_{t-1} \Gamma_{t-1}}-\bar{\lambda}_{I}\right) \frac{\tilde{I}_{t}}{\tilde{I}_{t-1}} \frac{Q_{t} \Gamma_{t}}{Q_{t-1} \Gamma_{t-1}}\right) \\
& +\beta \Omega \mathbb{E}_{t}\left[\frac{\tilde{\mu}_{e t+1}}{\tilde{\mu}_{e t}} \frac{Q_{t} \Gamma_{t}}{Q_{t+1} \Gamma_{t+1}} \tilde{q}_{k t+1}\left(\frac{\tilde{I}_{t+1}}{\tilde{I}_{t}} \frac{Q_{t+1} \Gamma_{t+1}}{Q_{t} \Gamma_{t}}-\bar{\lambda}_{I}\right)\left(\frac{\tilde{I}_{t+1}}{\tilde{I}_{t}} \frac{Q_{t+1} \Gamma_{t+1}}{Q_{t} \Gamma_{t}}\right)^{2}\right] \\
& \tilde{q}_{k t}=\mathbb{E}_{t}\left[\beta \frac{\tilde{\mu}_{e t+1}}{\tilde{\mu}_{e t}}\left(\alpha(1-\phi) \frac{\tilde{Y}_{t+1}}{\tilde{K}_{t}}+\tilde{q}_{k t+1} \frac{Q_{t} \Gamma_{t}}{Q_{t+1} \Gamma_{t+1}}(1-\delta)\right)+\frac{\tilde{\mu}_{b t}}{\tilde{\mu}_{e t}} \theta_{t} \tilde{q}_{k t+1} \frac{Q_{t}}{Q_{t+1}}\right] \\
& \tilde{q}_{l t}=\mathbb{E}_{t}\left[\beta \frac{\tilde{\mu}_{e t+1}}{\tilde{\mu}_{e t}}\left(\alpha \phi \frac{\tilde{Y}_{t+1}}{\tilde{L}_{e t}}+\tilde{q}_{l t+1}\right)+\frac{\tilde{\mu}_{b t}}{\tilde{\mu}_{e t}} \theta_{t} \tilde{q}_{l t+1} \frac{\Gamma_{t+1}}{\Gamma_{t}}\right] \\
& 1=\mathbb{E}_{t}\left[\beta \frac{\tilde{\mu}_{e t+1}}{\tilde{\mu}_{e t}} \frac{\Gamma_{t}}{\Gamma_{t+1}}+\frac{\tilde{\mu}_{b t}}{\tilde{\mu}_{e t}}\right] R_{t} \\
& \tilde{Y}_{t}=\left(\frac{Q_{t} Z_{t}}{Q_{t-1} Z_{t-1}}\right)^{\frac{-(1-\phi) \alpha}{1-(1-\phi) \alpha}} L_{e t-1}^{\phi \alpha} \tilde{K}_{t-1}^{(1-\phi) \alpha} N_{e t}^{1-\alpha} \\
& \tilde{K}_{t}=(1-\delta) \tilde{K}_{t-1} \frac{Q_{t-1} \Gamma_{t-1}}{Q_{t} \Gamma_{t}}+\left(1-\frac{\Omega}{2}\left(\frac{\tilde{I}_{t}}{\tilde{I}_{t-1}} \frac{Q_{t} \Gamma_{t}}{Q_{t-1} \Gamma_{t-1}}-\bar{\lambda}_{I}\right)^{2}\right) \tilde{I}_{t} \\
& \tilde{Y}_{t}=\tilde{C}_{h t}+\tilde{C}_{e t}+\tilde{I}_{t} \\
& \bar{L}=L_{h t}+L_{e t} \\
& \alpha \tilde{Y}_{t}=\tilde{C}_{e t}+\tilde{I}_{t}+\tilde{q}_{l t}\left(L_{e t}-L_{e t-1}\right)+\tilde{B}_{t-1} \frac{\Gamma_{t-1}}{\Gamma_{t}}-\frac{\tilde{B}_{t}}{R_{t}} \\
& \tilde{B}_{t}=\theta_{t} \mathbb{E}_{t}\left[\tilde{q}_{l t+1} \frac{\Gamma_{t+1}}{\Gamma_{t}} L_{e t}+\tilde{q}_{k t+1} \tilde{K}_{t} \frac{Q_{t}}{Q_{t+1}}\right]
\end{aligned}
$$

For simplicity we can define

$$
\begin{gathered}
g_{z t} \equiv \frac{Z_{t}}{Z_{t-1}}=\frac{Z_{t}^{p} v_{z t}}{Z_{t-1}^{p} v_{z t-1}}=\lambda_{z t} \frac{v_{z t}}{v_{z t-1}} \\
g_{q t} \equiv \frac{Q_{t}}{Q_{t-1}}=\frac{Q_{t}^{p} v_{q t}}{Q_{t-1}^{p} v_{q t-1}}=\lambda_{q} \frac{v_{q t}}{v_{q t-1}} \\
g_{\gamma t} \equiv \frac{\Gamma_{t}}{\Gamma_{t-1}}=\left(g_{z t} g_{q t}^{(1-\phi) \alpha}\right)^{\frac{1}{1-(1-\phi) \alpha}}
\end{gathered}
$$

\section{Calibration Strategy:}

We follow the calibration strategy used by Liu et al. (2013). First we have

$$
\begin{gathered}
\frac{1}{R}=\frac{\beta\left(1+\lambda_{a}\right)}{g_{\gamma}} \Leftrightarrow \lambda_{a}=\frac{g_{\gamma}}{\beta R}-1 \\
\frac{\tilde{\mu}_{b}}{\tilde{\mu}_{e}}=\frac{\beta \lambda_{a}}{g_{\gamma}}
\end{gathered}
$$


then we derive

$$
\frac{\tilde{q}_{l} L_{e}}{\tilde{Y}}=\frac{\beta \alpha \phi}{1-\beta-\beta \lambda_{a} \theta} \Leftrightarrow \phi=\frac{1-\beta-\theta \beta \lambda_{a}}{\beta \alpha} \frac{\tilde{q}_{l} L_{e}}{\tilde{Y}}
$$

On the other hand, define

$$
\lambda_{k}=g_{\gamma} \lambda_{q}
$$

it follows that the investment-capital ratio is

$$
\frac{\tilde{I}}{\tilde{K}}=1-\frac{1-\delta}{\lambda_{k}} \Leftrightarrow \delta=1-\lambda_{k}\left(1-\frac{\tilde{I}}{\tilde{K}}\right)
$$

and the capital-output ratio is

$$
\frac{\tilde{K}}{\tilde{Y}}=\frac{\beta \alpha(1-\phi)}{1-\frac{\beta}{\lambda_{k}}\left(\lambda_{a} \theta+1-\delta\right)}=\frac{\beta \alpha\left(1-\frac{1-\beta-\theta \beta \lambda_{a}}{\beta \alpha} \frac{\tilde{q}_{l} L_{e}}{\tilde{Y}}\right)}{1-\frac{\beta}{\lambda_{k}}\left(\lambda_{a} \theta+1-\delta\right)}=\frac{\beta\left(\alpha+\left(1+\theta \lambda_{a}\right) \frac{\tilde{q}_{l} L_{e}}{\tilde{Y}}\right)-\frac{\tilde{q}_{l} L_{e}}{\tilde{Y}}}{1-\frac{\beta}{\lambda_{k}}\left(\lambda_{a} \theta+1-\delta\right)}
$$

which gives the discount factor

$$
\beta=\frac{\frac{\tilde{K}}{\tilde{Y}}+\frac{\tilde{q}_{l} L_{e}}{\tilde{Y}}}{\alpha+\frac{\tilde{q_{l}} L_{e}}{\tilde{Y}}\left(1+\theta \lambda_{a}\right)+\frac{\tilde{K}}{\tilde{Y}} \frac{1}{\lambda_{k}}\left(\lambda_{a} \theta+1-\delta\right)}
$$

and the investment-output ratio

$$
\frac{\tilde{I}}{\tilde{Y}}=\frac{\tilde{I}}{\tilde{K}} \frac{\tilde{K}}{\tilde{Y}}=\frac{\beta \alpha(1-\phi)\left(\lambda_{k}-(1-\delta)\right)}{\lambda_{k}-\beta\left(\lambda_{a} \theta+1-\delta\right)}
$$

Besides, the credit-to-output ratio is

$$
\frac{\tilde{B}}{\tilde{Y}}=\theta\left(g_{\gamma} \frac{\tilde{q}_{l} L_{e}}{\tilde{Y}}+\frac{1}{\lambda_{q}} \frac{\tilde{K}}{\tilde{Y}}\right)
$$

which gives the entrepreneur's consumption as a fraction of output

$$
\frac{\tilde{C}_{e}}{\tilde{Y}}=\alpha-\frac{\tilde{I}}{\tilde{Y}}-\frac{1-\beta\left(1+\lambda_{a}\right)}{g_{\gamma}} \frac{\tilde{B}}{\tilde{Y}}
$$

and the household's consumption-to-output ratio as well

$$
\frac{\tilde{C}_{h}}{\tilde{Y}}=1-\frac{\tilde{C}_{e}}{\tilde{Y}}-\frac{\tilde{I}}{\tilde{Y}}
$$

In addition

$$
\begin{gathered}
\frac{\tilde{q}_{l} L_{h}}{\tilde{C}_{h}}=\frac{\varphi\left(g_{\gamma}-\gamma_{h}\right)}{g_{\gamma}\left(1-g_{\gamma} / R\right)\left(1-\gamma_{h} / R\right)} \Leftrightarrow \varphi=\frac{\frac{\tilde{q}_{l} L_{h}}{\tilde{Y}}}{\frac{\tilde{C}_{h}}{\tilde{Y}}} \frac{g_{\gamma}\left(1-g_{\gamma} / R\right)\left(1-\gamma_{h} / R\right)}{\left(g_{\gamma}-\gamma_{h}\right)} \\
\frac{L_{h}}{L_{e}}=\frac{\varphi\left(g_{\gamma}-\gamma_{h}\right)\left(1-\beta-\beta \lambda_{a} \theta\right)}{\beta \alpha \phi g_{\gamma}\left(1-g_{\gamma} / R\right)\left(1-\gamma_{h} / R\right)} \frac{\tilde{C}_{h}}{\tilde{Y}}
\end{gathered}
$$


and the steady-state quantity of labor is

$$
N=\frac{(1-\alpha) g_{\gamma}\left(1-\gamma_{h} / R\right)}{\psi\left(g_{\gamma}-\gamma_{h}\right)} \frac{\tilde{Y}}{\tilde{C}_{h}} \Leftrightarrow \psi=\frac{(1-\alpha) g_{\gamma}\left(1-\gamma_{h} / R\right)}{N\left(g_{\gamma}-\gamma_{h}\right)} \frac{\tilde{Y}}{\tilde{C}_{h}}
$$

\section{Linearization:}

Defining the following constant

$$
\begin{gathered}
\Omega_{h}=\left(g_{\gamma}-\beta\left(1+\lambda_{a}\right) \gamma_{h}\right)\left(g_{\gamma}-\gamma_{h}\right) \\
\Omega_{e}=\left(g_{\gamma}-\beta \gamma_{e}\right)\left(g_{\gamma}-\gamma_{h}\right)
\end{gathered}
$$

then we dynamic linear system follows

$$
\begin{aligned}
& \hat{\mu}_{h t} \Omega_{h}=-\left(g_{\gamma}^{2}+\beta \gamma_{h}^{2}\left(1+\lambda_{a}\right)\right) \hat{C}_{h t}+g_{\gamma} \gamma_{h}\left(\hat{C}_{h t-1}-\hat{g}_{\gamma t}\right)-\beta \lambda_{a} \gamma_{h}\left(g_{\gamma}-\gamma_{h}\right) \hat{\lambda}_{a t+1}+\beta\left(1+\lambda_{a}\right) g_{\gamma} \gamma_{h}\left(\hat{C}_{h t+1}+\hat{g}_{\gamma t+1}\right) \\
& \hat{w}_{t}+\hat{\mu}_{h t}=\hat{\psi}_{t} \\
& \hat{q}_{l t}+\hat{\mu}_{h t}=\beta\left(1+\lambda_{a}\right) \mathbb{E}_{t}\left[\hat{\mu}_{h t+1}+\hat{q}_{l t+1}\right]+\left(1-\beta\left(1+\lambda_{a}\right)\right)\left(\hat{\varphi}_{t}-\hat{L}_{h t}\right)+\beta \lambda_{a} \mathbb{E}_{t}\left[\hat{\lambda}_{a t+1}\right] \\
& \hat{\mu}_{h t}-\hat{R}_{t}=\mathbb{E}_{t}\left[\hat{\mu}_{h t+1}+\frac{\lambda_{a}}{1+\lambda_{a}} \hat{\lambda}_{a t+1}-\hat{g}_{\gamma t+1}\right] \\
& \Omega_{e} \hat{\mu}_{e t}=-\left(g_{\gamma}^{2}+\beta \gamma_{e}^{2}\right) \hat{C}_{e t}+g_{\gamma} \gamma_{e}\left(\hat{C}_{e t-1}-\hat{g}_{\gamma t}\right)+\beta g_{\gamma} \gamma_{e} \mathbb{E}_{t}\left[\hat{C}_{e t+1}+\hat{g}_{\gamma t+1}\right] \\
& \hat{w}_{t}=\hat{Y}_{t}-\hat{N}_{t} \\
& \hat{q}_{k t}=(1+\beta) \Omega \lambda_{k}^{2} \hat{I}_{t}-\Omega \lambda_{k}^{2} \hat{I}_{t-1}+\Omega \lambda_{k}^{2}\left(\hat{g}_{\gamma t}+\hat{g}_{q t}\right)-\beta \Omega \lambda_{k}^{2} \mathbb{E}_{t}\left[\hat{I}_{t+1}+\hat{g}_{\gamma t+1}+\hat{g}_{q t+1}\right] \\
& \hat{q}_{k t}+\hat{\mu}_{e t}=\frac{\tilde{\mu}_{b}}{\tilde{\mu}_{e}} \frac{\theta}{\lambda_{q}}\left(\hat{\mu}_{b t}+\hat{\theta}_{t}\right)+\frac{\beta(1-\delta)}{\lambda_{k}} \mathbb{E}_{t}\left[\hat{q}_{k t+1}-\hat{g}_{q t+1}-\hat{g}_{\gamma t+1}\right] \\
& +\left(1-\frac{\tilde{\mu}_{b}}{\tilde{\mu}_{e}} \frac{\theta}{\lambda_{q}}\right) \mathbb{E}_{t}\left[\hat{\mu}_{e t+1}\right]+\frac{\tilde{\mu}_{b}}{\tilde{\mu}_{e}} \frac{\theta}{\lambda_{q}} \mathbb{E}_{t}\left[\hat{q}_{k t+1}-\hat{g}_{q t+1}\right]+\beta \alpha(1-\phi) \frac{\tilde{Y}}{\tilde{K}} \mathbb{E}_{t}\left[\hat{Y}_{t+1}-\hat{K}_{t}\right] \\
& \hat{q}_{l t}+\hat{\mu}_{e t}=\frac{\tilde{\mu}_{b}}{\tilde{\mu}_{e}} g_{\gamma} \theta\left(\hat{\theta}_{t}+\hat{\mu}_{b t}\right)+\left(1-\frac{\tilde{\mu}_{b}}{\tilde{\mu}_{e}} g_{\gamma} \theta\right) \mathbb{E}_{t}\left[\hat{\mu}_{e t+1}\right]+\frac{\tilde{\mu}_{b}}{\tilde{\mu}_{e}} g_{\gamma} \theta \mathbb{E}_{t}\left[\hat{q}_{l t+1}+\hat{g}_{\gamma t+1}\right] \\
& +\beta \mathbb{E}_{t}\left[\hat{q}_{l t+1}\right]+\left(1-\beta-\beta \lambda_{a} \theta\right) \mathbb{E}_{t}\left[\hat{Y}_{t+1}-\hat{L}_{e}\right] \\
& \hat{\mu}_{e t}-\hat{R}_{t}=\frac{1}{1+\lambda_{a}}\left(\mathbb{E}_{t}\left[\hat{\mu}_{e t+1}-\hat{g}_{\gamma t+1}\right]+\lambda_{a} \hat{\mu}_{b t}\right) \\
& \hat{Y}_{t}=\alpha \phi \hat{L}_{e t-1}+\alpha(1-\phi) \hat{K}_{t-1}+(1-\alpha) \hat{N}_{t}-\frac{(1-\phi) \alpha}{1-(1-\phi) \alpha}\left(\hat{g}_{z t}+\hat{g}_{q t}\right) \\
& \hat{K}_{t}=\frac{1-\delta}{\lambda_{k}}\left(\hat{K}_{t-1}-\hat{g}_{\gamma t}-\hat{g}_{q t}\right)+\left(1-\frac{1-\delta}{\lambda_{k}}\right) \hat{I}_{t} \\
& \hat{Y}_{t}=\frac{\tilde{C}_{h}}{\tilde{Y}} \hat{C}_{h t}+\frac{C_{e}}{\tilde{Y}} \hat{C}_{e t}+\frac{\tilde{I}}{\tilde{Y}} \hat{I}_{t} \\
& 0=\frac{L_{h}}{\bar{L}} \hat{L}_{h t}+\frac{L_{e}}{\bar{L}} \hat{L}_{e t}
\end{aligned}
$$




$$
\begin{gathered}
\alpha \hat{Y}_{t}=\frac{\tilde{C}_{e}}{\tilde{Y}} \hat{C}_{e t}+\frac{\tilde{I}}{\tilde{Y}} \hat{I}_{t}+\frac{\tilde{q}_{l} L_{e}}{\tilde{Y}}\left(\hat{L}_{e t}-\hat{L}_{e t-1}\right)+\frac{1}{g_{\gamma}} \frac{\tilde{B}}{\tilde{Y}}\left(\hat{B}_{t-1}-\hat{g}_{\gamma t}\right)-\frac{1}{R} \frac{\tilde{B}}{\tilde{Y}}\left(\hat{B}_{t}-\hat{R}_{t}\right) \\
\hat{B}_{t}=\hat{\theta}_{t}+g_{\gamma} \theta \frac{\tilde{q}_{l} L_{e}}{\tilde{B}} \mathbb{E}_{t}\left[\hat{q}_{l t+1}+\hat{L}_{e t}+\hat{g}_{\gamma t+1}\right]+\left(1-g_{\gamma} \theta \frac{\tilde{q}_{l} L_{e}}{\tilde{B}}\right) \mathbb{E}_{t}\left[\hat{q}_{k t+1}+\hat{K}_{t}+\hat{g}_{q t+1}\right] \\
\hat{g}_{z t}=\hat{\lambda}_{z t}+\hat{\nu}_{z t}-\hat{v}_{z t-1} \\
\hat{g}_{q t}=\hat{\lambda}_{q t}+\hat{\nu}_{q t}-\hat{v}_{z q t-1} \\
\hat{g}_{\gamma t}=\frac{(1-\phi) \alpha}{1-(1-\phi) \alpha} \hat{g}_{z t}+\frac{(1-\phi) \alpha}{1-(1-\phi)} \\
\hat{\lambda}_{z t}=\rho_{z} \hat{\lambda}_{z t-1}+\hat{\varepsilon}_{z t} \\
\hat{\nu}_{z t}=\rho_{\nu_{z}} \hat{\nu}_{z t-1}+\hat{\varepsilon}_{\nu_{z} t} \\
\hat{\lambda}_{q t}=\rho_{q} \hat{\lambda}_{q t-1}+\hat{\varepsilon}_{q t} \\
\hat{\nu}_{q t}=\rho_{\nu_{q}} \hat{\nu}_{q t-1}+\hat{\varepsilon}_{\nu_{q} t} \\
\hat{\lambda}_{a t}=\rho_{a} \hat{\lambda}_{a t-1}+\hat{\varepsilon}_{a t} \\
\hat{\varphi}_{t}=\rho_{\varphi} \hat{\varphi}_{t-1}+\hat{\varepsilon}_{\varphi t} \\
\hat{\psi}_{t}=\rho_{\psi} \hat{\psi}_{t-1}+\hat{\varepsilon}_{\psi t} \\
\hat{\theta}_{t}=\rho_{\theta} \hat{\theta}_{t-1}+\hat{\varepsilon}_{\theta t}
\end{gathered}
$$

Following Sims (2001), the above linear system can be written in the following state-space form:

$$
\Gamma_{0} X_{t}=\Gamma_{1} X_{t-1}+\Gamma_{2} \varepsilon_{t}+\Gamma_{3} \eta_{t}
$$

where $X_{t}$ is a 39 dimensional vector containing all the endogenous variables and the forward looking variables, $\varepsilon_{t}$ is a 8 dimensional vector containing the 8 exogenous shocks, and $\eta_{t}$ is a 11 dimensional vector containing 11 endogenous expectation errors. In specific, we have

$$
X_{t}=\left(X_{1 t}^{\prime}, \mathbb{E}_{t}\left[X_{2 t+1}\right]^{\prime}, X_{3 t}^{\prime}\right)^{\prime}
$$

where

$$
\begin{gathered}
X_{1 t}=\left(\hat{\mu}_{h t}, \hat{w}_{t}, \hat{q}_{l t}, \hat{R}_{t}, \hat{\mu}_{e t}, \hat{\mu}_{b t}, \hat{N}_{t}, \hat{I}_{t}, \hat{Y}_{t}, \hat{C}_{h t}, \hat{C}_{e t}, \hat{q}_{k t}, \hat{L}_{h t}, \hat{L}_{e t}, \hat{K}_{t}, \hat{B}_{t}, \hat{g}_{\gamma t}, \hat{g}_{z t}, \hat{g}_{q t}, \hat{C}_{t}\right)_{20 \times 1}^{\prime} \\
X_{2 t+1}=\left(\hat{\mu}_{h t+1}, \hat{q}_{l t+1}, \hat{\mu}_{e t+1}, \hat{I}_{t+1}, \hat{Y}_{t+1}, \hat{C}_{h t+1}, \hat{C}_{e t+1}, \hat{q}_{k t+1}, \hat{g}_{\gamma t+1}, \hat{g}_{q t+1}, \hat{\lambda}_{a t+1}\right)_{11 \times 1}^{\prime} \\
X_{3 t}=\left(\hat{\theta}_{t}, \hat{\psi}_{t}, \hat{\varphi}_{t}, \hat{\nu}_{q t}, \hat{\nu}_{z t}, \hat{\lambda}_{z t}, \hat{\lambda}_{a t}, \hat{\lambda}_{q t}\right)_{8 \times 1}^{\prime} \\
\varepsilon_{t}=\left(\hat{\varepsilon}_{z t}, \hat{\varepsilon}_{\nu_{z} t}, \hat{\varepsilon}_{q t}, \hat{\varepsilon}_{\nu_{q} t}, \hat{\varepsilon}_{a t}, \hat{\varepsilon}_{\varphi t}, \hat{\varepsilon}_{\psi t}, \hat{\varepsilon}_{\theta t}\right)_{8 \times 1}^{\prime} \\
\eta_{t}=X_{2 t}-\mathbb{E}_{t-1}\left[X_{2 t}\right]
\end{gathered}
$$




\subsubsection{Model with State-Contingent Interest Rate}

This is the model described in Section 4.2. Equations are identical to those in Appendix 6.3.1 except for the following changes:

$(106) \rightarrow$

$$
\hat{\mu}_{h t}-\mathbb{E}_{t}\left[\hat{R}_{t+1}\right]=\mathbb{E}_{t}\left[\hat{\mu}_{h t+1}+\frac{\lambda_{a}}{1+\lambda_{a}} \hat{\lambda}_{a t+1}-\hat{g}_{\gamma t+1}\right]
$$

$(112) \rightarrow$

$$
\hat{\mu}_{e t}-\mathbb{E}_{t}\left[\hat{R}_{t+1}\right]=\frac{1}{1+\lambda_{a}}\left(\mathbb{E}_{t}\left[\hat{\mu}_{e t+1}-\hat{g}_{\gamma t+1}\right]+\lambda_{a} \hat{\mu}_{b t}\right)
$$

$(117) \rightarrow$

$$
\alpha \hat{Y}_{t}=\frac{\tilde{C}_{e}}{\tilde{Y}} \hat{C}_{e t}+\frac{\tilde{I}}{\tilde{Y}} \hat{I}_{t}+\frac{\tilde{q}_{l} L_{e}}{\tilde{Y}}\left(\hat{L}_{e t}-\hat{L}_{e t-1}\right)+\frac{1}{g_{\gamma}} \frac{\tilde{B}}{\tilde{Y}}\left(\hat{R}_{t}+\hat{B}_{t-1}^{l}-\hat{g}_{\gamma t}\right)-\frac{1}{R} \frac{\tilde{B}}{\tilde{Y}} \hat{B}_{t}^{l}
$$

$(118) \rightarrow$

$$
\hat{R}_{t+1}+\hat{B}_{t}^{l}=\hat{\theta}_{t}+g_{\gamma} \theta \frac{\tilde{q}_{l} L_{e}}{\tilde{B}} \mathbb{E}_{t}\left[\hat{q}_{l t+1}+\hat{L}_{e t}+\hat{g}_{\gamma t+1}\right]+\left(1-g_{\gamma} \theta \frac{\tilde{q}_{l} L_{e}}{\tilde{B}}\right) \mathbb{E}_{t}\left[\hat{q}_{k t+1}+\hat{K}_{t}+\hat{g}_{q t+1}\right]
$$

In state-space form the linearized system is now:

$$
\Gamma_{0} X_{t}=\Gamma_{1} X_{t-1}+\Gamma_{2} \varepsilon_{t}+\Gamma_{3} \eta_{t}
$$

where $X_{t}$ is a 39 dimensional vector containing all the endogenous variables and the forward looking variables, $\varepsilon_{t}$ is a 9 dimensional vector containing the 9 innovations (including the self-fulfilling one), and $\eta_{t}$ is a 12 dimensional vector containing 12 endogenous expectation errors. In specific, we have

$$
X_{t}=\left(X_{1 t}^{\prime}, \mathbb{E}_{t}\left[X_{2 t+1}\right]^{\prime}, X_{3 t}^{\prime}\right)^{\prime}
$$

where

$$
\begin{gathered}
X_{1 t}=\left(\hat{\mu}_{h t}, \hat{w}_{t}, \hat{q}_{l t}, \hat{\mu}_{e t}, \hat{\mu}_{b t}, \hat{N}_{t}, \hat{I}_{t}, \hat{Y}_{t}, \hat{C}_{h t}, \hat{C}_{e t}, \hat{q}_{k t}, \hat{L}_{h t}, \hat{L}_{e t}, \hat{K}_{t}, \hat{B}_{t}, \hat{g}_{\gamma t}, \hat{g}_{z t}, \hat{g}_{q t}, \hat{C}_{t}\right)_{19 \times 1}^{\prime} \\
X_{2 t+1}=\left(\hat{\mu}_{h t+1}, \hat{q}_{l t+1}, \hat{R}_{t+1}, \hat{\mu}_{e t+1}, \hat{I}_{t+1}, \hat{Y}_{t+1}, \hat{C}_{h t+1}, \hat{C}_{e t+1}, \hat{q}_{k t+1}, \hat{g}_{\gamma t+1}, \hat{g}_{q t+1}, \hat{\lambda}_{a t+1}\right)_{12 \times 1}^{\prime} \\
X_{3 t}=\left(\hat{\theta}_{t}, \hat{\psi}_{t}, \hat{\varphi}_{t}, \hat{\nu}_{q t}, \hat{\nu}_{z t}, \hat{\lambda}_{z t}, \hat{\lambda}_{a t}, \hat{\lambda}_{q t}\right)_{8^{\prime} \times 1}^{\prime} \\
\varepsilon_{t}=\left(\hat{\varepsilon}_{z t}, \hat{\varepsilon}_{\nu_{z} t}, \hat{\varepsilon}_{q t}, \hat{\varepsilon}_{\nu_{q} t}, \hat{\varepsilon}_{a t}, \hat{\varepsilon}_{\varphi t}, \hat{\varepsilon}_{\psi t}, \hat{\varepsilon}_{\theta t}, \hat{\varepsilon}_{s t}\right)_{9 \times 1}^{\prime} \\
\eta_{t}=X_{2 t}-\mathbb{E}_{t-1}\left[X_{2 t}\right]
\end{gathered}
$$




\section{References}

[1] Allen, F., Gale, D., 1994. Financial innovation and risk sharing. MIT Press.

[2] Auclert, A., 2016. Monetary policy and the redistribution channel. Mimeo Princeton University.

[3] Azariadis, C., Kaas, L., Wen Y., 2015. Self-fulfilling credit cycles. Forthcoming in Review of Economic Studies.

[4] Backus, D.K., Kehoe, P.J., Kydland F.E., 1994. Dynamics of the trade balance and the terms of trade: the J-curve? American Economic Review 84(1), 84-103.

[5] Benhabib, J., and Wang, P., 2013. Financial constraints, endogenous markups, and self-fulfilling equilibria. Journal of Monetary Economics 60(7), 789-805.

[6] Benhabib, J., Wang, P. and Wen, Y., 2015. Sentiments and aggregate demand fluctuations. Forthcoming Econometrica.

[7] Bernanke, B., and Gertler, M., 1989. Agency costs, net worth, and business fluctuations. American Economic Review $79(1), 14-31$.

[8] Bianchi, J., 2011. Overborrowing and systemic Externalities in the business cycle. American Economic Review 101(7), 3400-3426.

[9] Boháček, E., and Rodríguez Mendizábal, H., 2007. Credit markets and the propagation of monetary policy shocks. Journal of Money, Credit and Banking 39(6), 1429-1455.

[10] Boissay, F., Collard, F., and Smets, F., 2015. Booms and banking crisis. Forthcoming Journal of Political Economy.

[11] Boldrin, M., Christiano, L., Fisher, J., 2001. Habit persistence, asset returns, and the business cycle. American Economic Review 91(1), 149-166.

[12] Calza, A., Monacelli, T., Stracca, L., 2013. Housing finance and monetary policy. Journal of the European Economic Association 11(S1): 101-122.

[13] Campbell, J., and Hercowitz, Z., 2006. The role of collateralized household debt in macroeconomic stabilization. NBER Working Papers 11330.

[14] Carlstrom, C., and Fuerst, T., 1997. Agency costs, net worth, and business fluctuations: a computable general equilibrium analysis. American Economic Review 87(5), 893-910.

[15] Carlstrom, C., Fuerst, T., Paustian, M., 2016. Optimal contracts, aggregate risk, and the financial accelerator. American Economic Journal: Macroeconomics 8(1), 119-147.

[16] Chaney, T., Sraer, D., Thesmar D., 2012. The collateral channel: how real estate shocks affect corporate investment. American Economic Review 102(6), 2381-2409.

[17] Christiano, L., Motto, R., and Rostagno, M., 2010. Financial factors in economic fluctuations. ECB Working Papers 1192.

[18] Cooley, T., Marimon, R., and Quadrini, V., 2004. Aggregate consequences of limited contract enforceability. Journal of Political Economy 112(4), 817-847.

[19] Cordoba, J.-C., and Ripoll, M., 2004. Credit cycles redux.International Economic Review 45(4), 1011-1046. 
[20] Farmer, R., Khramov, V., Nicolò, G., 2015. Solving and estimating indeterminate DSGE models. Journal of Economic Dynamics and Control 54(C), 17-36.

[21] Garriga, C., Kydland, F.E., Šustek, R., 2013. Mortgages and monetary policy. St Louis Fed working paper 2013037A.

[22] Gomes, J., Jermann, U., Schmid, L., 2014. Sticky leverage. Mimeo University of Pennsylvania.

[23] Gomme, P., Kydland, F.E., Rupert, P., 2001. Home production meets time to build. Journal of Political Economy 109(5), 1115-11131.

[24] Gorton, G., Metrick, A., 2012. Securitized banking and the run on repo. Journal of Financial Economics 104(3), 425-451.

[25] Greenwood, J., Hercowitz, Z., Krusell, P., 1997. Long-run implications of investment-specific technological change. American Economic Review 87(3), 342-362.

[26] Guerrieri, L., and Iacoviello, M., 2013. Collateral constraints and macroeconomic asymmetries. Board of Governors of the Federal Reserve System, International Finance Discussion Papers 1082.

[27] Gu, C., Mattesini, F., Monnet, C., Wright, R., 2013. Endogenous credit cycles. Journal of Political Economy 121(5), 940-965.

[28] He, C., Wright, R., and Zhu, Y., 2014. Housing and liquidity. Forthcoming Review of Economics Dynamics.

[29] Iacoviello, M., 2005. House prices, borrowing constraints, and monetary policy in the business cycle. American Economic Review 95(3), 739-764.

[30] Iacoviello, M., and Neri, S., 2010. Housing market spillovers: evidence from an estimated DSGE model. American Economic Journal: Macroeconomics 2(2), 125-64.

[31] Justiniano, A., Primiceri, G., and Tambalotti, A., 2011. Investment shocks and business cycles. Journal of Monetary Economics 57(2), 132-145.

[32] Justiniano, A., Primiceri, G., and Tambalotti, A., 2015a. Household leveraging and deleveraging. Review of Economic Dynamics 18(1), 3-20.

[33] Justiniano, A., Primiceri, G., and Tambalotti, A., 2015b. Credit supply and the housing boom. New York Fed Staff Reports 709 .

[34] Kaas, L., Pintus, P.A., Ray, S., 2016. Land collateral and labor market dynamics in France. European Economic Review 84(4), 202-218.

[35] Kaplan, G., Moll, B., Violante, G., 2016. Monetary policy according to HANK. NBER Working Paper 21897.

[36] King, R.G., Watson, W.W., 1996. Money, prices, interest rates and the business cycle. The Review of Economics and Statistics $78(1), 35-53$.

[37] Kiyotaki, N., Michaelides, A., and Nikolov, K., 2011. Winners and losers in housing markets. Journal of Money, Credit and Banking 43 (3), 255-296.

[38] Kiyotaki, N., and Moore, J., 1997. Credit cycles. Journal of Political Economy 105(2), 211-248.

[39] Kocherlakota, N., 2000. Creating business cycles through credit constraints. Federal Reserve Bank of Minneapolis Quarterly Review 24(3), 2-10. 
[40] Krishnamurthy, A., 2003. Collateral constraints and the amplification mechanism. Journal of Economic Theory $111(2), 277-292$.

[41] Kydland, F. E., Rupert, P., Šustek, R., 2015. Housing dynamics over the business cycles. Forthcoming International Economic Review.

[42] Liu, Z., and Wang, P., 2014. Credit constraints and self-fulfilling business cycles. American Economic Journal: Macroeconomics 6(1), 32-69.

[43] Liu, Z., P. Wang, and Zha, T., 2013. Land-price dynamics and macroeconomic fluctuations. Econometrica 81(3), 1147-1184.

[44] Mendoza, E., 2010. Sudden stops, financial crises, and leverage. American Economic Review 100(5), $1941-66$.

[45] Moench, E., Vickery, J., Aragon, D., 2010. Why is the market share of adjustable-rate mortgages so low? New-York Fed Current Issues In Economics and Finance 16(8), 1-11.

[46] Pintus, P.A., and Wen, Y., 2013. Leveraged borrowing and boom-bust cycles. Review of Economic Dynamics 16(4), 617-633.

[47] Sims, C. A., 2001. Solving linear rational expectations models. Journal of Computational Economics 20(1-2), 1-20.

[48] Tirole, J., 2006. The theory of corporate finance. Princeton University Press.

[49] Vickery, J., 2008. How and why do small firms manage interest rate risk? Journal of Financial Economics 87(2), 446-470. 


\title{
Documents de Travail
}

600. M. Mogliani and T. Ferrière, "Rationality of announcements, business cycle asymmetry, and predictability of revisions. The case of French GDP” September 2016

601. R. S.J. Koijen; F. Koulischer; B. Nguyen and M. Yogo, "Quantitative Easing in the Euro Area: The Dynamics of Risk Exposures and the Impact on Asset Prices" September 2016

602. O. de Bandt and M. Chahad, “A DGSE Model to Assess the Post-Crisis Regulation of Universal Banks” September 2016

603. C. Malgouyres, "The Impact of Chinese Import Competition on the Local Structure of Employment and Wages: Evidence from France" September 2016

604. G. Cette, J. Lopez and J. Mairesse, "Labour market regulations and capital labour substitution” October 2016

605. C. Hémet and C. Malgouyres, "Diversity and Employment Prospects: Neighbors Matter!” October 2016

606. M. Ben Salem and B. Castelletti-Font, "Which combination of fiscal and external imbalances to determine the longrun dynamics of sovereign bond yields?" November 2016

607. M. Joëts, V. Mignon and T. Razafindrabe, "Does the volatility of commodity prices reflect macroeconomic uncertainty?" November 2016

608. M. Bussière, G. Gaulier and W. Steingress, "Global Trade Flows: Revisiting the Exchange Rate Elasticities" November 2016

609. V.Coudert and J. Idier, “An Early Warning System for Macro-prudential Policy in France” November 2016

610. S. Guilloux-Nefussi, “Globalization, Market Structure and Inflation Dynamics” December 2016

611. S.Fries, J-S. Mésonnier, S. Mouabbi, and J-P. Renne, "National natural rates of interest and the single monetary policy in the Euro Area" December 2016

612. J. Blaum, C. Lelarge and M. Peters, “The Gains from Input Trade with Heterogeneous Importers” December 2016

613. A. Penalver, “Optimal Monitoring of Long-Term Loan Contracts” December 2016

614. M. Isoré and U. Szczerbowicz, "Disaster Risk and Preference Shifts in a New Keynesian Model” December 2016

615. L. Chauvet and L. Jacolin, "Financial Inclusion, Bank Concentration and Firm Performance” December 2016

616. P. A. Pintus, Y. Wen, and X. Xing, "The Inverted Leading Indicator Property and Redistribution Effect of the Interest Rate" December 2016

Pour accéder à la liste complète des Documents de Travail publiés par la Banque de France veuillez consulter le site : www.banque-france.fr

For a complete list of Working Papers published by the Banque de France, please visit the website: www.banque-france.fr

Pour tous commentaires ou demandes sur les Documents de Travail, contacter la bibliothèque de la Direction Générale des Études et des Relations Internationales à l'adresse suivante :

For any comment or enquiries on the Working Papers, contact the library of the Directorate General Economics and International Relations at the following address :

\author{
BANQUE DE FRANCE \\ 49- 1404 Labolog \\ 75049 Paris Cedex 01 \\ tél : 0033 (0)1 42977724 ou 0142926340 ou 4890 ou 6981 \\ email : 1404-ut@banque-france.fr
}

